\title{
Emprego de um novo dispositivo intravaginal para liberação de progesterona em programa de IATF em vacas Nelore (Bos taurus indicus)
}

Dissertação apresentada ao Programa de Pós-Graduação em Reprodução Animal da Faculdade de Medicina Veterinária e Zootecnia da Universidade de São Paulo, para obtenção do título de Mestre em Medicina Veterinária

Departamento:

Reprodução Animal

Área de concentração:

Reprodução Animal

Orientador:

Prof. Dr. Ed Hoffmann Madureira 
Autorizo a reprodução parcial ou total desta obra, para fins acadêmicos, desde que citada a fonte.

DADOS INTERNACIONAIS DE CATALOGAÇÃO-NA-PUBLICAÇÃO

(Biblioteca Virginie Buff D’Ápice da Faculdade de Medicina Veterinária e Zootecnia da Universidade de São Paulo)

Braga, Fernando do Amaral

FMVZ

Emprego de um novo dispositivo intravaginal para liberação de progesterona em programa de IATF em vacas Nelore (Bos taurus indicus) / Fernando do Amaral Braga. - São Paulo: F. A. Braga, 2008.

$102 \mathrm{f}$ : : il.

Dissertação (mestrado) - Universidade de São Paulo. Faculdade de Medicina Veterinária e Zootecnia. Departamento de Reprodução Animal, 2008.

Programa de Pós-Graduação: Reprodução Animal.

Área de concentração: Reprodução Animal.

Orientador: Prof. Dr. Ed Hoffmann Madureira.

1. Dispositivo intravaginal. 2. Progesterona. 3. PHB. 4. IATF. 5. Nelore.I. Título. 
BRAGA, F. A. Emprego de um novo dispositivo intravaginal para liberação de progesterona em programa de IATF em vacas Nelore (Bos taurus indicus). 2008. $102 \mathrm{f}$. Dissertação (Mestrado em Medicina Veterinária) - Faculdade de Medicina Veterinária e Zootecnia, Universidade de São Paulo, São Paulo, 2008.

$\begin{array}{lllll}\begin{array}{lll}\text { Folha } \\ \text { RESUMO }\end{array} & \begin{array}{l}\text { Parágrafo } \\ 2^{\circ}\end{array} & \begin{array}{l}\text { Linha } \\ 1^{\mathrm{a}}\end{array} & \begin{array}{l}\text { Onde se lê } \\ \text { Emprego de um } \\ \text { dispositivo }\end{array} & \begin{array}{l}\text { Leia-se } \\ \text { Emprego de um novo } \\ \text { dispositivo }\end{array} \\ \text { RESUMO } & 2^{\circ} & 3^{\mathrm{a}} & \begin{array}{l}\text { an intravaginal } \\ \text { a new intravaginal }\end{array} \\ \text { ABSTRACT } & 2^{\circ} & 1^{a} & \text { an intravaginal } & \text { a new intravaginal } \\ \text { ABSTRACT } & 2^{\circ} & 2^{\circ} & \begin{array}{l}\text { Emprego de um } \\ \text { dispositivo }\end{array} & \begin{array}{l}\text { Emprego de um novo } \\ \text { dispositivo }\end{array}\end{array}$




\section{UNIVERSIDADE DE SÃO PAULO \\ Faculdade de Medicina Veterinaria e Zootecnia Assistência Acadêmica \\ Comissão Bioética}

\section{CERTIFICADO}

Certificamos que o Projeto intitulado "Emprego de um novo dispositivo intravaginal para liberação de progesterona em programa de IATF em vacas Nelore (Bos indicus)", protocolo $\mathrm{n}^{\circ} 736 / 2005$, utilizando 200 bovinos, sob a responsabilidade do Prof. Dr. Ed Hoffmann Madureira, está de acordo com os princípios éticos de experimentação animal da Comissão de Bioética da Faculdade de Medicina Veterinária e Zootecnia da Universidade de São Paulo e foi aprovado "ad referendun".

(We certify that the Research "Use of a new progesterone device for FTAI in Nellore cows (Bos indicus)" protocol number 736/2005, under the responsibility of Prof. Dr. Ed Hoffmann Madureira, utilizing 200 bovines, agree with Ethical Principles in Animal Research adopted by Bioethic Commission of the Faculty of Veterinary Medicine and Zootechny of University of São Paulo and was approved "ad referendun", meeting).

São Paulo, 30 de setembro de 2005

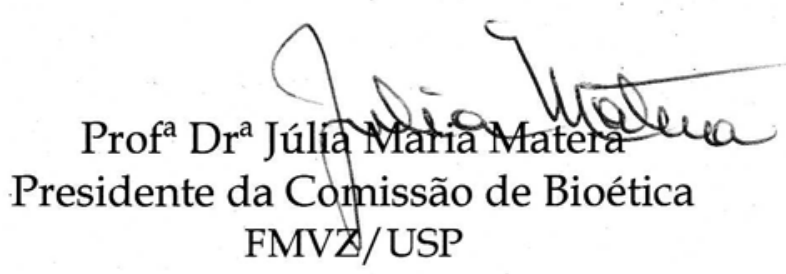

FMVZ/USP 


\section{FOLHA DE AVALIAÇÃO}

Nome: BRAGA, Fernando do Amaral

Título: Emprego de um novo dispositivo intravaginal para liberação de progesterona em programa de IATF em vacas Nelore (Bos taurus indicus)

Dissertação apresentada ao
Programa de Pós-Graduação em
Reprodução Animal da Faculdade de
Medicina Veterinária e Zootecnia da
Universidade de São Paulo para a
obtenção do título de Mestre em
Medicina Veterinária

Data:

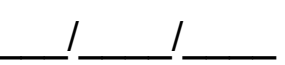

\section{Banca Examinadora}

Prof. Dr.

Instituição:

Assinatura:

Julgamento:

Prof. Dr.

Instituição:

Assinatura: Julgamento:

Prof. Dr. Instituição:

Assinatura: Julgamento: 


\section{DEDICATÓRIA}

Dedico este trabalho, esta experiência e esta lição de vida aprendida durante estes anos:

Aos meus pais Orlando e Silvana, sem os quais eu nunca conseguiria alcançar esta conquista e nenhuma das outras, pelo incentivo, conselhos e dedicação. Vocês me tornaram com eu sou no presente, passado de vocês e futuro para vocês.

Aos meus avós José Alfredo, Giselda e Mafalda, pelo amor, gratidão, carinho e apoio incondicional em todos os momentos.

Ao meu avô Leopoldo, pelo carisma e principalmente por sua alegria de viver. Você está presente comigo, muitas saudades...

A minha tia Rita de Cássia, pela presença, ajuda e apoio em todas as circunstâncias desde tempos antigos.

A minha namorada Jaqueline, pela sinceridade, amizade, carinho, amor e apoio em todas as situações alegres e algumas vezes tristes. Juntos, conseguiremos vencer muitas "pedras no caminho" desta vida. E também a sua família, obrigado por tudo.

Ao restante de minha família, meu irmão Rafael, meus tios e tias, meus primos e primas, e também aos amigos que fiz ao longo de todos estes anos, pela amizade, ajuda, conselhos e participação. 


\section{AGRADECIMENTOS}

Ao Prof. Dr. Ed Hoffmann Madureira pela orientação, conselhos, ensinamentos e superação.

Aos Professores: Dr. Mário Binelli, Dr. Rubens Paes de Arruda e Dra. Anneliese de Souza Traldi, pela amizade, confiança e ensinamentos.

A Universidade de São Paulo (USP) e à Faculdade de Medicina Veterinária e Zootecnia (FMVZ), assim como ao Departamento de Reprodução Animal (VRA), pela oportunidade e aprendizagem.

A Fapesp, pelo apoio financeiro e o incentivo na área de pesquisa acadêmica.

A Prefeitura do Campus Administrativo de Pirassununga (PCAPS), pelo apoio e disponibilização dos animais para a realização do experimento.

Aos demais Professores do VRA: Dr. José Antônio Visintin, Dr. Pietro Sampaio Baruselli e Dra. Mayra Elena O. A. Assumpção, pela amizade, incentivo, confiança e apoio.

A Isabel, secretária do VRA de Pirassununga, pela atenção e auxílio em várias ocasiões.

A Harumi, secretária da Pós-graduação do VRA, pela ajuda e conselhos em diversos momentos importantes.

Aos colegas pós-graduandos Fernando Pardo, José Rodrigo Pimentel, Patrícia Miguez, Luiz Gustavo Rossa, Alexandre Almeida, Filipe Fedozzi, André Andrade, Juliana Nascimento, Octavio Fabian Bao, Fabiane Zaffalon, Felipe Horta, Simone Martins, Flávio Alves, Fabiana Bressan, Lindsay Gimenes e Raquel Fernandes, pela amizade, incentivo, colaboração e convívio de fundamental importância durante estes anos. 
Aos funcionários do Centro de Biotecnologia em Reprodução Animal (CBRA) do VRA/FMVZ/USP, Márcio, José Maria, João e Edna, por toda ajuda oferecida e vivência durante todo este tempo.

Ao funcionário do Laboratório de Cromatografia VNP/FMVZ/USP, Ari, por toda ajuda, dedicação e trabalho durante este tempo.

Ao funcionário, assistente técnico de direção, Renato Nascimento Rodrigues, ao Médico Veterinário Fernando Schalch, ao funcionário da bovinocultura de corte Ismael e aos demais funcionários da PCAPS, sem os quais não seria possível a realização completa e adequada de todo este experimento.

A todos que de qualquer forma ajudaram e participaram na concretização deste trabalho. 
"Tudo o que somos é resultado do que pensamos" (Buddha)

"O que você irradia em seus pensamentos, sentimentos, imagens mentais e palavras você atrai para a sua vida" (Catherine Ponder) 


\section{RESUMO}

BRAGA, F. A. Emprego de um dispositivo intravaginal para liberação de progesterona em programa de IATF em vacas Nelore (Bos taurus indicus). [Use of an intravaginal device for releasing progesterone-based TAI program in Nelore cows (Bos taurus indicus)]. 2008. 102 f. Dissertação (Mestrado em Medicina Veterinária) - Faculdade de Medicina Veterinária e Zootecnia, Universidade de São Paulo, São Paulo, 2008.

A Inseminação Artificial (IA) é a biotécnica que proporciona a maior pressão de seleção no melhoramento genético de um rebanho e, portanto deveria ser imprescindível na pecuária moderna. A ineficiência na detecção de estro e a baixa ciclicidade ovariana no período pós-parto constituem um grande entrave na aplicabilidade de programas de IA. Frente a estas dificuldades, o uso da Inseminação Artificial em Tempo Fixo (IATF) vem incrementando os resultados obtidos, uma vez que elimina a necessidade de observação de estro e induz a ciclicidade de vacas em anestro pós-parto. Nos protocolos de IATF é de fundamental importância o uso dos dispositivos intravaginais para liberação de progesterona $\left(\mathrm{P}_{4}\right)$. No mercado atual, estes dispositivos importados são fabricados à base de silicone, um polímero biocompatível, porém não biodegradável. Recentemente, dispositivos intravaginais de $\mathrm{P}_{4}$, incorporada à matriz polimérica biodegradável de poli-hidroxibutirato $(\mathrm{PHB})$, vêm sendo estudados. Este trabalho teve como objetivo comparar a eficiência, em programa de IATF, de um novo dispositivo intravaginal (Progestar ${ }^{\circledR}$ ), na taxa de prenhez, em bovinos da raça Nelore, com a do dispositivo à base de silicone, $\mathrm{DIB}^{\circledR}$, atualmente disponível no mercado brasileiro. Foram utilizadas 240 vacas da raça Nelore, em um delineamento de blocos casualizados generalizados, divididas em dois grupos (controle - $\mathrm{DIB}^{\circledR}$ e tratamento - Progestar $^{\circledR}$, usados nos protocolos de sincronização e IATF). Foram realizados 2 experimentos distintos: no primeiro experimento utilizaram-se dispositivos de $1^{\circ}$ uso $(n=136)$, enquanto que no segundo experimento, dispositivos de $2^{\circ}$ uso $(n=104)$. As taxas de prenhez, decorrentes da IATF (TPIATF) e ao final da estação de monta (TPEM) (variáveis dependentes), foram comparadas por análise de variância, separando o efeito de tratamento, dos blocos e das interações. No experimento 1: não houve interação das variáveis com o tratamento; não houve efeito de tratamento sobre a TPIATF (DIB ${ }^{\circledR}$ $66,7 \%$ e $\left.\operatorname{Progestar}^{\circledR}-65,8 \%\right)$ nem sobre a TPEM $\left(\right.$ DIB $^{\circledR}-95 \%$ e $\operatorname{Progestar}^{\circledR}$ - 
94,7\%); houve interação entre período pós-parto (PPP) e escore de condição corporal (ECC). Animais no PPP1 (45 a 70 dias) e ECC4 apresentaram resultados inferiores na TPIATF em relação aos animais ECC5 e 6; houve também interação entre PPP e escore de condição ovariana (ECO), em que animais no PPP2 (71 a 90 dias) que não estavam ciclando apresentaram resultados inferiores de TPIATF, em relação aos animais ciclando; e também não houve efeito das demais variáveis sobre a TPIATF e TPEM. No experimento 2: não houve interação das variáveis com o tratamento; não houve efeito de tratamento sobre a TPIATF $\left(\right.$ DIB $^{\circledR} 2-61,6 \%$ e Progestar $^{\circledR} 2-55,8 \%$ ) nem sobre a TPEM (DIB ${ }^{\circledR} 2-94,2 \%$ e Progestar ${ }^{\circledR} 2-88,5 \%$ ); houve interação entre categoria animal (Cat) e PPP, em que primíparas no PPP1 (32 a 55 dias) apresentaram resultados inferiores na TPEM em relação às primíparas no PPP2 (56 a 90 dias); houve também interação entre PPP e ECC, em que animais no PPP2 e com ECC4 apresentaram resultados inferiores de TPEM, em relação aos animais com ECC5; e também houve efeito negativo do PPP1 sobre a TPIATF e de um dos touros na TPEM. Após a realização do experimento concluiu-se que o Progestar $^{\circledR}$ possui semelhante eficiência na taxa de prenhez, quando comparado ao $\mathrm{DIB}^{\circledR}$ e que ambos tratamentos têm potencial para proporcionar TPIATF acima de $50 \%$ e TPEM acima de $90 \%$.

Palavras-chave: Dispositivo Intravaginal. Progesterona. PHB. IATF. Nelore. 


\begin{abstract}
BRAGA, F. A. Use of an intravaginal device for releasing progesterone-based TAl program in Nelore cows (Bos taurus indicus). [Emprego de um dispositivo intravaginal para liberação de progesterona em programa de IATF em vacas Nelore (Bos taurus indicus)]. 2008. 102 f. Dissertação (Mestrado em Medicina Veterinária) Faculdade de Medicina Veterinária e Zootecnia, Universidade de São Paulo, São Paulo, 2008.
\end{abstract}

The artificial insemination $(\mathrm{Al})$ is a biotechnique that causes the fastest genetic improvement of a herd and, therefore should be essential in the modern livestock. Heat detection inefficiency and low ovarian ciclicity in the postpartum period establish a great obstacle on applicability of Al programs. In front of these difficulties, the use of timed artificial insemination (TAI) improves the results, because eliminates the heat detection and induces the ciclicity of cows in anestrous postpartum. In TAI protocols is fundamental the use of intravaginal devices for releasing progesterone $\left(\mathrm{P}_{4}\right)$. In the current market, these devices are imported and made of silicone, a biocompatible polymer, but not biodegradable. Recently intravaginal progesterone devices made of PHB, a biodegradable polymer, have been studied. The aim of this study was to compare the efficiency, in TAI program, of a new intravaginal device $\left(\right.$ Progestar $\left.^{\circledR}\right)$, on pregnancy rate, in Nelore cows, with a device made of silicone DIB ${ }^{\circledR}$, currently available in the brazilian market. Were used 240 Nelore cows, in a generalized randomized block design, divided in two groups (control - DIB ${ }^{\circledR}$ and treatment - Progestar $^{\circledR}$, used in the synchronization protocols and TAI). Two experiments were done: the first experiment used new intravaginal devices $(n=136)$, while the second experiment utilized used intravaginal devices $(n=104)$. The pregnancy rates, of TAI (TAIPR) and breeding season (BSPR) (dependent variables), were compared by analysis of variance, separating the treatment, blocks and interactions effect. In experiment 1: there was no interaction between variables and treatment; there was no effect of treatment on TAIPR $\left(D I^{\circledR}{ }^{\circledR}-66,7 \%\right.$ and Progestar ${ }^{\circledR}$ $65,8 \%$ ) and on BSPR $\left(\right.$ DIB $^{\circledR}-95 \%$ and Progestar $\left.^{\circledR}-94,7 \%\right)$; there was an interaction between postpartum period (PPP) and body condition score (BCS), in which animals in PPP1 (45 to 70 days) and BCS4 showed inferior results on TAIPR related to animals BCS5 and 6; there was also an interaction between PPP and ovary condition score (OCS), in which animals in PPP2 (71 to 90 days) not cyclic 
showed inferior results on TAIPR, related to cyclic animals; and there was also no effect of variables on TAIPR and BSPR. In experiment 2: there was no interaction between variables and treatment; there was no effect of treatment on TAIPR (DIB ${ }^{\circledR} 2$ $-61,6 \%$ and $\left.\operatorname{Progestar}^{\circledR} 2-55,8 \%\right)$ and on BSPR $\left(\right.$ DIB $^{\circledR} 2-94,2 \%$ and $\operatorname{Progestar}^{\circledR} 2$ - 88,5\%); there was an interaction between animal category (Cat) and PPP, in which primiparous in PPP1 (32 to 55 days) showed inferior results on BSPR, related to primiparous in PPP2 (56 to 90 days); there was also an interaction between PPP and BCS, in which animals in PPP2 and BCS4 showed inferior results on BSPR, related animals BCS5; and there was also negative effect of PPP1 on TAIPR and one of the bulls on BSPR. This experiment showed that the Progestar ${ }^{\circledR}$ had the same efficiency on pregnancy rate, as the commercially available $\mathrm{DIB}^{\circledR}$ and both treatments have the potential to provide TAIPR above $50 \%$ and BSPR above $90 \%$.

Keywords: Intravaginal Device. Progesterone. PHB. TAI. Nelore 


\section{LISTA DE QUADROS}

Quadro 1 - Escores de condição ovariana. 


\section{LISTA DE FIGURAS}

Figura 1 - Fórmula estrutural do (a) ácido-3-hidroxi-butirato e (b) poli-ácido-

3-hidroxi-butirato (PHB). .44

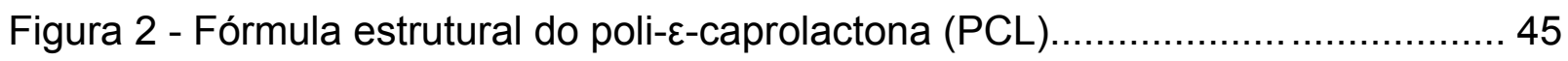

Figura 3 - Amostra de animais utilizados nos experimentos.............................49

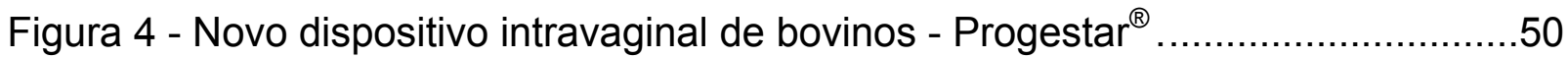

Figura 5 - Dispositivo Interno Bovino - DIB ${ }^{\circledR}$ (Syntex, Argentina) ........................50

Figura 6 - Protocolos de sincronização e IATF............................................53 


\section{LISTA DE TABELAS}

Tabela 1 - Causas de Variação e graus de liberdade da análise de variância da TPIATF do experimento 1

Tabela 2 - Causas de Variação e graus de liberdade da análise de variância da TPEM do experimento 1

Tabela 3 - Causas de Variação e graus de liberdade da análise de variância da TPIATF do experimento 2 ......

Tabela 4 - Causas de Variação e graus de liberdade da análise de variância da TPEM do experimento 2

Tabela 5 - TPIATF e TPEM segundo tratamento, categoria animal, período pós-parto, escores de condição corporal e ovariana, touro e interações.

Tabela 6 - TPIATF e TPEM segundo tratamento, escore de condição ovariana, categoria animal, período pós-parto, escore de condição corporal, touro e interações 


\section{LISTA DE GRÁFICOS}

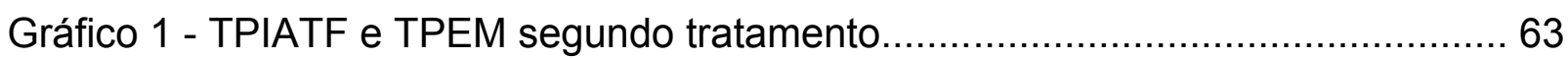

Gráfico 2 - TPIATF nos PPP1 e PPP2 segundo escore de condição corporal........... 63

Gráfico 3 - TPIATF nos PPP1 e PPP2 segundo escore de condição ovariana.......... 65

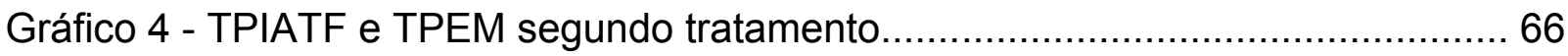

Gráfico 5 - TPEM de primíparas e multíparas segundo período pós-parto.................68 68

Gráfico 6 - TPEM nos PPP1 e PPP2 segundo escore de condição corporal ............. 68 


\section{LISTA DE ABREVIATURAS}

BE Benzoato de Estradiol

Cat Categoria Animal

CE Cipionato de Estradiol

CL Corpo Lúteo

ECC Escore de Condição Corporal

ECO Escore de Condição Ovariana

$\mathrm{E}_{2} \quad$ Estrógeno

eCG Gonadotrofina Coriônica Equina

FSH Hormônio Folículo Estimulante

LH Hormônio Luteinizante

GnRH Hormônio Liberador de Gonadotrofinas

IA Inseminação Artificial

IATF Inseminação Artificial em Tempo Fixo

PPP Período Pós-Parto

PHA Poli-hidroxi-alcanoato

PHB Poli-hidroxi-butirato

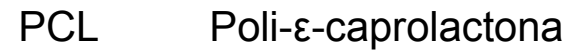

$\mathrm{P}_{4} \quad$ Progesterona

PGF $_{2 \alpha} \quad$ Prostaglandina $F_{2 \alpha}$

TPIATF Taxa de Prenhez na IATF

TPEM Taxa de Prenhez ao Final da Estação de Monta

VE Valerato de Estradiol 


\section{SUMÁRIO}

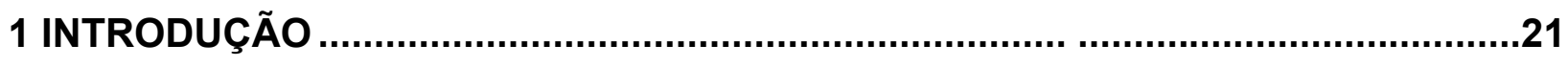

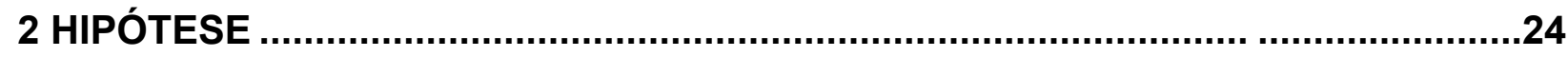

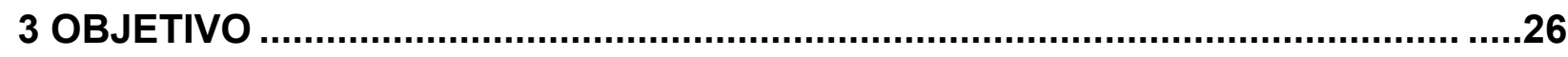

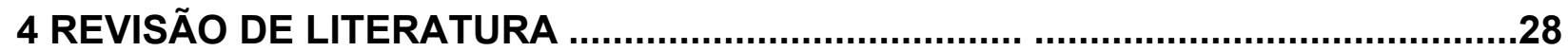

4.1 DINÂMICA FOLICULAR E FISIOLOGIA REPRODUTIVA..................................28

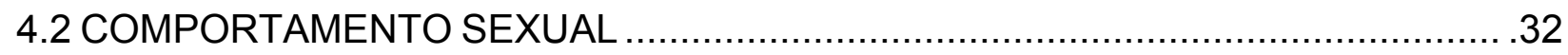

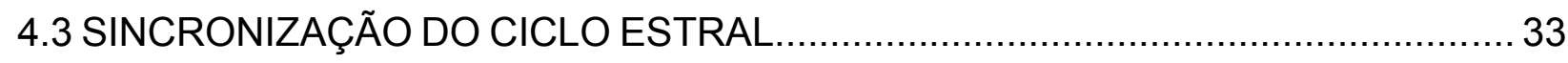

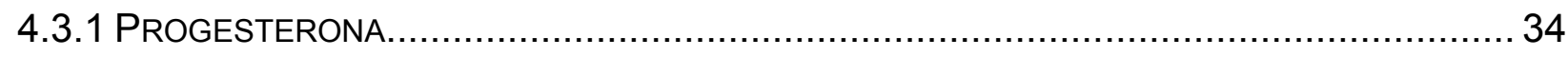

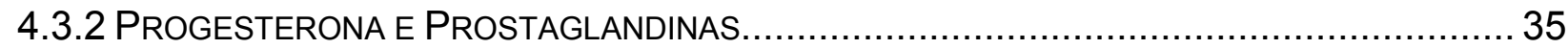

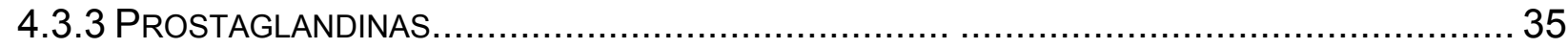

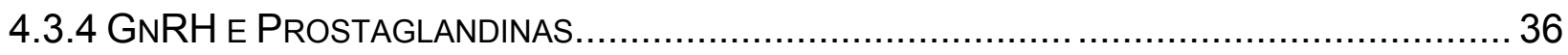

4.3.5 Progesterona, Prostaglandinas, eCG e Estrógenos....................................... 38

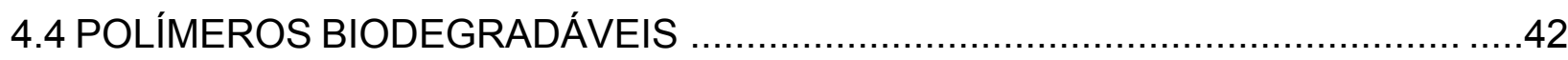

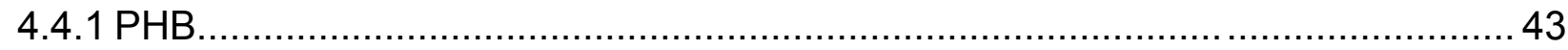

4.4.2 PCL

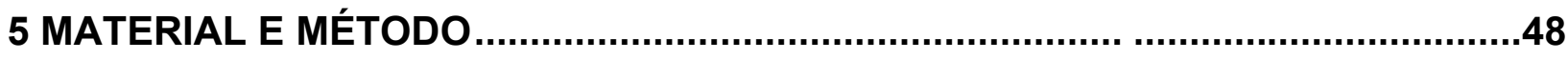

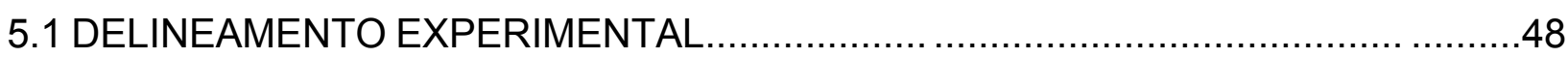

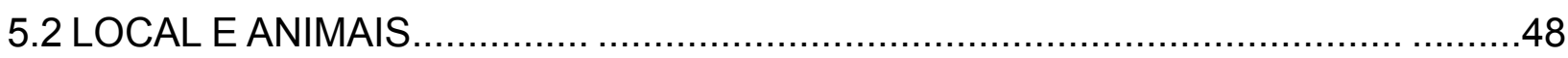

5.3 DISPOSITIVOS INTRAVAGINAIS E TRATAMENTOS ......................................50

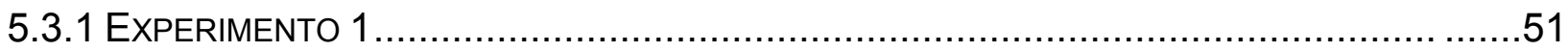

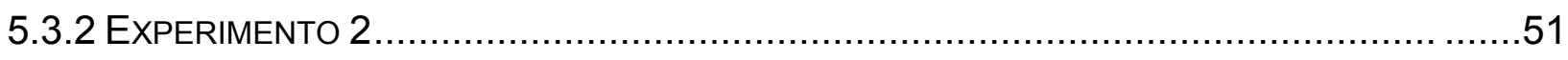

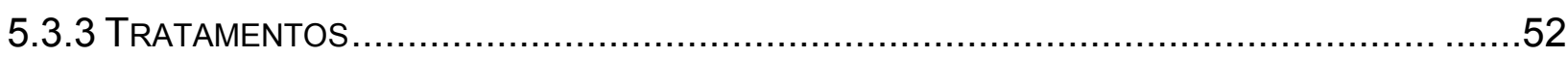

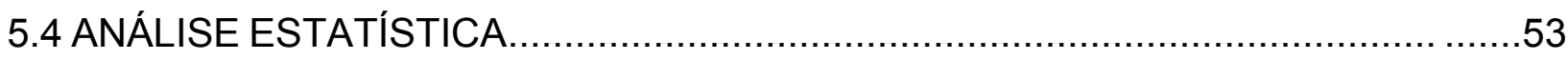




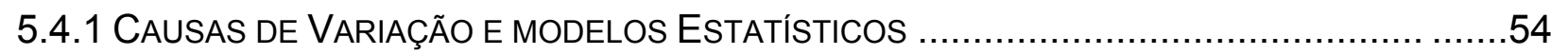

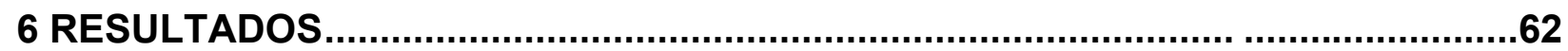

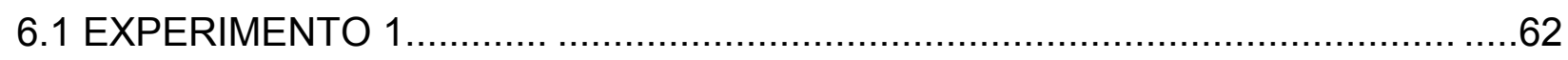

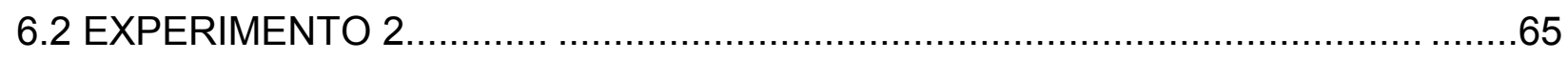

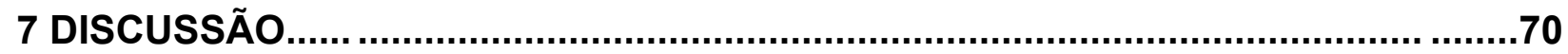

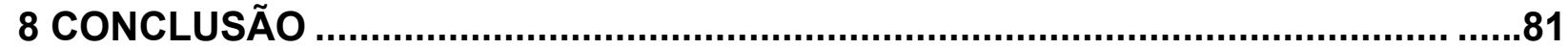

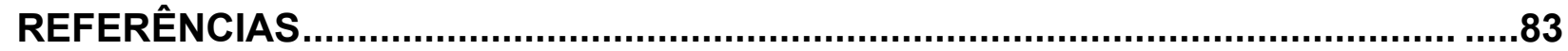




\section{INTRODUÇÃO}

O Brasil é um país que tem como fonte de renda fundamental, o agronegócio. Somente no ano de 2007, totalizou mais de 207 milhões de cabeças bovinas, aproximadamente 80 milhões de fêmeas em reprodução, abate superior a 45 milhões de animais, produção de 9 milhões de toneladas de carne sendo 2,4 milhões para exportação, obtendo assim 4,5 bilhões de dólares (ABIEC, 2008). Com o crescimento de quase $8 \%$ do agronegócio brasileiro em 2007, o PIB do setor primário (agricultura e pecuária) somou aproximadamente $R \$ 150$ bilhões, e apesar das turbulências iniciais, vinculadas aos problemas do setor imobiliário nos EUA, as perspectivas são otimistas para o ano de 2008 (CEPEA, 2008). É o primeiro exportador de carne bovina e possui o maior rebanho bovino comercial do mundo e também grande produção leiteira. Tal posição foi atingida devido ao grande processo de tecnificação ocorrido nesta área, nas últimas décadas (ANBR, 2007).

É neste contexto que se insere o gado zebuíno brasileiro, representado principalmente pela raça Nelore, um dos mais importantes patrimônios genéticos da bovinocultura mundial. O rebanho brasileiro apresenta uma prevalência de aproximadamente $80 \%$ de sangue zebu (Bos taurus indicus) criadas na sua grande maioria a pasto e em condições extensivas.

O maior impacto no processo de tecnificação surgiu com a inseminação artificial (IA). Esta biotécnica é prática, econômica e sua principal vantagem é o rápido melhoramento genético. No Brasil o uso desta ferramenta ainda é limitado, pois somente $7 \%$ do rebanho são inseminados artificialmente (ASBIA, 2008), devendo este número ser aprimorado. Para o sucesso da IA os manejos sanitário, nutricional e reprodutivo do rebanho são de fundamental importância.

O uso da IA provou ser viável técnica e economicamente, entretanto para obtenção de resultados satisfatórios é necessário compreender as limitações do emprego desta biotécnica. Baixas taxas de serviço em bovinos são causadas principalmente por ineficiência na detecção de estro e baixa ciclicidade ovariana no período pós-parto (STEVENSON, 2001).

Desta maneira o recente desenvolvimento de tecnologias de sincronização de estro e programas de inseminação artificial em tempo fixo (IATF) colabora 
sobremaneira para o aumento do emprego da IA, obtendo assim aumento de lucratividade das propriedades. $O$ aumento das taxas de serviço pela indução de ciclicidade de vacas em anestro pós-parto e pela IA sem necessidade de se detectarem os estros são vantagens da utilização de programas de IATF. Poderíamos citar também outras vantagens da IATF como: diminuição do intervalo parto - concepção (período de serviço ideal de 85 dias); altas taxas de prenhez no início da estação de monta; diminuição do intervalo entre partos (ideal de 12 meses), aumentando o número de bezerros nascidos e concentração de mão-de-obra nos partos, desmame e manejos.

Os produtos atualmente disponíveis no mercado brasileiro para possibilitar a liberação sustentada de $\mathrm{P}_{4}$ nos protocolos de programas de IATF são importados e confeccionados em silicone. O silicone é uma matriz biocompatível, porém não biodegradável. Novos dispositivos vêm sendo fabricados utilizando-se biopolímeros obtidos a partir da fermentação da cana-de-açúcar pelo Bacillus megaterium. Estes dispositivos foram confeccionados em PHB e possuem cinética de liberação in vitro e in vivo bastante semelhante à dos dispositivos comerciais (PIMENTEL, 2006). 


\section{HIPÓTESE}

O novo dispositivo intravaginal, fabricado a partir dos biopolímeros PHB e PCL (Progestar ${ }^{\circledR}$ ), possui eficiência semelhante nas taxas de prenhez de fêmeas da espécie bovina, quando comparado ao dispositivo à base de silicone DIB ${ }^{\circledR}$, atualmente disponível no mercado brasileiro. 


\section{OBJETIVO}

Comparar as taxas de prenhez obtidas com o novo dispositivo intravaginal Progestar $^{\circledR}$, em programas de IATF para bovinos de corte da raça Nelore, com as proporcionadas pelo dispositivo à base de silicone DIB $^{\circledR}$, atualmente disponível no mercado brasileiro. 


\section{REVISÃO DE LITERATURA}

\subsection{DINÂMICA FOLICULAR E FISIOLOGIA REPRODUTIVA}

O ciclo estral em fêmeas bovinas varia de 17 a 25 dias (VACA et al., 1985), sendo dividido em 4 etapas: estro (dias 0 a 1), níveis elevados de estrógeno $\left(E_{2}\right)$ e sintomas característicos do estro; metaestro (dias 1 a 6), ovulação e formação do corpo lúteo (CL); diestro (dias 7 a 16), secreção de progesterona $\left(\mathrm{P}_{4}\right)$ e proestro (dias 17 a 21 ), luteólise induzida pela prostaglandina $F_{2 \alpha}\left(P_{G} F_{2 \alpha}\right)$ e crescimento final do folículo dominante ovulatório. A fase considerada folicular ou estrogênica envolve as etapas proestro, estro e metaestro e a fase luteínica (progestacional) envolve a etapa de diestro (HAFEZ, 2004).

Por meio da ultra-sonografia foi possível um estudo mais aprofundado sobre a dinâmica folicular e comprovou-se que o crescimento dos folículos durante o ciclo estral ocorria em ondas foliculares (SAVIO et al., 1988; SIROIS; FORTUNE; QUIRK, 1988). A dinâmica folicular ovariana em fêmeas zebuínas da raça Nelore foi caracterizada pelo predomínio de 2 ondas de crescimento folicular em vacas e 3 ondas em novilhas (BARROS et al., 1995; RHODES et al., 1995; FIGUEIREDO et al., 1997; GAMBINI et al., 1998). Este padrão de crescimento folicular também foi descrito para fêmeas taurinas (SAVIO et al., 1988). Cada onda folicular possui 4 diferentes etapas: emergência, seleção, dominância e atresia ou ovulação dos folículos ovarianos (GINTHER; KASTELIC; KNOPF, 1989; DISKIN; AUSTIN; ROCHE, 2002).

A foliculogênese é a sucessão de diferentes etapas do crescimento e desenvolvimento folicular, desde o momento em que o folículo primordial entra em fase de crescimento e maturação até sua regressão ou ruptura na ovulação (HANSEL; CONVEY, 1983). Os folículos ovarianos são classificados como folículos

pré-antrais (primordial, primário e secundário) e folículos antrais (terciário e maduro ou pré-ovulatório). A foliculogênese é dividida em 2 etapas básicas: do folículo primordial ao secundário e do folículo pré-antral ao folículo maduro, sendo que o desenvolvimento folicular pré-antral independe de gonadotrofinas e mecanismos 
parácrinos de controle são de fundamental importância nesta fase (GONG et al., 1996).

No ciclo estral a emergência da primeira onda folicular ocorre no dia da ovulação, quando é verificado um pico transitório do hormônio folículo estimulante (FSH) na corrente sanguínea (ADAMS et al., 1992). O FSH é essencial no início do crescimento folicular e com sua diminuição ocorre o fim do processo de seleção (GONG et al., 1996; MONNIAUX et al., 1997).

Em fêmeas bovinas que apresentam 2 ondas foliculares as emergências destas ocorrem no dia da ovulação e dia 10 do ciclo e em fêmeas com 3 ondas foliculares, as emergências ocorrem no dia da ovulação, no dia 12 e no dia 16 do ciclo estral (GINTHER et al., 1989). Mas pode existir uma variação individual quanto ao dia da emergência de cada onda, principalmente da segunda onda folicular, que pode emergir do dia 6 ao dia 12 do ciclo estral (GINTHER et al., 1996; FIGUEIREDO et al., 1997). Dessa forma sucessivas ondas foliculares permanecem anovulatórias até o momento da luteólise (BERGFELT et al., 1991).

$\mathrm{Na}$ emergência de uma onda folicular em zebuínos ocorre o recrutamento de aproximadamente 33,4 folículos, enquanto que nos taurinos este recrutamento ocorre em 25,4 folículos (CARVALHO et al., 2007). Nos primeiros 2 dias esses folículos apresentam um crescimento semelhante, até que ocorre a chamada seleção (divergência ou desvio), no qual um folículo dominante é selecionado para continuar seu crescimento e desenvolvimento enquanto que os demais folículos subordinados interrompem seu crescimento e entram em atresia folicular (BÓ et al., 2000). Folículos subordinados podem se tornar dominantes caso ocorra a remoção do folículo dominante original (ADAMS et al., 1993).

O início da seleção é caracterizado por uma maior taxa de crescimento do folículo dominante em relação ao segundo maior folículo presente no ovário (GINTHER et al., 1997), possuindo uma duração média de 8 horas culminando com a redução de $\mathrm{FSH}$ à concentrações basais (GINTHER et al., 1999). O período médio compreendido entre a emergência da onda folicular e a seleção é de aproximadamente 2,5 dias (GINTHER et al., 1997). Os tamanhos dos folículos dominante e subordinado em taurinos são de 8,5 e $7,2 \mathrm{~mm}$, respectivamente (GINTHER et al., 1996) e em zebuínos esta diferença é de 6,2 e 5,4 mm, respectivamente (GIMENES et al., 2005). 
Os fatores que determinam a seleção do folículo específico para continuar seu crescimento parecem ser a de adquirir primeiramente receptores para o hormônio luteinizante (LH) nas células da granulosa (DRIANCOURT, 2001). Xu et al. (1995) observaram que nesta fase há um aumento significativo na concentração de RNAs mensageiros (mRNAs) para os receptores de LH nas células da teca em folículos de $10 \mathrm{~mm}$ de diâmetro aproximadamente. É importante ressaltar que no folículo ovariano dominante existem as células da teca (responsáveis pela síntese de andrógenos) e mais internamente as células da granulosa (responsáveis pela síntese de estrógenos) (HAFEZ, 2004).

Existem receptores específicos para as gonadotrofinas nas células da granulosa (FSH e posteriormente $\mathrm{LH}$ ) e da teca (LH) do folículo ovariano. A ligação do LH com seu respectivo receptor nas células da teca estimula a conversão da pregnenolona em androstenediona, que é então metabolizada à $E_{2}$ pela enzima P450 aromatase quando ocorre a ligação do $\mathrm{FSH}$ com seu respectivo receptor nas células da granulosa (FORTUNE; QUIRK, 1988). O FSH inicia o crescimento dos folículos enquanto que o LH promove a continuidade deste crescimento folicular e a maturação final do folículo dominante (LUCY et al., 2001). As gonadotrofinas são produzidas na hipófise anterior (adenohipófise) pelo estímulo do $\mathrm{GnRH}$ do hipotálamo (HAFEZ, 2004).

O folículo dominante se caracteriza pelo aumento da produção de $E_{2}$ e pela alteração na relação $E_{2} / P_{4}$ intrafolicular (SUNDERLAND et al., 1994). Seu crescimento é limitado pela ação da $\mathrm{P}_{4}$ e só se tornará um folículo ovulatório quando ocorrer a luteólise e consequentemente um pico de LH (GINTHER; KASTELIC; KNOPF, 1989; LUCY et al., 2001). Altas concentrações de $\mathrm{P}_{4}$ reduzem a freqüência de pulsos de LH, acarretando na perda de dominância do folículo e início de uma nova onda folicular (STOCK; FORTUNE, 1993). Os folículos dominantes de zebuínos apresentaram medidas de diâmetro máximo de 10 a $12 \mathrm{~mm}$, enquanto que este valor em taurinos é de 14 a 20 mm (BÓ et al., 1993).

A capacidade do folículo dominante em continuar seu crescimento pode ser devido à inibição das IGFBPs (insulin like growth factor binding protein) com conseqüente aumento da biodisponibilidade dos fatores de crescimento semelhante à insulina - IGFs (FORTUNE; QUIRK, 1988). O IGF-1 se liga às células da granulosa e da teca, estimulando a mitose e aumentando a síntese de $E_{2}, P_{4} e$ andrógenos (SPICER et al., 1995), exercendo assim uma importante função no 
crescimento folicular através do estímulo da proliferação das células da granulosa, conjuntamente com a ação das gonadotrofinas (GONG et al., 1996). A indução dos receptores de LH nos folículos dominantes pode ser também mediada pelo IGF-1 (CHASE et al., 1998).

O FSH sofre feedback negativo do $E_{2}$ e da inibina, este último hormônio parece ser sintetizado e secretado por todos os folículos ovarianos maiores do que 3 $\mathrm{mm}$, enquanto que as concentrações de $E_{2}$ aumentam proporcionalmente com 0 crescimento do folículo dominante (WILTBANK et al., 1996). Desta forma os folículos que respondem ao LH sobreviverão em baixos níveis de $\mathrm{FSH}$, enquanto que os demais folículos entrarão em atresia (BÓ et al., 2000). A liberação de LH é regulada principalmente pelos níveis de $\mathrm{P}_{4}$ e $\mathrm{E}_{2}$ (KINDER et al., 1996) e o pico pré-ovulatório de LH não ocorre na fase luteínica devido à elevada concentração de $\mathrm{P}_{4}$ que impede que o $\mathrm{E}_{2}$ exerça feedback positivo no hipotálamo (BROWNING et al., 1994).

Rahe et al. (1980) revelaram diferentes padrões de secreção de LH ao longo da onda folicular: fase luteínica inicial - alta freqüência e baixa amplitude; fase luteínica intermediária - baixa freqüência e alta amplitude e fase luteínica final - alta frequência e alta amplitude, causando crescimento do folículo e conseqüente aumento de $E_{2}$ (CUPP et al., 1995). Esse aumento de $E_{2}$ irá aumentar os pulsos de LH que subseqüentemente induzirá o pico pré-ovulatório de LH (STUMPF et al., 1991). O intervalo entre a liberação de LH e a ovulação em zebuinos foi de aproximadamente 25,9 horas (CAVALIERI et al., 1997).

A capacidade ovulatória em taurinos ocorre quando o folículo dominante atinge o tamanho de $10 \mathrm{~mm}$ (SARTORI et al., 2001), enquanto que nos zebuínos esta capacidade é alcançada a partir de $7 \mathrm{~mm}$ (GIMENES et al., 2005). O LH é o hormônio que desencadeia a seqüência de eventos para a ovulação, mediados por duas vias, a da adenilciclase - AMPc e a da fosfolipase C - inositol fosfato (GILCHRIST et al., 1996).

No folículo ovulatório existe uma camada avascular de células da granulosa envolvidas por uma membrana basal. Após o processo ovulatório esta membrana se rompe e o ovócito é eliminado juntamente com o fluido folicular, ocorrendo a formação do CL no local em que estava presente o folículo ovulatório (MILVAE et al., 1996). A estrutura ovariana remanescente do folículo recém ovulado é chamada de corpo hemorrágico $(\mathrm{CH})$ que se reorganiza para a posterior formação do $\mathrm{CL}$, sob a influência de fatores angiogênicos e mitogênicos como o fator de crescimento de 
fibroblastos (GOSPODAROWICZ et al., 1985) e o fator de crescimento semelhante à insulina (SUH et al., 1992). Predominantemente as células da granulosa darão origem às células luteínicas grandes (maior produção de $\mathrm{P}_{4}$ ) e as células da teca às células luteínicas pequenas (menor produção de $\mathrm{P}_{4}$ ). Gradualmente ocorre o aumento do tamanho do CL e da sua capacidade de secretar $\mathrm{P}_{4}$ (NISWENDER et al., 2000). O CL de zebuínos apresentou tamanho de medida máxima de 17 a 21 $\mathrm{mm}$, enquanto que em taurinos esta mesma medida foi de 20 a $30 \mathrm{~mm}$ (BÓ et al., 1993). Depois de atingida a capacidade máxima a produção de $P_{4}$ se estabiliza até em torno do dia 16 a 17 do ciclo estral (RATHBONE et al., 2001).

Em vacas cíclicas o CL sofre regressão morfológica e funcional (RATHBONE et al., 2001) aproximadamente 17 a 20 dias após a ovulação. Este processo, induzido pela PGF $2 \alpha$ (HORTON; POYSER, 1975) determina a duração do ciclo estral e é caracterizado pela diminuição na produção de $\mathrm{P}_{4}$, fragmentação de componentes celulares, redução do suporte vascular, degeneração e fagocitose das células luteínicas (MILVAE et al., 1996).

A produção deste agente luteolítico ocorre no endométrio, em um padrão pulsátil durante o período da luteólise (SHEMESH; HANSEL, 1975), estimulada pela ocitocina proveniente do próprio CL (FUCHS et al., 1990) e atingindo-o por um sistema de transporte local veno-arterial de contracorrente (HIXON; HANSEL, 1974). Estes receptores de ocitocina no endométrio são estimulados pelo $E_{2}$ e foi verificado também que o CL possui um sistema de feedback positivo na produção intraluteal de PGF $_{2 \alpha}$ (WILTBANK, 1997). Uma totalidade de $98 \%$ da PGF $_{2 \alpha}$ é metabolizada em 13,14diidro-15cetoprostaglandina $F_{2 \alpha}$ (PGFM) logo na primeira passagem pelos pulmões (HIXON; HANSEL, 1974).

\subsection{COMPORTAMENTO SEXUAL}

Durante a fase do estro as fêmeas bovinas apresentam manifestações comportamentais características como imobilidade durante a monta, movimentação excessiva, mugidos e micções freqüentes e homossexualismo (LANDAETA- 
HERNÁNDEZ et al., 2004). A duração do estro mostrou-se mais curto em zebuínos do que em taurinos, dificultando ainda mais sua detecção (GALINA; ARTHUR, 1990). A duração média do estro nos zebuínos foi de 12,9 horas, enquanto que nos taurinos este período foi de 16,3 horas (MIZUTA, 2003). Segundo Xu et al. (1998) a duração do estro sofre influência também da idade dos animais e do tipo de manejo. O intervalo início de estro até a ovulação em fêmeas bovinas foi de 25 a 29 horas (BARROS et al., 1995; CAVALIERI et al., 1997; PINHEIRO et al., 1998; MEMBRIVE, 2000; MIZUTA, 2003).

O zebu tende a mostrar sinais de estro durante a noite (GALINA; ARTHUR, 1990; CHENOWETH, 1994). Pinheiro et al. (1998) reportaram manifestações de estro noturno em $53,8 \%$ de vacas da raça Nelore, no qual $30 \%$ destas iniciaram e terminaram o estro durante a noite, dificultando o manejo e diminuindo a eficácia da detecção do estro. Entretanto Membrive (2000) e Rocha (2000), não verificaram uma significativa concentração de estros durante o período noturno. Lamothe-Zavaleta et al. (1991) verificaram que a temperatura ambiental influencia a duração do estro em vacas zebuínas, na qual em temperaturas menores do que $27^{\circ} \mathrm{C}$ a duração do estro foi maior quando comparadas às temperaturas maiores do que $27^{\circ} \mathrm{C}(12,4$ vs 9,3 horas, respectivamente).

\subsection{SINCRONIZAÇÃO DO CICLO ESTRAL}

O controle endógeno e endócrino do ciclo estral e da sincronização de fêmeas bovinas envolve uma complexa relação de hormônios hipotalâmicos, hipofisários, ovarianos e uterinos (MILVAE et al., 1996). As principais formas de controle e manipulação do ciclo estral estão baseadas na extensão ou na redução da fase luteínica e na modificação dos padrões da onda folicular através do uso de diversos hormônios (MACMILLAN; BURKE, 1996). 


\subsubsection{Progesterona}

No início da década de 40 a progesterona tornou-se disponível a partir de precursores de origem vegetal (RATHBONE et al., 2001), enquanto que na década de 50 , diversos progestágenos ativos por via oral foram sintetizados na busca por contraceptivos para mulheres. Rapidamente estes produtos poderiam substituir a $\mathrm{P}_{4}$ produzida pelo CL (BURSI; GROEN, 2000).

Progestágenos e $\mathrm{P}_{4}$ têm sido utilizados desde a década de 60 com o objetivo de mimetizar uma fase luteínica por período que permita a regressão espontânea do $\mathrm{CL}$, levando a uma sincronização de estro dentro de aproximadamente 4 dias após a remoção do agente progestacional (RATHBONE et al., 2001). Os progestágenos são compostos similares à $\mathrm{P}_{4}$ e podem ser administrados por via oral (acetato de melengestrol - MGA) ou por meio de implantes subcutâneos de norgestomet $\left(\right.$ Crestar $^{\circledR}$ e Syncro-Mate-B $\left.{ }^{\circledR}\right)(B O ́, 2000)$.

$\mathrm{A}_{4}$ foi a primeira droga a ser utilizada para controlar o ciclo estral de ruminantes (CHRISTIAN; CASIDA, 1948). Os tratamentos por meio de administrações diárias de $\mathrm{P}_{4}$ resultavam em altas taxas de sincronização do estro, no entanto, apresentavam baixa concepção e fertilidade (MACMILLAN; PETERSON, 1993). Posteriormente o MGA substituiu a $P_{4}$ para a sincronização do estro, obtendo também resultados insatisfatórios (ZIMBELMAN; SMITH, 1966). Esta baixa fertilidade está relacionada principalmente com a maturação espontânea dos ovócitos, com o posterior envelhecimento dos mesmos dentro dos folículos dominantes persistentes (MIHM et al., 1994; REVAH; BUTLER, 1996).

Animais tratados com norgestomet apresentaram maior freqüência de pulsos de LH quando comparadas à animais na fase de diestro, mesmo na presença de concentrações plasmáticas similares de $\mathrm{P}_{4}$ (KINDER et al., 1996). $\mathrm{A}_{4}$ e os progestágenos inibem o estro, a ovulação e alteram a dinâmica folicular agindo sobre o hipotálamo e regulando a liberação de $\mathrm{GnRH}$ e consequentemente a de $\mathrm{LH}$ (PETERS et al., 1994). É importante lembrar que tratamentos com $\mathrm{P}_{4}$ e progestágenos são apontados como indutores de ciclicidade ovariana no período pós-parto em fêmeas bovinas (MIHM, 1999). 


\subsubsection{Progesterona e Prostaglandinas}

$\mathrm{A} \mathrm{PGF}_{2 \alpha}$ pode ser utilizada em combinação com $\mathrm{P}_{4}$ e progestágenos a fim de promover uma melhor sincronização de estro, pela regressão do CL, especialmente se for administrada entre 24 a 48 horas antes da retirada do agente progestacional (SMITH et al., 1984; ODDE, 1990; MACMILLAN; PETERSON, 1993; MADUREIRA et al., 1997). Wiltbank e Kasson (1968) observaram que tratamentos com progestágenos por menos de 14 dias não reduziam as taxas de concepção, mas para serem eficazes na sincronização do estro havia a necessidade da administração de um agente luteolítico. O aumento da secreção pulsátil de LH permite um crescimento mais uniforme do folículo pré-ovulatório durante o período entre a luteólise induzida pela $\mathrm{PGF}_{2 \alpha}$ exógena e a remoção do agente progestacional (SCHMITT et al., 1996).

Embora se obtenha a sincronização dos estros, a precisão do momento do estro e a taxa de fertilidade após o tratamento com $\mathrm{P}_{4}$ ou progestágenos e $\mathrm{PGF}_{2 \alpha}$ ainda estão abaixo das expectativas, mas superior com relação à taxa de concepção se comparado aos tratamentos que utilizam somente com o agente progestacional (ODDE, 1990; MADUREIRA et al., 1997; BEAL et al., 1984).

\subsubsection{Prostaglandinas}

A PGF $_{2 \alpha}$ foi descoberta no início da década de 70 como um potente agente luteolítico (MCCRACKEN, 1972). Após esta data, vários análogos desta molécula foram sintetizados para o uso na indução prematura da luteólise, com conseqüente redução nos níveis plasmáticos de $\mathrm{P}_{4}$ (COOPER, 1974) e sincronização de estros em bovinos (LARSON; BALL, 1992). A PGF P $_{\alpha}$ e seus análogos não possuem ação na ausência do CL (ROWSON; TERVIT; BRAND, 1972) ou no CL recém formado, sendo efetiva esta luteólise somente após o dia 7 do ciclo estral (ODDE, 1990), todavia a presença de receptores de $\mathrm{PGF}_{2 \alpha}$ no $\mathrm{CL}$ foi demonstrada a partir de dois dias após a ovulação (WILTBANK et al., 1995). 
A aplicação de uma única dose de $\mathrm{PGF}_{2 \alpha}$ em um rebanho cujos animais estejam ciclando provoca luteólise em, no máximo, $70 \%$ das fêmeas. Como alternativa podem ser aplicadas 2 doses com intervalo de 11 a 14 dias para se obterem melhores índices de sincronização de estro, pela regressão do CL (LAUDERDALE et al., 1981; ODDE, 1990; CHENAULT, 1992). Embora a administração de $\mathrm{PGF}_{2 \alpha}$ na presença de um $\mathrm{CL}$ funcional induza altas taxas de manifestação de estro em taurinos - 70 a 90\% (TANABE; HANN, 1984) e 66 a 97\% (LAVERDIERE et al., 1995), os resultados em zebuínos mostraram-se conflitantes.

Uma das limitações do uso da $\mathrm{PGF}_{2 \alpha}$ para a sincronização do estro é a alta variação no intervalo entre o tratamento e a manifestação do estro (TANABE; HANN, 1984), o que impede a utilização de protocolos de IATF. O intervalo entre a aplicação da $\mathrm{PGF}_{2 \alpha}$ e a manifestação de estro varia em função do estágio de desenvolvimento dos folículos ovarianos, nos quais animais no início da onda folicular manifestam o estro cerca de 6 dias após a aplicação, enquanto que animais com folículos dominantes entram em estro entre 48 a 60 horas após o tratamento (KASTELIC; GINTHER, 1991).

\subsubsection{GnRH e Prostaglandinas}

A combinação dos hormônios $\mathrm{GnRH}$ e $\mathrm{PGF}_{2 \alpha}$ em um tratamento para sincronização de estro e ovulação é um método bastante prático e tem sido cada vez mais usado em bovinos de leite e de corte (PURSLEY; KOSOROK; WILTBANK, 1997).

Pursley, Mee e Wiltbank (1995) desenvolveram um protocolo experimental denominado Ovsynch (dia 0 - GnRH, dia 7 - PGF $_{2 \alpha}$, dia 9 - GnRH e IA 16 horas depois) para sincronizar a ovulação de vacas leiteiras, possibilitando assim a IATF sem a necessidade de detecção dos estros. Este protocolo apresenta resultados superiores em vacas leiteiras em relação ao rebanho de corte. Tal fato se deve pelo maior estoque de LH presente nas vacas leiteiras, devido à ausência do bezerro e melhores condições nutricionais. 
O tratamento com $\mathrm{GnRH}$ em dias desconhecidos do ciclo estral promove a ovulação do folículo dominante presente no momento (WILTBANK, 1997) ou a atresia do folículo não dominante e uma nova onda folicular se iniciando após 1 a 2 dias (PURSLEY; MEE; WILTBANK, 1995; TWAGIRAMUNGU; GUIBAULT; BUFOUR, 1995; BODENSTEINER et al., 1996). Com o segundo tratamento de $\mathrm{GnRH}$, após a aplicação da $\mathrm{PGF}_{2 \alpha}$, assegura-se a ovulação de um novo folículo dominante melhorando a precisão do estro e da ovulação (TWAGIRAMUNGU; GUIBAULT; BUFOUR, 1995).

A sincronização do estro e da ovulação é maximizada pela administração da segunda dose de $\mathrm{GnRH}, 36$ a 48 horas após a $\mathrm{PGF}_{2 \alpha}$, assim como o aumento da taxa de concepção dos animais inseminados em tempo fixo, 16 a 24 horas após a última aplicação de $\mathrm{GnRH}$. Estes resultados foram muito semelhantes quando comparados com animais inseminados após a detecção de estro (PURSLEY; MEE; WILTBANK, 1995). O dia do ciclo estral em que o Ovsynch é iniciado afeta o programa de sincronização das fêmeas bovinas, uma vez que a resposta do folículo ovariano ao primeiro $\mathrm{GnRH}$ é de fundamental importância para a continuidade do protocolo, ou seja, o dia do início do programa é dependente do estágio de desenvolvimento do folículo (MOREIRA et al., 2000). Para uma melhor sincronização da ovulação do folículo dominante após a segunda dose de $\mathrm{GnRH}$, o ideal é que ocorra a ovulação do folículo dominante inicial após a primeira dose de $\mathrm{GnRH}$ (MARTINEZ et al., 2000). A aplicação do primeiro GnRH em momentos aleatórios do ciclo estral induz a ovulação em apenas $45,7 \%$ das fêmeas bovinas (BARUSELLI et al., 2003).

Este tipo de sincronização tem mostrado melhores resultados em vacas do que em novilhas (PURSLEY; KOSOROK; WILTBANK, 1997; MARTINEZ et al., 2000). As maioria das vacas apresentam 2 ondas foliculares no ciclo estral, se adaptando melhor a este protocolo em relação às novilhas que, predominantemente, apresentam 3 ondas foliculares. O aumento da taxa de prenhez em animais que receberam o protocolo Ovsynch se deve principalmente pelo aumento do número de animais inseminados (100\% de taxa de serviço), pois as taxas de concepção não mostraram este mesmo aumento (PURSLEY et al., 1997).

Algumas novilhas mostram sintomas de estro antes da segunda aplicação de $\mathrm{GnRH}$. A utilização de uma fonte exógena de $\mathrm{P}_{4}$ durante o tratamento pode prevenir 
essas ovulações precoces e aumentar significativamente as taxas de prenhez de novilhas inseminadas em tempo fixo (MARTINEZ et al., 2000).

\subsubsection{Progesterona, Prostaglandinas, eCG e Estrógenos}

A sincronização de estro e da ovulação não depende exclusivamente do controle da fase luteínica, mas também depende do controle do desenvolvimento folicular (KASTELIC; GINTHER, 1991).

Atualmente existem no mercado diversos dispositivos liberadores de $\mathrm{P}_{4} \mathrm{e}$ progestágenos com a finalidade de sincronizar a ovulação para a IATF. Como exemplo, temos: DIB $^{\circledR}$ (Syntex) - 1,0g de $\mathrm{P}_{4}$, dispositivo intravaginal (BÓ; BARUSELLI, MARTINEZ, 2003); CIDR $^{\circledR}$ (Pfizer) - 1,9g de $\mathrm{P}_{4}$, dispositivo intravaginal (MACMILLAN et al., 1991), posteriormente reconfigurado com $1,38 \mathrm{~g}$ de $\mathrm{P}_{4}$ (RATHBONE et al., 2002); PRID ${ }^{\circledR}$ (Sanofi) - 1,55g de $\mathrm{P}_{4}$, dispositivo intravaginal (WINKLER et al., 1977); Crestar $^{\circledR}$ (Intervet) - 3,0mg de norgestomet, dispositivo auricular e Cronipres ${ }^{\circledR}$ (Biogenesis-Bagó) - 1,0g de $\mathrm{P}_{4}$, dispositivo intravaginal. Inserido por um determinado período evita a ovulação do folículo dominante, mas permite o crescimento folicular. A quantidade de $P_{4}$ liberada pelo $\operatorname{CIDR}^{\circledR}\left(1,9 \mathrm{~g}\right.$ de $\left.\mathrm{P}_{4}\right)$ é altamente predizível com valores médios de concentrações plasmáticas em torno de 5 a $6 \mathrm{ng} / \mathrm{mL}$ e conteúdo médio residual de 0,92g (MACMILLAN et al., 1991).

Níveis elevados de $\mathrm{P}_{4}$ parecem ser pré-requisitos para uma expressão do estro e para uma fase luteínica normal (YAVAS; JOHSON; WALTON, 1999; BÓ et al., 2000; LUCY et al., 2001). A exposição à $P_{4}$ exógena seguida por sua diminuição (priming de $\mathrm{P}_{4}$ ) aumenta a freqüência de pulsos de $\mathrm{LH}$, a produção de $\mathrm{E}_{2}$ folicular, os receptores para LH e melhora a luteinização das células foliculares de animais em anestro (CROWE et al., 1993).

A administração de $E_{2}$ suprime o crescimento do folículo dominante, tendo-se observado que esta supressão é mais intensa quando o tratamento é combinado com $\mathrm{P}_{4}$ (BÓ et al., 1995). É importante que elevados níveis de $\mathrm{P}_{4}$ estejam presentes no momento da administração de $E_{2}$, já que picos de $\mathrm{LH}$ foram detectados em 
novilhas tratadas somente com $\mathrm{E}_{2}$ (BÓ et al., 1994). Novilhas tratadas com o implante auricular de norgestomet juntamente com a aplicação de $17 \beta$ estradiol em diferentes fases do desenvolvimento folicular tiveram seu crescimento folicular bloqueado, com uma nova onda folicular emergindo 3 a 5 dias depois (BÓ et al., 1994). Tribulo et al. (1995) também observaram a emergência de uma nova onda folicular 4,3 dias após o tratamento de $17 \beta$ estradiol associado à $\mathrm{P}_{4}$ e ao CIDR $^{\circledR}$ por sete dias, com alto grau de sincronização da ovulação (75\% dos animais ovularam entre 72 e 84 horas após a retirada do dispositivo).

Existem diferentes ésteres de $\mathrm{E}_{2}: 17 \beta$ estradiol, benzoato de estradiol (BE), valerato de estradiol (VE) e o cipionato de estradiol (CE). O BE (SÁ FILHO et al., 2004) e o 17 estradiol (BÓ et al., 1995) apresentam meia vida mais curta que os demais, induzindo uma emergência mais sincronizada de uma nova onda de crescimento folicular. A aplicação do $2 \mathrm{mg} \mathrm{BE}$ induz a emergência 3 a 4 dias após o tratamento (CACCIA; BÓ, 1998), enquanto que a aplicação de 5mg VE resulta em uma nova onda folicular em um momento menos previsível (BÓ et al., 1993) em torno de 5 a 6 dias após o tratamento. Ambos em conjunto com a inserção do um dispositivo de $\mathrm{P}_{4}$ ou progestágeno (CACCIA; BÓ, 1998).

Johnson et al. (1991) concluíram que o a concentração de $E_{2}$ circulante e no fluido folicular foi maior no tratamento por 10 dias com norgestomet em comparação aos tratamentos com 6 ou 8 dias. A utilização do CIDR $^{\circledR}$ por um período de 8 dias apresentou tendência de taxas de prenhez superiores $(54,1 \%$ vs $39,4 \%)$ em relação aos tratamentos por 7 dias em novilhas zebuínas (COLAZO et al., 1999). Não houve diferença nas taxas de prenhez no final da estação de monta de vacas zebuínas entre os grupos tratados com CIDR $^{\circledR}$ (8 dias) associado ao BE $(79 \%)$, Crestar $^{\circledR}$ (9 dias) associado ao VE $(88,3 \%)$ ou IA após detecção de estro (durante 45 dias $80,9 \%$ ), todos com repasse de touros por um período de 45 dias (BARUSELLI et al., 2002).

Não foi observado diferenças nas taxas de prenhez nos trabalhos em que foram comparados o CIDR $^{\circledR}$ e o DIB $^{\circledR}$ em programas de IATF em vacas não lactantes $(61,5 \%$ vs $60,7 \%$, respectivamente) (BÓ et al., 2002) ou em vacas zebuínas com 66 dias pós-parto com o uso de 300 UI de eCG (53,7\% vs 48,5\%, respectivamente) (MARQUES et al., 2003). Frisch e O'neill (1996) compararam as

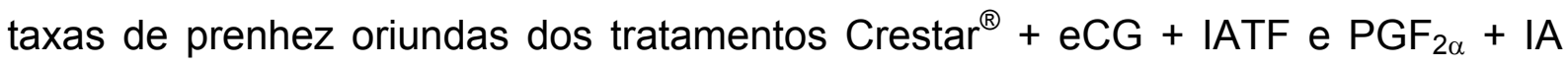


após 12 horas da detecção do estro em vacas e novilhas cruzadas. Os resultados para as novilhas não apresentaram diferença (51,3\% vs 47,2\%, respectivamente), entretanto, para as vacas o primeiro tratamento apresentou resultados superiores $(46,4 \%)$ em relação ao segundo tratamento $(37,1 \%)$.

$\mathrm{O}$ tratamento com $\mathrm{P}_{4}$ ou progestágenos associado a $\mathrm{E}_{2}$ para a sincronização de uma nova onda folicular e a $\mathrm{PGF}_{2 \alpha}$ administrada juntamente com a remoção do implante de $\mathrm{P}_{4}$ (CAVALIERI et al., 2002), proporciona adequadas taxas de sincronização de estro e de ovulação, possibilitando assim a IATF (BÓ et al., 2002). É preconizada a aplicação da $\mathrm{PGF}_{2 \alpha}$ no momento da retirada do agente progestacional para a indução da luteólise e queda dos níveis endógenos de $\mathrm{P}_{4}$, proporcionando condições favoráveis à ovulação (BÓ et al., 2002).

Para aumentar as concentrações plasmáticas de $\mathrm{P}_{4}$ é possível usar a gonadotrofina coriônica eqüina (eCG) que possui ação folículo estimulante e luteinizante em fêmeas bovinas. Produzido pelos cálices endometriais da égua prenhe entre $\circ 40^{\circ}$ e o $130^{\circ}$ dias da gestação, a eCG é um potente agente de indução de foliculogênese, sendo capaz de se ligar nos receptores de FSH e LH, além de possuir um meia-vida de aproximadamente 46 horas (MURPHY; MARTINUK, 1991). A aplicação de eCG após a fase de divergência folicular pode aumentar a taxa de crescimento dos folículos, resultando em um folículo préovulatório maior e, conseqüentemente, em um $\mathrm{CL}$ também maior. Foi verificado em fêmeas tratadas com eCG um maior número de ovulações, maior concentração plasmática de $\mathrm{P}_{4}$ e maior taxa de concepção e de prenhez, em relação às fêmeas que não foram tratadas com eCG (BARUSELLI et al., 2002).

Estudos mostraram resultados satisfatórios quanto à taxa de ovulação e aumento da concentração plasmática de $\mathrm{P}_{4}$ em animais tratados com eCG no momento da retirada do dispositivo de $\mathrm{P}_{4}$ (BARUSELLI et al., 2004). Cavalieri et al. (1997) mostraram uma melhor sincronização do estro, da ovulação e da onda préovulatória de LH em zebuínos tratados com eCG do que naqueles não tratados. Bó, Baruselli e Martinez (2003) sugeriram que a utilização de $400 U$ I de eCG em protocolos com dispositivos de $\mathrm{P}_{4}$ associados ao $\mathrm{BE}$ é mais compensador quando utilizados em animais em condições de anestro, baixa condição corporal e pós-parto precoce, aumentando significativamente a taxa de prenhez (CUTAIA et al., 2003). Como mostrou o trabalho de Baruselli et al. (2003), no qual o uso desta dose de eCG na retirada do dispositivos de $\mathrm{P}_{4}$ em programas de IATF aumentou as taxas de 
prenhez de vacas em anestro (56,5\% vs $29,4 \%)$, com baixa condição corporal (35,5\% vs $26,7 \%)$ e pós-parto precoce menor do que 40 dias ( $58 \%$ vs $45 \%$ ).

Outro experimento testou diferentes dosagens de eCG $(0,50,150,300,500$ ou 750Ul) em vacas de corte, não cíclicas, no período pós-parto de 70 a 90 dias, tratadas por 10 dias com norgestomet, não obtendo diferenças na taxa de prenhez (SMITH et al., 1979). Cutaia et al. (2003) avaliaram os efeitos da aplicação de $400 \mathrm{UI}$ de eCG no dia 6 após a inserção ou na retirada do dispositivo (dia 8), concluindo não haver diferença na taxa de prenhez.

A administração de $E_{2}$ durante a fase folicular do ciclo estral associado ao $E_{2}$ endógeno leva a um efeito ovulatório (BÓ et al., 1994). O tratamento de $\mathrm{P}_{4}$ exógena bloqueia pico de LH (ROBERSON et al., 1989; KOJIMA et al., 1992; BERGFELT et al., 1991). O BE mostrou-se eficiente tanto na dose de $0,75 \mathrm{mg}$ como na de $1 \mathrm{mg}$, aplicado 24 horas após a retirada do dispositivo de $\mathrm{P}_{4}$, na indução do pico de LH 16 horas e ovulação 40 horas após sua administração (MACMILLAN; PETERSON, 1993). As ovulações ocorreram em média 44,1 horas após a aplicação de $1 \mathrm{mg} B E$ em vacas Nelore (BARROS et al., 2000).

Como indutor de ovulação pode ser utilizado o próprio BE administrado 24 horas após a retirada do implante de $\mathrm{P}_{4}$ (LEMASTER et al., 1999), com a IATF realizada 30 horas após esta aplicação, ou seja, os animais são submetidos à IATF entre 52 a 56 horas após a remoção do implante de $\mathrm{P}_{4}$ (BÓ et al., 1996). Cutaia et al. (2003) não observaram diferenças significativas entre a IATF realizada 48 ou 54 horas após a retirada do dispositivo, todavia, resultados numericamente superiores foram encontrados nos animais submetidos à IATF 54 horas após a retirada: 51,4\% vs $45,5 \%$.

A reprodução de um determinado rebanho mantém uma estreita relação com sua nutrição (WILTBANK, 2003). Uma forma muito prática para se avaliar a situação nutricional de um animal é através do escore de condição corporal, que influencia sobremaneira na ciclicidade ovariana e nas taxas de prenhez (VISCARRA et al., 1998). Cutaia et al. (2003) mostraram uma alta correlação $\left(R^{2}=0,9\right)$ entre o escore de condição corporal (1 a 5) e a taxa de prenhez. Os escores de condição corporal de 1,$5 ; 2 ; 2,5 ; 3 ; 3,5$ e 4 obtiveram taxas de prenhez, respectivamente de $27 \%$; $46,5 \% ; 52,3 \% ; 57,7 \%$ e $57,6 \%$. Os resultados também foram semelhantes no que diz respeito à ciclicidade de vacas, na qual as taxas de prenhez de vacas cíclicas $(56,3 \%)$ foram superiores em relação às vacas em anestro $(47 \%)$. 


\subsection{POLÍMEROS BIODEGRADÁVEIS}

Do início do século passado aos dias atuais o uso dos polímeros tem se tornado cada vez mais freqüente na sociedade. Podemos citar diversos exemplos como: garrafas, sacos plásticos, tubos de encanamento, latas de conserva, tintas, escovas de dente, pára-choques de veículos, pneus, entre muitos outros. No setor da pecuária, o maior uso acontece com os dispositivos hormonais.

Os polímeros sintéticos convencionais de origem petroquímica são inertes ao ataque imediato de microorganismos, gerando desta forma um sério impacto ambiental (LUO et al., 2003). Os plásticos convencionais como o polipropileno, poliestireno, polietileno e policloreto de vinila apresentam taxas extremamente baixas de degradação (CHIELLINI; SOLARO, 1996), demorando em média 100 anos para se decomporem totalmente (HUANG; SHETTY; WANG, 1990; CHIELLINI; SOLARO, 1998).

Diversas alternativas têm sido buscadas para minimizar o impacto ambiental causado por estes polímeros convencionais. Como uma solução para este problema surge os polímeros de origem bacteriana, genericamente denominados polihidroxialcanoatos ou PHAS (CHIELLINI; SOLARO, 1998). A biodegradação destes biopolímeros é resultado da ação de bactérias, fungos e algas de ocorrência natural (RAGHAVAN, 1995), variando de seis meses a um ano e meio (SOUZA; AMARAL; NEVES; FOSECA, 2000) e derivando deste processo $\mathrm{CO}_{2}, \mathrm{CH}_{4}, \mathrm{H}_{2} \mathrm{O}$, componentes celulares microbianos e outros produtos (ABR, 1999).

Os polímeros biodegradáveis têm sido amplamente estudados em sistemas de liberação de drogas tanto no campo da medicina humana como da medicina veterinária. Como exemplo destes sistemas na medicina veterinária, podemos citar os implantes intravaginais e também os produtos injetáveis (WINZENBURG; SCHMIDT; FUCHS; KISSEL, 2004).

O alto custo de produção dos polímeros biodegradáveis em comparação aos plásticos convencionais ainda é um problema a ser resolvido (GOMES; BUENO NETTO, 1997; ROSA; FRANCO, 1999). Como uma solução para a questão do alto custo desses materiais, emerge a necessidade de desenvolvimento de misturas poliméricas biodegradáveis que consistam numa mistura física de dois ou mais tipos 
de materiais poliméricos ou copolímeros que não são ligados por ligações covalentes (STEVENS, 1999).

No processo de fabricação dos dispositivos de biopolímeros são empregadas temperaturas mais baixas ao redor de 100 à $140^{\circ} \mathrm{C}$ (RATHBONE et al., 2002), se comparadas ao mesmo processo de fabricação dos dispositivos à base de silicone, na qual são atingidas temperaturas acima de $190^{\circ} \mathrm{C}$. A $\mathrm{P}_{4}$ possui uma excelente estabilidade térmica e desta forma é adequada para ser incorporada nos dispositivos à base de silicone, porém outras drogas de interesse médico não possuem esta mesma estabilidade. Neste contexto, está o dispositivo de biopolímero, que pelo seu diferenciado processo de fabricação é capaz de incorporar outras drogas de interesse em sistemas de liberação sustentada (BURGRAAF et al., 1997).

No Brasil a produção de polímeros biodegradáveis é realizada principalmente a partir da cana-de-açúcar, produto abundante no país, tornando assim o produto mais competitivo, sobretudo no mercado internacional (SOUZA; AMARAL; NEVES; FOSECA, 2000).

\subsubsection{PHB}

Entre os polímeros biodegradáveis o mais conhecido é o poli-ácido-3-hidroxibutirato ou PHB (Figura 1). Sua produção em grande escala acontece por um processo de fermentação bacteriana, sendo ainda um processo relativamente caro (CHIELLINI; SOLARO, 1996). Com a mesma utilidade que os plásticos convencionais, o PHB se presta à fabricação de diversos materiais como embalagens de alimentos, vasilhames, copos, filmes, dispositivos hormonais, entre outros.

O PHB apresenta propriedades mecânicas similares ao polipropileno (ANDERSON; DAWES, 1990). Devido a sua origem natural, este poliéster tem uma excepcional regularidade estereoquímica; suas cadeias são lineares com interações tipo van der Waals entre os oxigênios da carbonila e os grupos metila e interações por pontes de hidrogênio devido à presença de hidroxilas (LUO et al., 2003). 


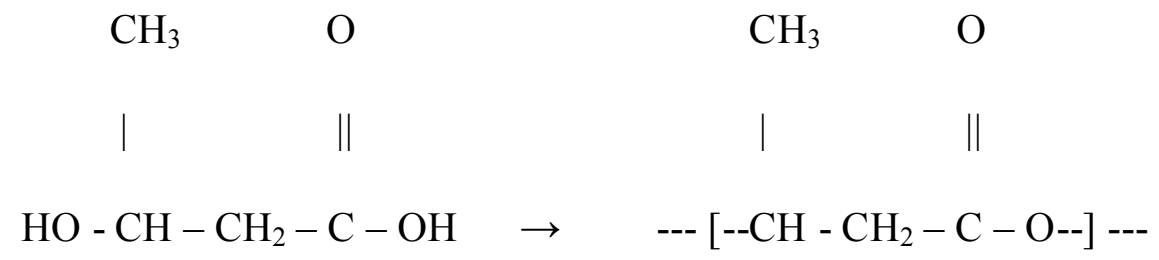

(a)

(b)

Figura 1 - Fórmula estrutural do (a) ácido-3-hidroxi-butirato e (b) poli-ácido-3-hidroxi-butirato (PHB)

O PHB é obtido a partir da sacarose, oriunda da industrialização da cana-deaçúcar e o Bacillus megaterium é a principal bactéria envolvida neste processo (SOUZA; AMARAL; NEVES; FOSECA, 2000). Um estudo realizado com biopolímeros mostrou que o PHB foi o polímero que mais sofreu a biodegradação, provavelmente por causa de sua estrutura química que pode ser atacada mais facilmente (ROSA; CHUI; FILHO; AGNELLI, 2002).

Um estudo demonstrou a possibilidade da liberação sustentada de $\mathrm{P}_{4}$ a partir de microcápsulas (ou microesferas) feitas de PHB, e também a formação de cristais superficiais com uma porcentagem acima de 5\% deste esteróide na mistura, diminuindo desta forma sua flexibilidade (GANGRADE; PRICE, 1991).

Foi desenvolvido um implante subcutâneo de microcápsulas de PHB contendo $\mathrm{P}_{4}$ para eqüinos. Neste estudo fez-se o monitoramento in vivo do perfil de liberação de $\mathrm{P}_{4}$ de éguas tratadas com o novo implante e de éguas controle. Foi observada nas primeiras cinco horas após a inserção do implante uma diferença no nível de $\mathrm{P}_{4}$ plasmático $(12,01 \mathrm{ng} / \mathrm{mL}$ - éguas tratadas vs $0,73 \mathrm{ng} / \mathrm{mL}$ - éguas controle), assim como os níveis deste esteróide se mantiveram mais elevados (acima de $1 \mathrm{ng} / \mathrm{mL}$ ) durante 11 dias nas éguas tratadas (SILVA et al., 2006).

A perspectiva de viabilidade econômica do PHB a partir do açúcar é promissora, uma vez que o Brasil tem larga experiência em processos de produção biotecnológica nesta área e é o maior produtor mundial de açúcar (ABR, 1999). 


\subsubsection{PCL}

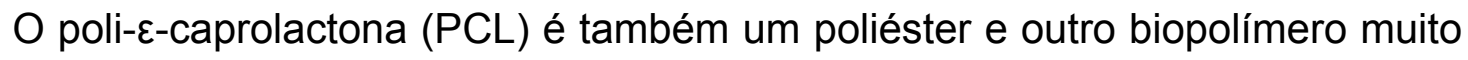
estudado como substrato para biodegradação e como matriz em sistemas de liberação de drogas (PITT; MARKS; SCHINDLER, 1980; PITT; CHASALDO; HIBIONADA; KLIMAS; MARKS; SCHINDLER, 1981). O PCL (Figura 2) surge da abertura do anel de polimerização do caprolactona (CHANDRA; RUSTGI, 1998; DERVAL et al., 2002).

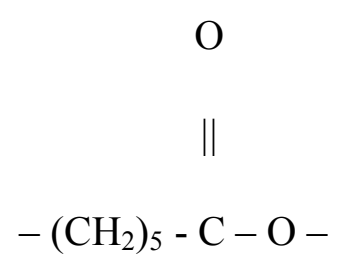

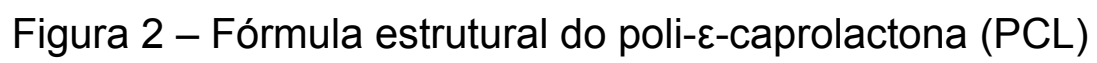

Rathbone et al. (2002) desenvolveram um dispositivo intravaginal à base do biopolímero PCL. Seus primeiros resultados foram de que o novo dispositivo (área superficial de $58 \mathrm{~cm}^{2}$ ) possuía liberação in vivo, em vacas ovariectomizadas da raça Holandesa, inferior se comparado ao $\mathrm{CIDR}^{\circledR}$ (área superficial de $120 \mathrm{~cm}^{2}$ ), porém mantinha um nível plasmático de $\mathrm{P}_{4}$ acima de $1 \mathrm{ng} / \mathrm{mL}$ durante 7 dias. Mesmo com 0 aumento de sua área superficial para $120 \mathrm{~cm}^{2}$, com 5,10 ou $15 \%$ de $P_{4}$, os níveis plasmáticos proporcionados pelo novo dispositivo ainda era menor se comparado ao CIDR $^{\circledR}$. Sendo que com apenas $5 \%$ de $\mathrm{P}_{4}$ o novo dispositivo não conseguia manter níveis de $\mathrm{P}_{4}$ na corrente sanguínea acima de $1 \mathrm{ng} / \mathrm{mL}$ do $4^{\circ}$ ao $8^{\circ}$ dia. Com estes resultados os autores sugeriam que a $\mathrm{P}_{4}$ oriunda do dispositivo de $\mathrm{PCL}$ possuía uma taxa diferente de liberação à $\mathrm{P}_{4}$ presente no $\mathrm{CIDR}^{\circledR}$ e que a solução seria aumentar ainda mais a área superficial do novo dispositivo. Desta forma, o dispositivo foi reformulado para $142,9 \mathrm{~cm}^{2}$ de área superficial, $10 \%$ de $\mathrm{P}_{4}$ e peso total de $22 \mathrm{~g}$. Este novo dispositivo apresentou resultados muito semelhantes em relação ao $\mathrm{CIDR}^{\circledR}$, como taxa de liberação in vitro de $\mathrm{P}_{4}$ por $\mathrm{cm}^{2}$ em função da raiz quadrada do tempo (1342 vs $\left.1290 \mu \mathrm{g} / \mathrm{cm}^{2} / \mathrm{t}^{1 / 2}\right)$, concentração máxima de $P_{4}$ plasmático $(5,3 \mathrm{vs} 5,1 \mathrm{ng} / \mathrm{mL}$ ), período para esta concentração de $\mathrm{P}_{4}$ máxima $\left(0,4\right.$ vs 0,5 dia), quantidade de $\mathrm{P}_{4}$ 
liberada $(0,64$ vs $0,58 \mathrm{~g})$ e tensão superficial de deformação $(4,02$ vs $3,8 \mathrm{Kg})$, extremamente importante para a manutenção do dispositivo no interior da cavidade vaginal do animais. Este dispositivo também apresentou taxas de concepção na IATF similares ao $\operatorname{CIDR}^{\circledR}$ nas vacas Holandesas em reprodução (40,2 vs $35,7 \%$, respectivamente).

Bunt et al. (1999) mostraram que um dispositivo intravaginal fabricado a partir de PCL (contendo $10 \%$ de $\mathrm{P}_{4}$ ) manteve níveis plasmáticos de $\mathrm{P}_{4}$ similares ao $\mathrm{CIDR}^{\circledR}$ ao redor de 2 a $5 \mathrm{ng} / \mathrm{mL}$, durante o tempo de permanência no animal ( $2^{\circ}$ ao $7^{\circ}$ dia) e apresentou também uma flexibilidade adequada para sua manutenção no interior da cavidade vaginal dos animais. A adição de lactose na composição do dispositivo de $\mathrm{PCL}$ não alterou os níveis plasmáticos de $\mathrm{P}_{4}$ e comprometeu a flexibilidade destes. Por outro lado, a incorporação do hidroxipropil- $\beta$-ciclodextrina (40\%) causou uma elevação dos níveis plasmáticos de $\mathrm{P}_{4}(6$ a $10 \mathrm{ng} / \mathrm{mL})$, mas também reduziu sua flexibilidade. Neste trabalho demonstrou-se também que um dispositivo de PCL contendo apenas $20 \%$ de hidroxipropil- $\beta$-ciclodextrina e $5 \%$ de $\mathrm{P}_{4}$, manteve níveis plasmáticos de $\mathrm{P}_{4}$ semelhantes aos proporcionados pelo $\mathrm{CIDR}^{\circledR}$.

Chang et al. (2005) mostraram que a taxa de difusão da $\mathrm{P}_{4}$ aumentava de 8 para $24 \mu \mathrm{g} / \mathrm{mg}$ matrix/dia ${ }^{0.5}$ quando a porcentagem do esteróide aumentava de 3,6 para $12,4 \%$ e uma liberação total de 75 a $95 \%$ da $\mathrm{P}_{4}$ inicial incorporada ocasionada pelo aumento da densidade da matrix polimérica de 0,22 para $0,39 \mathrm{~g} / \mathrm{cm}^{3}$ dos dispositivos de PCL.

O PCL apresentou menor biodegradação quando comparado ao PHB (ROSA; CHUI; FILHO; AGNELLI, 2002). Para que seja atingido um relacionamento específico de processamento, estrutura, propriedades e custo, a composição polimérica além do $\mathrm{PHB}$ deve conter teores variáveis deste outro polímero biodegradável, o PCL (STEVENS, 1999). 


\section{MATERIAL E MÉTODO}

\subsection{DELINEAMENTO EXPERIMENTAL}

Foram realizados 2 experimentos, sendo que, no experimento 1, utilizaram-se dispositivos novos e no experimento 2, os mesmos dispositivos foram utilizados pela $2^{\circ}$ vez. Em ambos os experimentos, o delineamento experimental utilizado foi o de blocos casualizados generalizados, cujos tratamentos corresponderam aos dois protocolos de sincronização do estro e IATF. Os blocos foram formados, no dia da inserção do implante de $\mathrm{P}_{4}$, em função dos escores de condição ovariana e corporal, período pós-parto, categoria animal e também do touro de repasse na estação de monta.

\subsection{LOCAL E ANIMAIS}

O experimento foi realizado no período da estação de monta, de novembro de 2007 a fevereiro de 2008, no campus administrativo de Pirassununga (PCAPS) da Universidade de São Paulo.

As vacas paridas possuíam pelo menos 30 dias pós-parto (Figura 3). $\mathrm{O}$ escore de condição corporal (1 a 9, segundo Richards et al., 1986), de condição ovariana (Quadro 1, segundo Madureira e Pimentel, 2005), período pós-parto e categoria animal foram utilizadas para proporcionar uma divisão eqüitativa dos grupos. As vacas foram mantidas em pastagens de capim Brachiaria brizantha $v$. marandu, com fornecimento de água ad libitum e suplementação mineral, sendo que no período que antecedeu a estação de monta, a suplementação foi com sal mineral proteinado. 


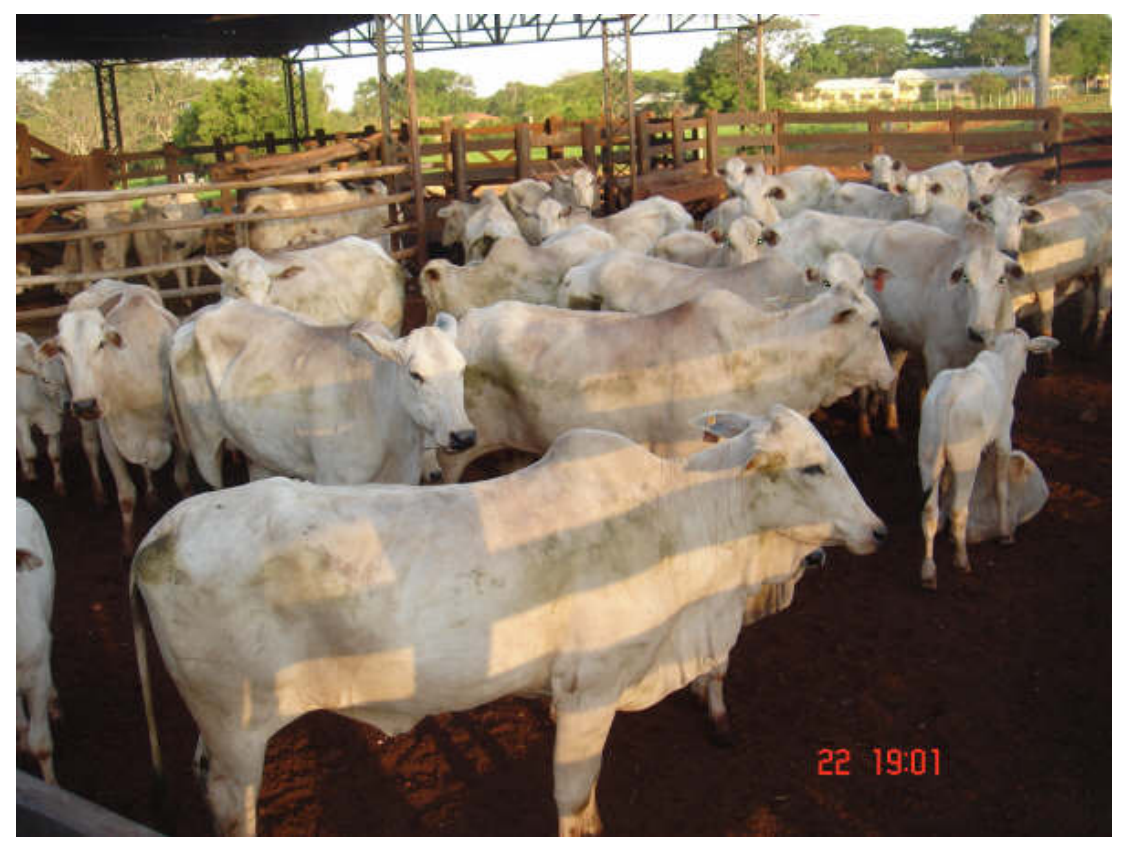

Figura 3 - Amostra de animais utilizados nos experimentos

\begin{tabular}{|c|c|}
\hline Escore de condição ovariana & Características \\
\hline 1 & $\begin{array}{l}\text { Fêmeas ciclando com ovários de } \\
\text { tamanho acima de } 30 \mathrm{~mm} \text {, macios e presença } \\
\text { de CL; ou também com útero de turgidez } \\
\text { acentuada, denotando a existência de } \\
\text { fóliculos grandes estrógeno-ativos (>10 mm). }\end{array}$ \\
\hline 2 & $\begin{array}{c}\text { Fêmeas que possuem ovários com comprimento } \\
\text { entre } 15 \text { e } 30 \mathrm{~mm} \text {, ausência de } C L \text { e de turgidez } \\
\text { no útero. Nesta categoria, estão incluidas as } \\
\text { fêmeas cujos folículos atingem a fase de } \\
\text { dominância ( } \geq 8,5 \mathrm{~mm} \text { ), porém não sofrem a ovulação. }\end{array}$ \\
\hline 3 & $\begin{array}{c}\text { Fêmeas que possuem os ovários pequenos, duros } \\
\text { e lisos. Estão incluídas nesta categoria as fêmeas } \\
\text { cujos folículos que não conseguem atingir a fase } \\
\text { de divergência e acabam não ovulando, } \\
\text { sofrendo atresia folicular. }\end{array}$ \\
\hline
\end{tabular}

\section{Quadro 1 - Escores de condição ovariana (ECO)}

Obs: Folículos ovarianos maiores do que $20 \mathrm{~mm}$, na ausência de $\mathrm{CL}$ e que persistem por mais do que 10 dias no ovário são considerados Cistos foliculares. 


\subsection{DISPOSITIVOS INTRAVAGINAIS E TRATAMENTOS}

O novo dispositivo intravaginal de bovinos, Progestar $^{\circledR}$ (Innovare, Brasil) (Figura 4), foi produzido no Núcleo de Reologia e Processamento de Polímeros no Departamento de Engenharia de Materiais (DEMA - UFSCAR). O dispositivo apresenta uma proporção de $46 \%$ de $\mathrm{PHB}, 46 \%$ de $\mathrm{PCL}$ e $8 \%$ de $\mathrm{P}_{4}$, possui área superficial de $197,2 \mathrm{~cm}^{2}, 1,72 \mathrm{~g}$ de $\mathrm{P}_{4}$ inicial e $21,5 \mathrm{~g}$ de peso total. A confecção dos novos dispositivos envolve as seguintes fases: a) mistura e incorporação de $\mathrm{P}_{4}$ no PHB; b) extrusão da mistura e obtenção dos "pellets" e c) obtenção dos dispositivos pelo processo de injeção em molde de aço.

O outro dispositivo intravaginal, à base de silicone, utilizado como controle neste trabalho foi $\circ \mathrm{DIB}^{\circledR}$ (Syntex, Argentina) (Figura 5), com área superficial de $120 \mathrm{~cm}^{2}, 1,0 \mathrm{~g}$ de $\mathrm{P}_{4}$ inicial e $37,5 \mathrm{~g}$ de peso total.

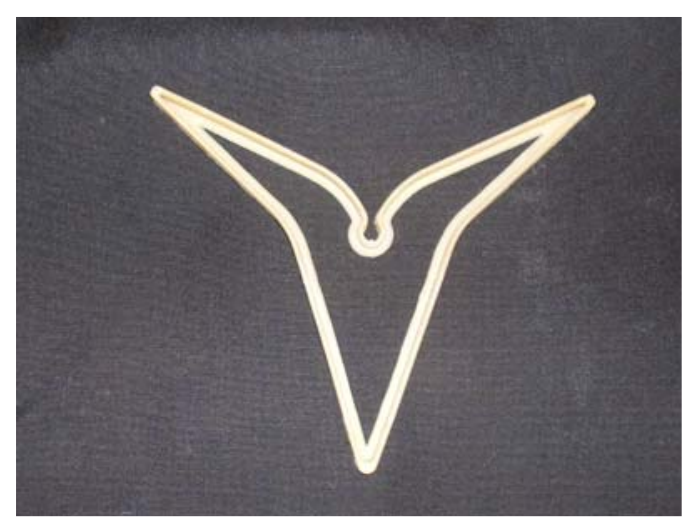

Figura 4 - Novo dispositivo intravaginal de bovinos - Progestar $^{\circledR}$ (Innovare, Brasil)

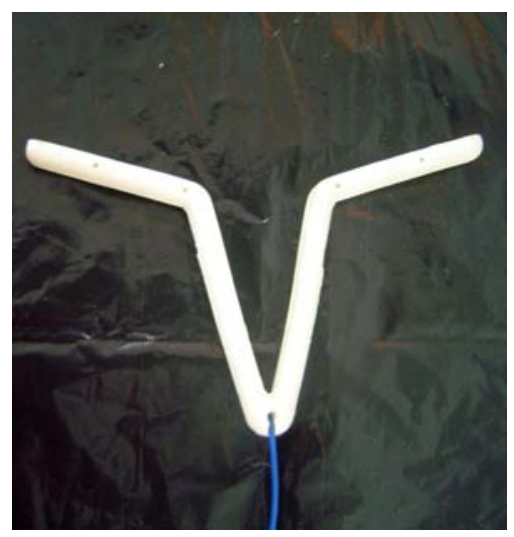

Figura 5 - Dispositivo Interno Bovino - DIB ${ }^{\circledR}$ (Syntex, Argentina) 


\subsubsection{Experimento 1}

No primeiro experimento, nos tratamentos que foram instituídos, utilizaram-se os dispositivos DIB ${ }^{\circledR}$ e Progestar $^{\circledR}$ de $1^{\circ}$ uso. Foram utilizados 136 animais, entre vacas paridas $(n=122)$ e solteiras $(n=14)$. As vacas paridas foram divididas em 2 classes de período pós-parto: PPP1 - 45 a 70 dias (n=58) e PPP2 - 71 a 90 dias $(n=64)$. Os animais também foram divididos quanto ao: escore de condição corporal $4(n=13), 5(n=67)$ e $6(n=56)$; escore de condição ovariana 1 - ciclando $(n=98)$ e 2 não ciclando $(n=38)$ e categoria animal 1 - primípara $(n=31), 2-$ multípara $(n=91)$ e 3 - solteira $(n=14)$. Os animais foram sincronizados com os dispositivos novos DIB ${ }^{\circledR}$ $(n=60)$ e $\operatorname{Progestar}^{\circledR}(n=76)$. Vale-se ressaltar que nenhum animal recebeu a classificação 3 de escore de condição ovariana. Na estação de monta foram utilizados 5 diferentes touros: 1 (número 1961), 2 (número 1447), 3 (número 17), 4 (número 2293) e 5 (número 141).

\subsubsection{Experimento 2}

No segundo experimento, os dispositivos intravaginais utilizados foram de $2^{\circ}$ uso, oriundos dos tratamentos dos animais pertencentes ao primeiro experimento, após sua lavagem e desinfecção com dióxido de cloro (Tecsa Clor ${ }^{\circledR}$, Brasil). Foram utilizadas 104 vacas paridas, que foram divididas em 2 classes de período pós-parto: PPP1 - 32 a 55 dias ( $n=56)$ e PPP2 - 56 a 90 dias $(n=48)$. Houve também a divisão dos animais em relação ao: escore de condição corporal $4(n=27)$ e $5(n=77)$; escore de condição ovariana 1 - ciclando $(n=52)$ e 2 - não ciclando $(n=52)$ e categoria animal 1 - primípara $(n=35)$ e 2 - multípara $(n=69)$. Os dispositivos de $2^{\circ}$ uso,

utilizados para a sincronização dos animais foram: DIB $^{\circledR} 2(n=52)$ e Progestar $^{\circledR} 2$ $(n=52)$. Também, neste experimento, nenhum animal recebeu a classificação 3 de escore de condição ovariana. Foram utilizados, na estação de monta, 4 diferentes touros: 1 (número 1447), 2 (número 4878), 3 (número 5012) e 4 (número 141). 


\subsubsection{Tratamentos}

No primeiro dia de tratamento (D0), todas as vacas receberam um dos dois dispositivos intravaginais para liberação sustentada de $\mathrm{P}_{4}$ : as vacas do grupo controle receberam o dispositivo DIB $^{\circledR}$ e os animais do grupo tratamento, o Progestar $^{\circledR}$.

No mesmo dia da colocação dos dispositivos, todas as vacas receberam uma aplicação intramuscular (IM) de $2 \mathrm{mg}$ de benzoato de estradiol ${ }^{\circledR}$ (Innovare, Brasil). No D8, foram retirados os dispositivos intravaginais e todas as vacas receberam uma aplicação IM de D-cloprostenol, um análogo sintético da PGF $_{2 \alpha}$ (Croniben $^{\circledR}$, Biogenesis-Bagó, Argentina), na dose de $150 \mu \mathrm{g}$ e uma injeção IM contendo $300 \mathrm{UI}$ de eCG (Novormon ${ }^{\circledR}$, Tecnopec, Brasil). No D9, foi aplicada uma injeção IM de $1 \mathrm{mg}$ de benzoato de estradiol, em todas as vacas, com o intuito de sincronizar a ovulação, possibilitando a IATF, que foi realizada 30 horas após.

Após a IATF, foi realizado o diagnóstico de gestação, aos 35 dias, com o auxílio do aparelho de ultra-sonografia. O repasse com touros foi realizado até o $90^{\circ}$ dia da estação de monta. Nova ultra-sonografia foi realizada 35 dias após o final da estação de monta. As variáveis resposta, destes experimentos, foram as taxas de prenhez na IATF (TPIATF), referente ao número de vacas prenhes, 35 dias após a IATF, dividido pelo número total de vacas inseminadas em tempo fixo, multiplicando esta razão por 100 e taxa de prenhez ao final da estação de monta (TPEM), referente ao número de vacas prenhes, 35 dias após o término da estação de monta, dividido pelo número total de vacas inseminadas em tempo fixo, multiplicando esta razão por 100.

Os protocolos de sincronização e os tratamentos estão apresentados abaixo (Figura 6): 


\section{Grupo Controle}

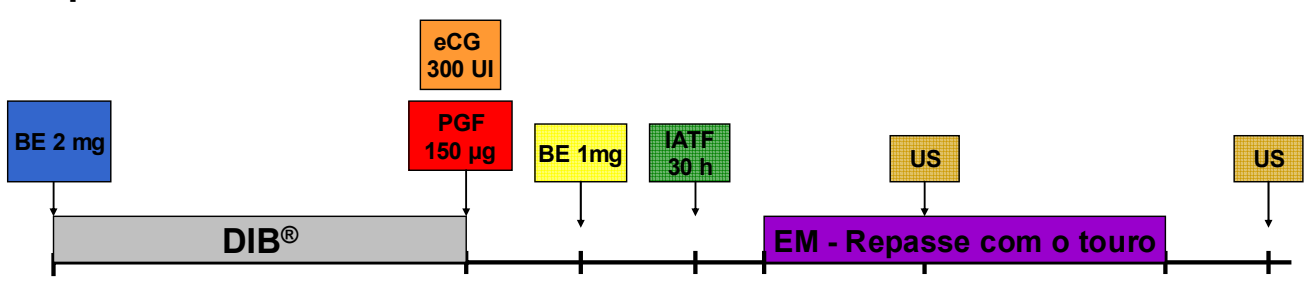

$\begin{array}{llllllll}\text { d0 } & d 8 & d 9 & d 10 & d 17 & d 45 & d 107 & \text { d142 }\end{array}$

\section{Grupo Tratamento}

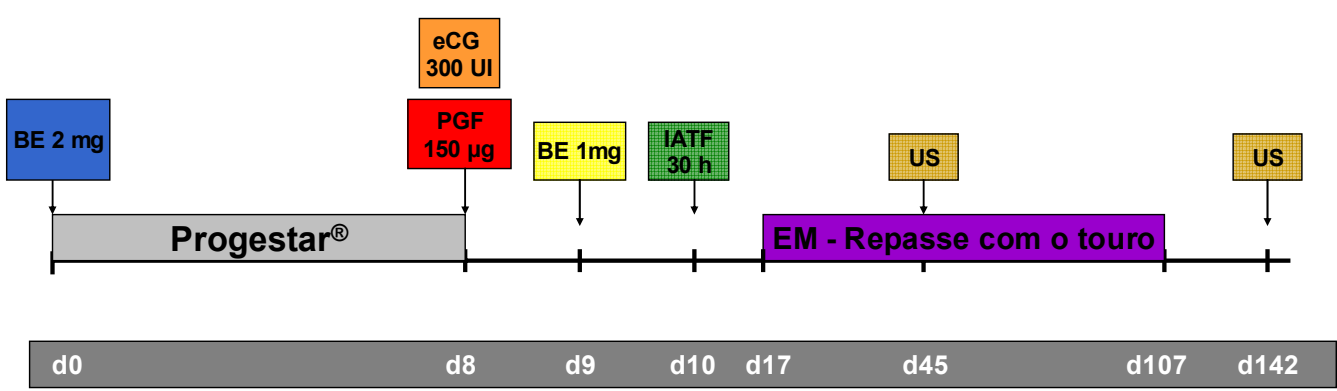

\section{Legenda:}

$\mathrm{BE}$ - benzoato de estradiol; PGF - prostaglandina $\mathrm{F}_{2 \alpha}$; eCG gonadotrofina coriônica equina; IATF - inseminação artificial em tempo fixo; EM - estação de monta e US - ultra-sonografia.

Figura 6 - Protocolos de sincronização e IATF

\subsection{ANÁLISE ESTATÍSTICA}

Os dados foram analisados com emprego do programa computacional Statistical Analysis System (SAS, 2001, versão 8). Todos os dados foram submetidos às premissas estatísticas quanto à normalidade de distribuição dos resíduos pelo teste de SHAPHIRO-WILK (PROC UNIVARIATE) e homogeneidade das variâncias pelo teste $\mathrm{F}$. Os dados originais ou transformados, quando este último procedimento foi necessário, foram submetidos à análise de variância que separou como causas de variação efeito de tratamento, efeito dos blocos e efeito das interações. Tal análise foi realizada utilizando-se o procedimento General Linear Model (PROC GLM do SAS). Quando as interações apresentaram significância, 
estas foram separadas por contrastes ortogonais. No caso do bloco formado em função do touro, quando significativo, utilizou-se o teste de Tukey para comparar as médias. Foi admitido um nível de significância de $5 \%$ e tendência entre 5 e 10\%. As TPIATF e TPEM foram comparadas pela análise de variância.

\subsubsection{Causas de Variação e Modelos Estatísticos}

Abaixo estão demonstrados as tabelas referentes às causas de variação e graus de liberdade da análise de variância, assim como os modelos estatísticos das TPIATF e TPEM para os experimentos 1 e 2.

Tabela 1 - Causas de Variação e graus de liberdade da análise de variância do TPIATF do experimento 1

\begin{tabular}{|c|c|c|}
\hline & Causas de Variação & Graus de Liberdade \\
\hline \multirow[t]{25}{*}{ TPIATF } & Tratamento (Trat) & 1 \\
\hline & Categoria Animal (Cat) & 2 \\
\hline & Período pós-parto (PPP) & 1 \\
\hline & Escore de condição corporal (ECC) & 2 \\
\hline & Escore de condição ovariano (ECO) & 1 \\
\hline & Trat*Cat & 2 \\
\hline & Trat*PPP & 1 \\
\hline & Trat*ECC & 2 \\
\hline & TratECO & 1 \\
\hline & Cat*PPP & 2 \\
\hline & Cat ${ }^{\star} E C C$ & 4 \\
\hline & Cat*ECO & 2 \\
\hline & $P P P^{*} E C C$ & 2 \\
\hline & PPP*ECO & 1 \\
\hline & ECC*ECO & 2 \\
\hline & Trat ${ }^{*} \mathrm{Cat}^{*} \mathrm{PPP}$ & 2 \\
\hline & Trat ${ }^{\star}$ Cat $^{\star}$ ECC & 4 \\
\hline & Trat ${ }^{*}$ Cat*ECO & 1 \\
\hline & Trat*PPP*ECC & 2 \\
\hline & Trat*PPP*ECO & 1 \\
\hline & Cat $^{*} P^{2}{ }^{*} E C C$ & 4 \\
\hline & Cat*PPP*ECO & 2 \\
\hline & Trat $^{\star} \mathrm{Cat}^{\star} \mathrm{PPP}^{*} \mathrm{ECO}$ & 2 \\
\hline & Resíduo & 91 \\
\hline & Total & 135 \\
\hline
\end{tabular}


Modelo estatístico

$y_{i j k l m}=\mu+\alpha_{i}+d_{j}+\beta_{k}+\gamma_{l}+\delta_{m}+(\alpha d)_{i j}+(\alpha \beta)_{i k}+(\alpha \gamma)_{i l}+(\alpha \delta)_{i m}+(d \beta)_{j k}+(d y)_{j l}+(d \delta)_{j m}+$ $(\beta \gamma)_{k l}+(\beta \delta)_{k m}+(\gamma \delta)_{l m}+(\alpha d \beta)_{i j k}+(\alpha d \gamma)_{i j l}+(\alpha d \delta)_{i j m}+(\alpha \beta \gamma)_{i k l}+(\alpha \beta \delta)_{i k m}+(d \beta \gamma)_{j k l}+$ $(d \beta \delta)_{j k m}+(\alpha d \beta \delta)_{i j k m}+e_{i j k l m}$

y = resposta do i-ésimo tratamento, na j-ésima categoria animal, no k-ésimo período pós-parto, no l-ésimo escore de condição corporal, no m-ésimo escore de condição ovariana; $\mu=$ média geral; $\alpha_{i}=$ efeito fixo do tratamento $\mathrm{i} ; d_{j}=$ efeito fixo da categoria animal $\mathrm{j} ; \beta_{k}=$ efeito fixo do período pós-parto $\mathrm{k} ; \gamma_{l}=$ efeito fixo do escore de condição corporal $\mathrm{l} ; \delta_{m}=$ efeito fixo do escore de condição ovariana $\mathrm{m}$; $(\alpha d)_{i j}=$ efeito da interação tratamento i $\mathrm{x}$ categoria $\mathrm{j} ;(\alpha \beta)_{i k}=$ efeito da interação tratamento $\mathrm{i} \times$ período pós-parto $\mathrm{k} ;(\alpha y)_{i l}=$ efeito da interação tratamento i $\mathrm{x}$ escore de condição corporal $\mathrm{I}$; $(\alpha \delta)_{i m}=$ efeito da interação tratamento i $\mathrm{x}$ escore de condição ovariana $\mathrm{m} ;(d \beta)_{j k}=$ efeito da interação categoria j x período pós-parto $\mathrm{k} ;(d y)_{j l}=$ efeito da interação categoria j x escore de condição corporal I; $(d \delta)_{m j}=$ efeito da interação categoria j x escore de condição ovariana $\mathrm{m} ;(\beta \gamma)_{k l}=$ efeito da interação período pós-parto $\mathrm{k} x$ escore de condição corporal $\mathrm{I} ;(\beta \delta)_{\mathrm{km}}=$ efeito da interação período pós-parto $\mathrm{k} x$ escore de condição ovariana $\mathrm{m} ;(\gamma \delta)_{l m}=$ efeito da interação escore de condição corporal I x escore de condição ovariana $\mathrm{m} ;(\alpha d \beta)_{i j k}=$ efeito da interação tratamento i $\mathrm{x}$ categoria $\mathrm{j} \times$ período pós-parto $\mathrm{k} ;(\alpha d y)_{i j l}=$ efeito da interação tratamento $\mathrm{i} \times$ categoria j x escore de condição corporal I; $(\alpha d \delta)_{i j m}=$ efeito da interação tratamento i $\mathrm{x}$ categoria j $\mathrm{x}$ escore de condição ovariana $\mathrm{m} ;(\alpha \beta \gamma)_{i k l}=$ efeito da interação tratamento i x período pós-parto $\mathrm{k} x$ escore de condição corporal l; $(\alpha \beta \delta)_{i k m}=$ efeito da interação tratamento i x período pós-parto $\mathrm{k} x$ escore de condição ovariana $\mathrm{m}$; $(d \beta \gamma)_{j k l}=$ efeito da interação categoria $\mathrm{j} \times$ período pós-parto $\mathrm{k} \times$ escore de condição corporal I; $(d \beta \delta)_{j k m}=$ efeito da interação categoria $\mathrm{j} x$ período pós-parto $\mathrm{k} x$ escore de condição ovariana $\mathrm{m} ;(\alpha d \beta \delta)_{i j k m}=$ efeito da interação tratamento $\mathrm{i} \times$ categoria $\mathrm{j} \times$ período pós-parto $\mathrm{k} x$ escore de condição ovariana $\mathrm{m} ; \mathrm{e}_{i j k l m}=$ erro aleatório associado a cada observação. 
Tabela 2 - Causas de Variação e graus de liberdade da análise de variância do TPEM do experimento 1

\begin{tabular}{|c|c|c|}
\hline & Causas de Variação & Graus de Liberdade \\
\hline \multirow[t]{26}{*}{ TPEM } & Tratamento (Trat) & 1 \\
\hline & Categoria Animal (Cat) & 2 \\
\hline & Período pós-parto (PPP) & 1 \\
\hline & Escore de condição corporal (ECC) & 2 \\
\hline & Escore de condição ovariano (ECO) & 1 \\
\hline & Touro & 4 \\
\hline & Trat $^{\star}$ Cat & 2 \\
\hline & Trat*PPP & 1 \\
\hline & Trat ${ }^{\star}$ ECC & 2 \\
\hline & Trat*ECO & 1 \\
\hline & Cat ${ }^{*}$ PPP & 2 \\
\hline & Cat ${ }^{*} E C C$ & 4 \\
\hline & $\mathrm{Cat}^{\star} \mathrm{ECO}$ & 2 \\
\hline & $P P{ }^{*} E C C$ & 2 \\
\hline & PPP*ECO & 1 \\
\hline & ECC ${ }^{*}$ ECO & 2 \\
\hline & Trat $^{\star}$ Cat $^{\star}$ PPP & 2 \\
\hline & Trat ${ }^{*}$ Cat $^{\star} E C C$ & 4 \\
\hline & Trat ${ }^{\star}$ Cat ${ }^{\star} E C O$ & 1 \\
\hline & Trat*PPP*ECC & 2 \\
\hline & Trat*PPP*ECO & 1 \\
\hline & $\mathrm{Cat}^{*} \mathrm{PPP}{ }^{*} \mathrm{ECC}$ & 4 \\
\hline & Cat*PPP*ECO & 2 \\
\hline & Trat $^{*}$ Cat $^{*}$ PPP*ECO & 2 \\
\hline & Resíduo & 87 \\
\hline & Total & 135 \\
\hline
\end{tabular}

Modelo estatístico

$$
\begin{aligned}
& y_{i j k l m n}=\mu+\alpha_{i}+d_{j}+\beta_{k}+\gamma_{l}+\delta_{m}+\varepsilon_{n}+(\alpha d)_{i j}+(\alpha \beta)_{i k}+(\alpha \gamma)_{i l}+(\alpha \delta)_{i m}+(d \beta)_{j k}+(d \gamma)_{j l}+ \\
& (d \delta)_{j m}+(\beta \gamma)_{k l}+(\beta \delta)_{k m}+(\gamma \delta)_{l m}+(\alpha d \beta)_{i j k}+(\alpha d \gamma)_{i j l}+(\alpha d \delta)_{i j m}+(\alpha \beta \gamma)_{i k l}+(\alpha \beta \delta)_{i k m}+ \\
& (d \beta \gamma)_{j k l}+(d \beta \delta)_{j k m}+(\alpha d \beta \delta)_{i j k m}+e_{i j k l m}
\end{aligned}
$$

$y=$ resposta do i-ésimo tratamento, na j-ésima categoria animal, no k-ésimo período pós-parto, no l-ésimo escore de condição corporal, no m-ésimo escore de condição ovariana, no n-ésimo touro; $\mu=$ média geral; $\alpha_{i}=$ efeito fixo do tratamento $\mathrm{i} ; d_{j}=$ efeito fixo da categoria animal j; $\beta_{k}=$ efeito fixo do período pós-parto $k ; y_{l}=$ efeito fixo do escore de condição corporal l; $\delta_{m}=$ efeito fixo do escore de condição ovariana $\mathrm{m} ; \varepsilon_{n}$ $=$ efeito fixo de touro $\mathrm{n} ;(\alpha d)_{i j}=$ efeito da interação tratamento i $\times$ categoria $\mathrm{j} ;(\alpha \beta)_{i k}=$ efeito da interação tratamento i $x$ período pós-parto $\mathrm{k} ;(\alpha y)_{i \text { il }}=$ efeito da interação tratamento i $x$ escore de condição corporal $\mathrm{l} ;(\alpha \delta)_{i m}=$ efeito da interação tratamento $\mathrm{i}$ $\mathrm{x}$ escore de condição ovariana $\mathrm{m} ;(d \beta)_{j k}=$ efeito da interação categoria $\mathrm{j} x$ período 
pós-parto $\mathrm{k} ;(d y)_{j l}=$ efeito da interação categoria j $\mathrm{x}$ escore de condição corporal I; $(d \delta)_{m j}=$ efeito da interação categoria $\mathrm{j} x$ escore de condição ovariana $\mathrm{m} ;(\beta \gamma)_{k l}=$ efeito da interação período pós-parto $\mathrm{k} \times$ escore de condição corporal $\mathrm{l} ;(\beta \delta)_{\mathrm{km}}=$ efeito da interação período pós-parto $\mathrm{k} x$ escore de condição ovariana $\mathrm{m} ;(\gamma \delta)_{l m}=$ efeito da interação escore de condição corporal I x escore de condição ovariana m; $(\alpha d \beta)_{i j k}=$ efeito da interação tratamento $\mathrm{i} \times$ categoria $\mathrm{j} \times$ período pós-parto $\mathrm{k} ;(\alpha d \gamma)_{i j l}=$ efeito da interação tratamento i $x$ categoria $\mathrm{j} x$ escore de condição corporal $\mathrm{l}$; $(\alpha d \delta)_{\text {ijm }}$ $=$ efeito da interação tratamento $\mathrm{i} x$ categoria $\mathrm{j} x$ escore de condição ovariana $\mathrm{m}$; $(\alpha \beta \gamma)_{i k l}=$ efeito da interação tratamento $\mathrm{i} x$ período pós-parto $\mathrm{k} \times$ escore de condição corporal $\mathrm{l} ;(\alpha \beta \delta)_{i k m}=$ efeito da interação tratamento i $\times$ período pós-parto $\mathrm{k} \times$ escore de condição ovariana $\mathrm{m} ;(d \beta \gamma)_{j k l}=$ efeito da interação categoria $\mathrm{j} \times$ período pós-parto $\mathrm{k} x$ escore de condição corporal $\mathrm{l} ;(d \beta \delta)_{j k m}=$ efeito da interação categoria $\mathrm{j} x$ período pós-parto $\mathrm{k} \times$ escore de condição ovariana $\mathrm{m} ;(\alpha d \beta \delta)_{i j k m}=$ efeito da interação tratamento $\mathrm{i} x$ categoria $\mathrm{j} x$ período pós-parto $\mathrm{k} \times$ escore de condição ovariana $\mathrm{m}$; $\mathrm{e}_{i j k / m}=$ erro aleatório associado a cada observação.

Tabela 3 - Causas de Variação e graus de liberdade da análise de variância do TPIATF do experimento 2

\begin{tabular}{|c|c|c|}
\hline & Causas de Variação & Graus de Liberdade \\
\hline \multirow[t]{21}{*}{ TPIATF } & Tratamento (Trat) & 1 \\
\hline & Categoria Animal (Cat) & 1 \\
\hline & Período pós-parto (PPP) & 1 \\
\hline & Escore de condição corporal (ECC) & 1 \\
\hline & Escore de condição ovariano (ECO) & 1 \\
\hline & $\operatorname{Trat}^{*}$ Cat & 1 \\
\hline & Trat*PPP & 1 \\
\hline & Trat ${ }^{\star} \mathrm{ECC}$ & 1 \\
\hline & Trat*ECO & 1 \\
\hline & Cat*PPP & 1 \\
\hline & Cat*ECC & 1 \\
\hline & Cat*ECO & 1 \\
\hline & $P P P^{*} E C C$ & 1 \\
\hline & $P P P^{*} E C O$ & 1 \\
\hline & $\mathrm{ECC} * \mathrm{ECO}$ & 1 \\
\hline & Trat $^{*}{ }^{C}$ at $^{\star}$ PPP & 1 \\
\hline & Trat $^{*} \mathrm{Cat}^{*} \mathrm{ECO}$ & 1 \\
\hline & Trat*PPP*ECO & 1 \\
\hline & $\mathrm{Cat}^{\star} \mathrm{PPP}{ }^{*} \mathrm{ECO}$ & 1 \\
\hline & Resíduo & 84 \\
\hline & Total & 103 \\
\hline
\end{tabular}


Modelo estatístico

$y_{i j k l m}=\mu+\alpha_{i}+d_{j}+\beta_{k}+\gamma_{l}+\delta_{m}+(\alpha d)_{i j}+(\alpha \beta)_{i k}+(\alpha \gamma)_{i l}+(\alpha \delta)_{i m}+(d \beta)_{j k}+(d y)_{j l}+(d \delta)_{j m}+$ $(\beta \gamma)_{k l}+(\beta \delta)_{k m}+(\gamma \delta)_{l m}+(\alpha d \beta)_{i j k}+(\alpha d \delta)_{i j m}+(\alpha \beta \delta)_{i k m}+(d \beta \delta)_{j k m}+e_{i j k l m}$

y = resposta do i-ésimo tratamento, na j-ésima categoria animal, no k-ésimo período pós-parto, no l-ésimo escore de condição corporal, no m-ésimo escore de condição ovariana; $\mu$ = média geral; $\alpha_{i}=$ efeito fixo do tratamento $\mathrm{i} ; d_{j}=$ efeito fixo da categoria animal j; $\beta_{k}=$ efeito fixo do período pós-parto $\mathrm{k} ; \gamma_{l}=$ efeito fixo do escore de condição corporal $\mathrm{I} ; \delta_{m}=$ efeito fixo do escore de condição ovariana $\mathrm{m} ;(\alpha d)_{i j}=$ efeito da interação tratamento i $\times$ categoria j; $(\alpha \beta)_{i k}=$ efeito da interação tratamento i $\times$ período pós-parto $\mathrm{k} ;(\alpha \gamma)_{i l}=$ efeito da interação tratamento i $\mathrm{x}$ escore de condição corporal I; $(\alpha \delta)_{i m}=$ efeito da interação tratamento $\mathrm{i} x$ escore de condição ovariana $\mathrm{m} ;(d \beta)_{j k}=$ efeito da interação categoria $\mathrm{j} \times$ período pós-parto $\mathrm{k} ;(d y)_{j l}=$ efeito da interação categoria j x escore de condição corporal I; $(d \delta)_{m j}=$ efeito da interação categoria $\mathrm{j} x$ escore de condição ovariana $\mathrm{m} ;(\beta \gamma)_{k l}=$ efeito da interação período pós-parto $\mathrm{k} x$ escore de condição corporal I; $(\beta \delta)_{k m}=$ efeito da interação período pós-parto $\mathrm{k} x$ escore de condição ovariana $\mathrm{m} ;(\gamma \delta)_{l m}=$ efeito da interação escore de condição corporal I x escore de condição ovariana $\mathrm{m} ;(\alpha d \beta)_{i j k}=$ efeito da interação tratamento i $\mathrm{x}$ categoria $\mathrm{j} \times$ período pós-parto $\mathrm{k} ;(\alpha d \delta)_{i j m}=$ efeito da interação tratamento $\mathrm{i} \mathrm{x}$ categoria j x escore de condição ovariana $\mathrm{m} ;(\alpha \beta \delta)_{i k m}=$ efeito da interação tratamento i x período pós-parto $\mathrm{k} x$ escore de condição ovariana $\mathrm{m} ;(d \beta \delta)_{j k m}=$ efeito da interação categoria j x período pós-parto k x escore de condição ovariana m; $\mathrm{e}_{i j k l m}$ = erro aleatório associado a cada observação. 
Tabela 4 - Causas de Variação e graus de liberdade da análise de variância do TPEM do experimento 2

\begin{tabular}{|c|c|c|}
\hline & Causas de Variação & Graus de Liberdade \\
\hline \multirow[t]{22}{*}{ TPEM } & Tratamento (Trat) & 1 \\
\hline & Categoria Animal (Cat) & 1 \\
\hline & Período pós-parto (PPP) & 1 \\
\hline & Escore de condição corporal (ECC) & 1 \\
\hline & Escore de condição ovariano (ECO) & 1 \\
\hline & Touro & 3 \\
\hline & Trat ${ }^{\star}$ Cat & 1 \\
\hline & Trat*PPP & 1 \\
\hline & Trat*ECC & 1 \\
\hline & Trat ${ }^{\star} \mathrm{ECO}$ & 1 \\
\hline & Cat*PPP & 1 \\
\hline & Cat ${ }^{\star} E C C$ & 1 \\
\hline & Cat ${ }^{\star} \mathrm{ECO}$ & 1 \\
\hline & $P P P^{\star} E C C$ & 1 \\
\hline & PPP*ECO & 1 \\
\hline & $\mathrm{ECC}{ }^{*} \mathrm{ECO}$ & 1 \\
\hline & Trat $^{\star}$ Cat $^{\star}$ PPP & 1 \\
\hline & Trat $^{*} \mathrm{Cat}^{*} \mathrm{ECO}$ & 1 \\
\hline & Trat ${ }^{*} P P P^{*} E C O$ & 1 \\
\hline & Cat*PPP*ECO & 1 \\
\hline & Resíduo & 81 \\
\hline & Total & 103 \\
\hline
\end{tabular}

Modelo estatístico

$y_{i j k l m}=\mu+\alpha_{i}+d_{j}+\beta_{k}+\gamma_{l}+\delta_{m}+\varepsilon_{n}+(\alpha d)_{i j}+(\alpha \beta)_{i k}+(\alpha \gamma)_{i l}+(\alpha \delta)_{i m}+(d \beta)_{j k}+(d y)_{j l}+$ $(d \delta)_{j m}+(\beta \gamma)_{k l}+(\beta \delta)_{k m}+(\gamma \delta)_{l m}+(\alpha d \beta)_{i j k}+(\alpha d \delta)_{i j m}+(\alpha \beta \delta)_{i k m}+(d \beta \delta)_{j k m}+e_{i j k l m}$

$y=$ resposta do i-ésimo tratamento, na j-ésima categoria animal, no k-ésimo período pós-parto, no l-ésimo escore de condição corporal, no m-ésimo escore de condição ovariana; $\mu=$ média geral; $\alpha_{i}=$ efeito fixo do tratamento $\mathrm{i} ; d_{j}=$ efeito fixo da categoria animal $\mathrm{j} ; \beta_{k}=$ efeito fixo do período pós-parto $\mathrm{k} ; \gamma_{l}=$ efeito fixo do escore de condição corporal I; $\delta_{m}=$ efeito fixo do escore de condição ovariana $\mathrm{m} ; \varepsilon_{n}=$ efeito fixo de touro $\mathrm{n} ;(\alpha d)_{i j}=$ efeito da interação tratamento $\mathrm{i} x$ categoria $\mathrm{j} ;(\alpha \beta)_{i k}=$ efeito da interação tratamento $\mathrm{i} \times$ período pós-parto $\mathrm{k} ;(\alpha \gamma)_{i l}=$ efeito da interação tratamento $\mathrm{i} x$ escore de condição corporal I; $(\alpha \delta)_{i m}=$ efeito da interação tratamento i $\mathrm{x}$ escore de condição ovariana $\mathrm{m} ;(d \beta)_{j k}=$ efeito da interação categoria $\mathrm{j} \times$ período pós-parto $\mathrm{k} ;(d \gamma)_{j l}=$ efeito da interação categoria $\mathrm{j} x$ escore de condição corporal $\mathrm{I} ;(d \delta)_{m j}=$ efeito da interação categoria $\mathrm{j} x$ escore de condição ovariana $\mathrm{m} ;(\beta \gamma)_{k l}=$ efeito da interação período pósparto $\mathrm{k} \times$ escore de condição corporal I; $(\beta \delta)_{k m}=$ efeito da interação período pós- 
parto $\mathrm{k} x$ escore de condição ovariana $\mathrm{m} ;(\gamma \delta)_{l m}=$ efeito da interação escore de condição corporal I x escore de condição ovariana $\mathrm{m} ;(\alpha d \beta)_{i j k}=$ efeito da interação tratamento $\mathrm{i} \times$ categoria $\mathrm{j} \times$ período pós-parto $\mathrm{k} ;(\alpha d \delta)_{i j m}=$ efeito da interação tratamento i x categoria j $\mathrm{x}$ escore de condição ovariana $\mathrm{m} ;(\alpha \beta \delta)_{i k m}=$ efeito da interação tratamento i $x$ período pós-parto $\mathrm{k} x$ escore de condição ovariana $\mathrm{m}$; $(d \beta \delta)_{j k m}=$ efeito da interação categoria $\mathrm{j} x$ período pós-parto $\mathrm{k} \times$ escore de condição ovariana m; $\mathrm{e}_{i j k l m}=$ erro aleatório associado a cada observação. 


\section{RESULTADOS}

\subsection{EXPERIMENTO 1}

No experimento 1, nenhum dos animais perdeu seu dispositivo intravaginal de $1^{\circ}$ uso ( DIB $^{\circledR}$ ou Progestar ${ }^{\circledR}$ ) durante o período da sincronização (taxa de retenção de 100\%).

Observou-se que não houve interação entre tratamento e as demais variáveis estudadas. $E$ também não houve efeito de tratamento sobre as taxas de prenhez (Tabela 5): 1) TPIATF: DIB ${ }^{\circledR}-66,7 \%$ vs Progestar $^{\circledR}-65,8 \%$, $p=0,3606$ e 2) TPEM: DIB ${ }^{\circledR}-95 \%$ vs Progestar ${ }^{\circledR}-94,7 \%, p=0,5683$, gráfico 1.

Houve interação entre período pós-parto e escore de condição corporal $(p=0,0013)$ e entre período pós-parto e escore de condição ovariana $(p=0,0292)$ na TPIATF. No PPP1, os animais apresentaram diferentes taxas de prenhez, segundo escore de condição corporal $(p=0,0280)$, tabela 5 e gráfico 2 : escore de condição corporal $4(20 \%)$ vs $5(72,4 \%)$ vs $6(79,2 \%)$. Entretanto, no PPP2 esta diferença não foi observada $(p=0,8254)$. Também foi observado que, no PPP2, as taxas de prenhez variaram conforme o escore de condição ovariana $(p=0,0633)$, tabela 5 e gráfico 3 : animais ciclando $(75 \%)$ vs não ciclando (50\%); no entanto, no PPP1 esta diferença não foi observada $(p=0,7943)$.

Não houve efeito de categoria animal sobre as taxas de prenhez (Tabela 5): 1) TPIATF: primípara $-63,3 \%$ vs multípara $-71,4 \%$ vs solteira $-40 \%$, $p=0,6969$ e 2) TPEM: primípara $-93,3 \%$ vs multípara $-96,7 \%$ vs solteira $86,7 \%, p=0,8008$.

Da mesma forma, também não houve efeito das variáveis período pósparto, escores de condição corporal e ovariana e touro na TPEM (Tabela 5): 1) período pós-parto (PPP1 - 94,8\% vs PPP2 - 96,9\%, p=0,6978); 2 ) escore de condição corporal (4-100\% vs 5 - 92,5\% vs $6-96,4 \%, p=0,4492$ ); 3) escore de condição ovariana (ciclando - 95,9\% vs não ciclando - 92,1\%, p=0,6089) e 4) touro $(1-86,7 \%$ vs $2-100 \%$ vs $3-95,6 \%$ vs $4-97,4 \%$ vs $5-85,7 \%$, 
$p=0,2632)$. A média geral da TPIATF foi de $66,2 \%$, enquanto que para a TPEM foi de $94,9 \%$.

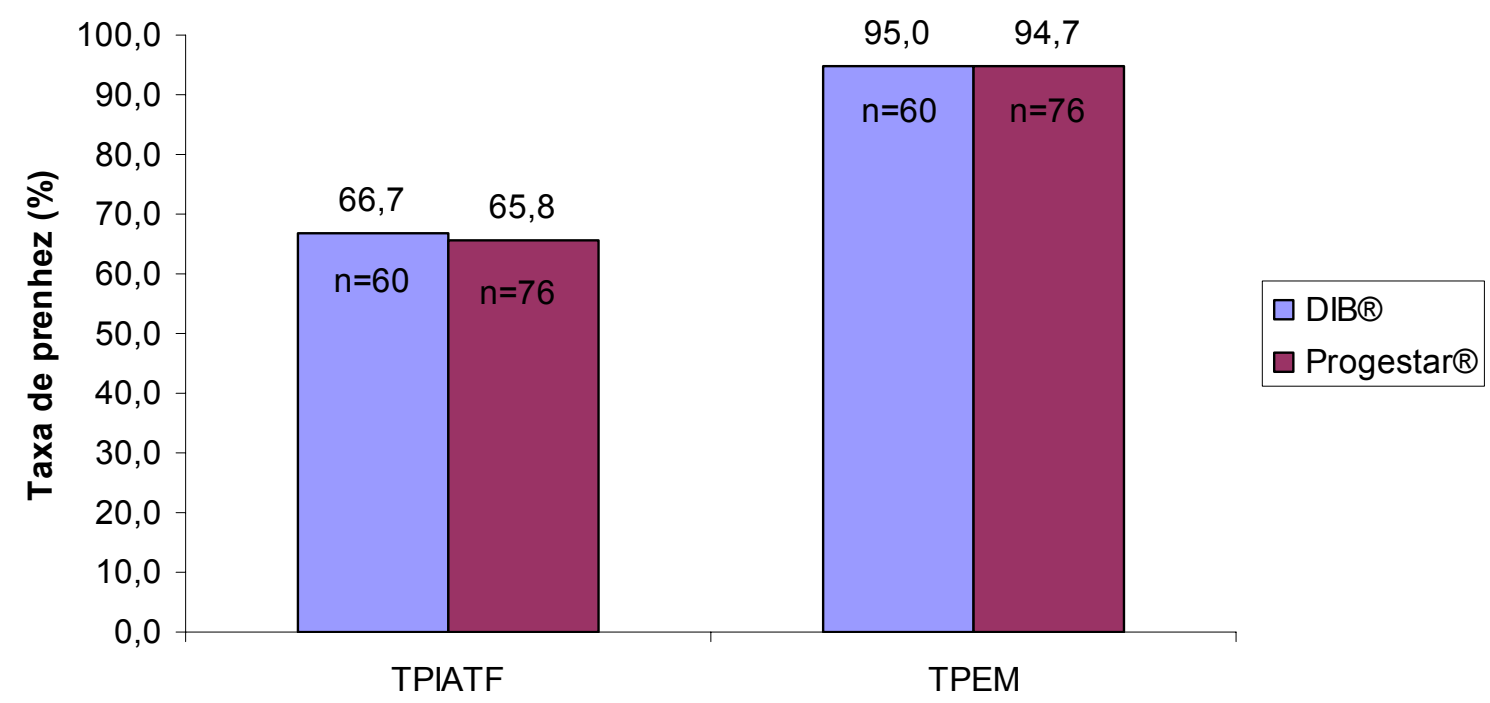

Gráfico 1 - TPIATF e TPEM segundo tratamento

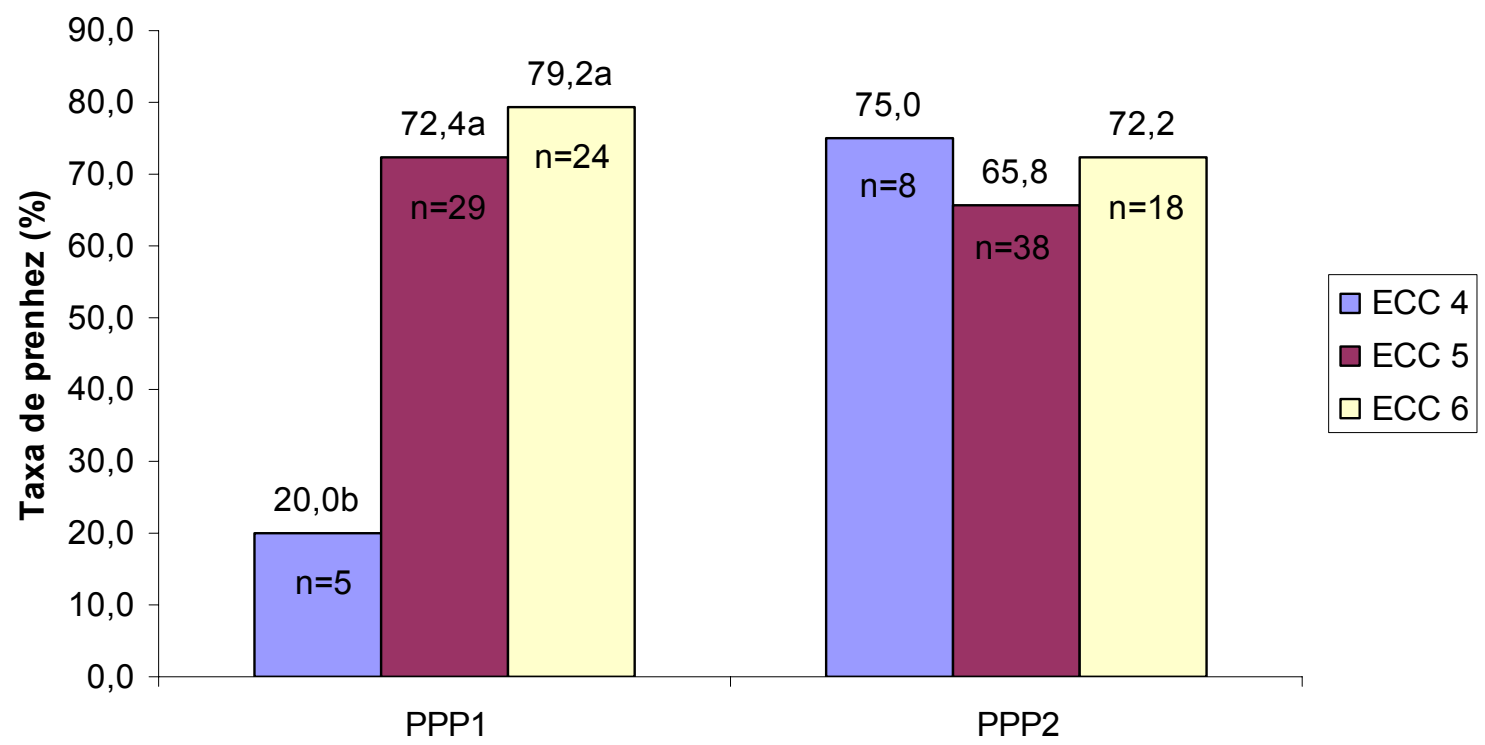

Gráfico 2 - TPIATF nos PPP1 e PPP2 segundo escore de condição corporal 
Tabela 5 - TPIATF e TPEM segundo tratamento, categoria animal, período pós-parto, escores de condição corporal e ovariana, touro e interações

\begin{tabular}{|c|c|c|c|c|c|c|}
\hline \multicolumn{7}{|c|}{ Efeitos Principais } \\
\hline & & $\mathrm{n}$ & TPIATF (\%) & $p=$ & TPEM (\%) & $p=$ \\
\hline \multirow{2}{*}{ Trat } & $\mathrm{DIB} \otimes$ & 60 & 66,7 & \multirow{2}{*}{0,3606} & 95,0 & \multirow{2}{*}{0,5683} \\
\hline & Progestar $®$ & 76 & 65,8 & & 94,7 & \\
\hline \multirow{3}{*}{ Cat } & Primípara & 31 & 63,3 & \multirow{3}{*}{0,6969} & 93,3 & \multirow{3}{*}{0,8008} \\
\hline & Multípara & 91 & 71,4 & & 96,7 & \\
\hline & Solteira & 14 & 40,0 & & 86,7 & \\
\hline \multirow{2}{*}{ PPP } & 1 & 58 & 70,7 & \multirow{2}{*}{0,5959} & 94,8 & \multirow{2}{*}{0,6978} \\
\hline & 2 & 64 & 68,7 & & 96,9 & \\
\hline \multirow{3}{*}{ ECC } & 4 & 13 & 53,8 & & 100 & \multirow{3}{*}{0,4492} \\
\hline & 5 & 67 & 68,7 & 0,8004 & 92,5 & \\
\hline & 6 & 56 & 65,1 & & 96,4 & \\
\hline \multirow{2}{*}{ ECO } & 1 & 98 & 67,3 & \multirow{2}{*}{0,8693} & 95,9 & \multirow{2}{*}{0,6089} \\
\hline & 2 & 38 & 63,2 & & 92,1 & \\
\hline \multirow{5}{*}{ Touro } & 1 & 15 & - & \multirow{5}{*}{-} & 86,7 & \multirow{5}{*}{0,2632} \\
\hline & 2 & 23 & - & & 100,0 & \\
\hline & 3 & 45 & - & & 95,6 & \\
\hline & 4 & 39 & - & & 97,4 & \\
\hline & 5 & 14 & - & & 85,7 & \\
\hline \multicolumn{7}{|c|}{ Interações } \\
\hline & & $\mathrm{n}$ & TPIATF (\%) & $p=$ & TPEM (\%) & $p=$ \\
\hline \multirow{3}{*}{ PPP1 } & ECC 4 & 5 & $20 b$ & \multirow{3}{*}{0,0280} & - & \\
\hline & ECC 5 & 29 & $72,4 a$ & & - & - \\
\hline & ECC 6 & 24 & $79,2 a$ & & - & \\
\hline & ECC 4 & 8 & 75,0 & & - & \\
\hline PPP2 & ECC 5 & 38 & 65,8 & 0,8254 & - & - \\
\hline & ECC 6 & 18 & 72,2 & & - & \\
\hline PPP1 & ECO 1 & 36 & 69,4 & 07943 & - & - \\
\hline & ECO 2 & 22 & 72,7 & 0,1040 & - & - \\
\hline PPP? & ECO 1 & 48 & $75 \mathrm{~A}$ & 00633 & - & - \\
\hline rirz & ECO 2 & 16 & $50 \mathrm{~B}$ & 0,0030 & - & 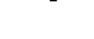 \\
\hline & & & Interações & & & \\
\hline & Cat & - & - & 0,4752 & - & 0,2432 \\
\hline & PPP & - & - & 0,3227 & - & 0,5408 \\
\hline & ECC & - & - & 0,3822 & - & 0,5289 \\
\hline & ECO & - & - & 0,2184 & - & 0,3660 \\
\hline & PPP & - & - & 0,1068 & - & 0,4463 \\
\hline & ECC & - & - & 0,6414 & - & 0,8322 \\
\hline & ECO & - & - & 0,2597 & - & 0,4181 \\
\hline & ECC & - & - & 0,0013 & - & 0,7833 \\
\hline & ECO & - & - & 0,0292 & - & 0,7497 \\
\hline & ECO & - & - & 0,9083 & - & 0,9970 \\
\hline Trat & $t^{\star} P P P$ & - & - & 0,9692 & - & 0,8536 \\
\hline Trat & $t^{\star} \mathrm{ECO}$ & - & - & 0,2743 & - & 0,1173 \\
\hline Trat' & $P^{*} E C O$ & - & - & 0,9863 & - & 0,1754 \\
\hline Cat $^{*}$ & $P * E C O$ & - & - & 0,8757 & - & 0,2033 \\
\hline Trat & $t^{\star} E C C$ & - & - & 0,3284 & - & 0,6378 \\
\hline Trat & $P^{*} E C C$ & - & - & 0,8561 & - & 0,3421 \\
\hline Cat* & $P^{*} E C C$ & - & - & 0,8890 & - & 0,9241 \\
\hline Trat $^{*} \mathrm{C}$ & $P P * E C O$ & - & - & 0,4976 & - & 0,2688 \\
\hline
\end{tabular}

Período pós-parto: PPP1 (45 a 70 dias) e PPP2 (71 a 90 dias)

$a \neq b$ e $A \neq B(p<0,05)$ 


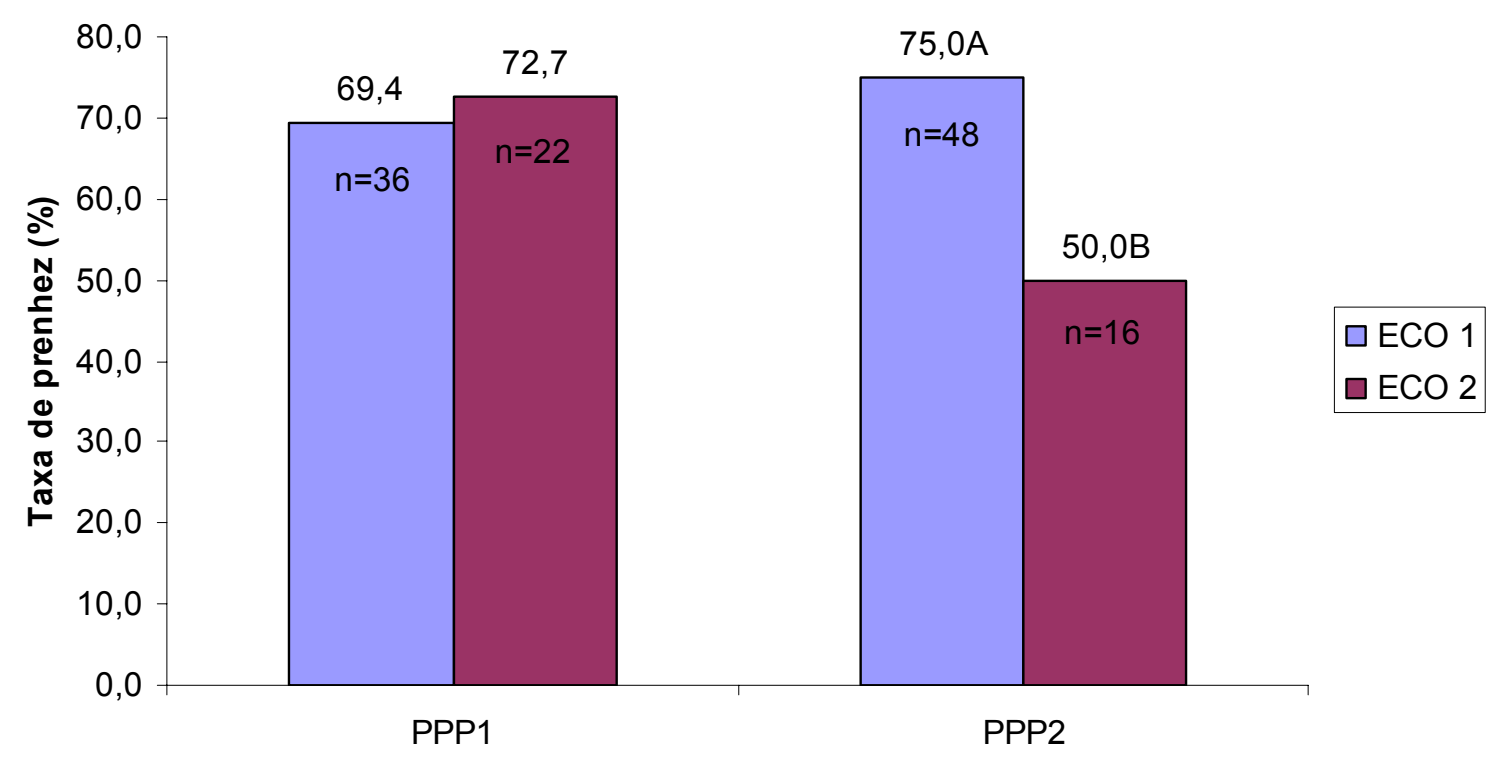

Gráfico 3 - TPIATF nos PPP1 e PPP2 segundo escore de condição ovariana

\subsection{EXPERIMENTO 2}

Dos animais sincronizados com os dispositivos de $2^{\circ}$ uso, 4 perderam o $\operatorname{DIB}^{\circledR}$ (taxa de retenção de 92,3\%), enquanto somente 1 perdeu o Progestar $^{\circledR}$ (taxa de retenção de $98 \%$ ).

Foi observado, neste experimento, que não houve interação entre tratamento e as demais variáveis estudadas. Não houve efeito de tratamento sobre as taxas de prenhez (Tabela 6): 1) TPIATF: DIB $^{\circledR} 2-61,6 \%$ vs Progestar $^{\circledR} 2-55,8 \%, p=0,7791$ e 2 ) TPEM: DIB ${ }^{\circledR} 2-94,2 \%$ vs Progestar $^{\circledR} 2$ $88,5 \%, p=0,3246$, gráfico 4 .

Houve interação entre período pós-parto e escore de condição corporal $(p=0,0185)$ e tendência de efeito da interação entre categoria animal e período pós-parto $(p=0,0690)$ na TPEM. As primíparas apresentaram diferentes taxas de prenhez segundo período pós-parto $(\mathrm{p}=0,0210)$, tabela 6 e gráfico 5: PPP1 $(57,1 \%)$ vs PPP2 $(90,5 \%)$; no entanto, as multíparas não apresentaram esta diferença em relação ao período pós-parto $(p=0,3265)$. Também foi observado 
que, no PPP2, as taxas de prenhez variavam conforme o escore de condição corporal ( $p=0,0828)$, tabela 6 e gráfico 6 : animais com escore $4(84,2 \%)$ vs escore $5(100 \%)$; porém esta diferença não foi observada no PPP1 $(p=0,8631)$.

Também não houve efeito do escore de condição ovariana sobre as taxas de prenhez (Tabela 6): 1) TPIATF: ciclando $50 \%$ vs não ciclando $67,3 \%, p=0,1854$ e 2) TPEM: ciclando $-94,2 \%$ vs não ciclando $-88,5 \%$, $\mathrm{p}=0,2428$.

Também não houve efeito de categoria animal e escore de condição corporal sobre a TPIATF (Tabela 6): 1 ) categoria animal (primípara $-54,3 \%$ vs multípara $-60,9 \%, p=0,6339)$ e 2$)$ escore de condição corporal $(4-70,4 \%$ vs 5 $-54,6 \%, p=0,5732$ ). O período pós-parto apresentou efeito na TPIATF (Tabela $6)$ : PPP1 $-48,2 \%$ vs PPP2 - 70,8\% ( $p=0,0165)$. Também houve efeito de touro na TPEM $(p=0,0004)$, tabela 6 : touro $1(100 \%)$ vs $2(100 \%)$ vs $3(95,3 \%)$ vs 4 $(41,7 \%)$. O touro 4 obteve desempenho inferior em relação aos demais. A TPIATF média foi de 58,7\%, enquanto que para a TPEM foi de $91,3 \%$.

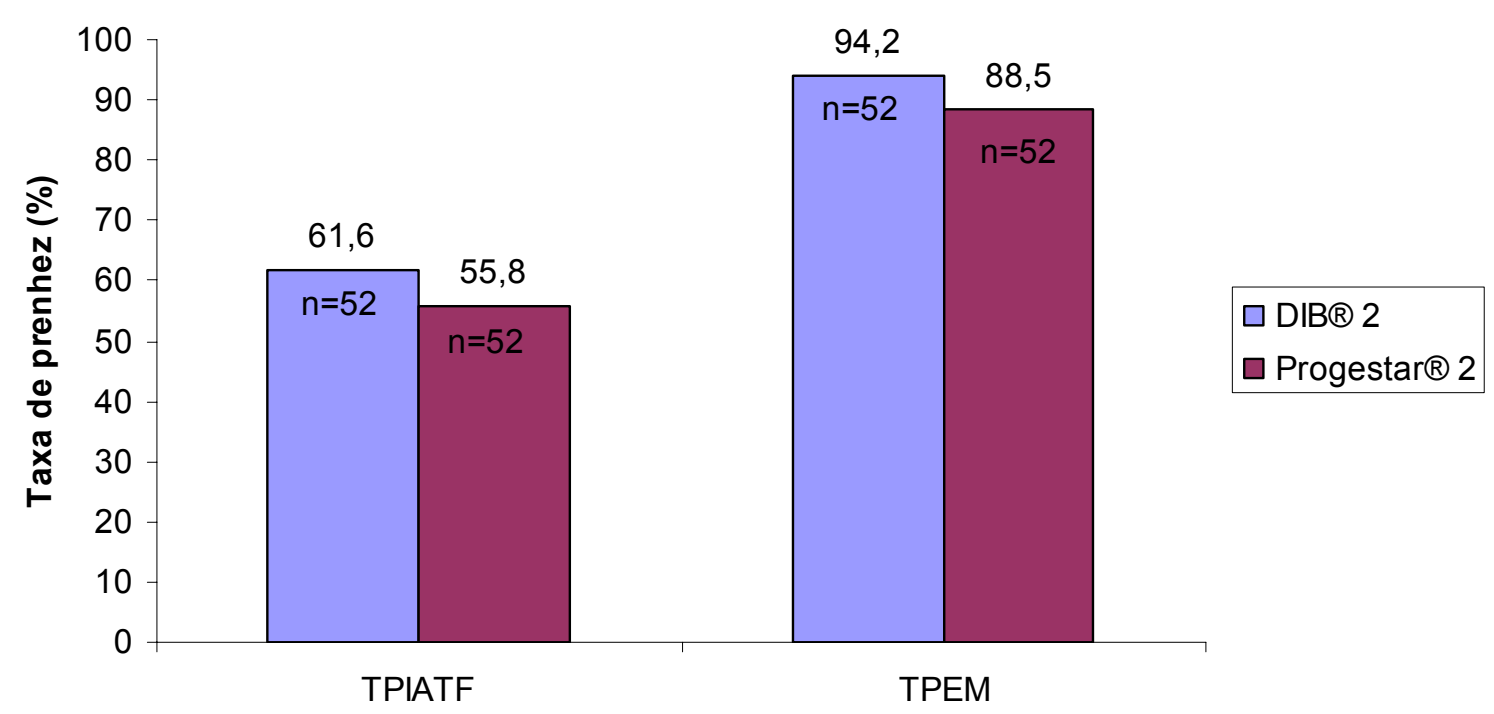

Gráfico 4 - TPIATF e TPEM segundo tratamento 
Tabela 6 - TPIATF e TPEM segundo tratamento, escore de condição ovariana, categoria animal, período pós-parto, escore de condição corporal, touro e interações

\begin{tabular}{|c|c|c|c|c|c|c|}
\hline \multicolumn{7}{|c|}{ Efeitos Principais } \\
\hline & & $n$ & TPIATF $(\%)$ & $p=$ & TPEM (\%) & $p=$ \\
\hline \multirow{2}{*}{ Trat } & $\mathrm{DIB} \otimes 2$ & 52 & 61,6 & \multirow{2}{*}{0,7791} & 94,2 & \multirow{2}{*}{0,3246} \\
\hline & Progestar 2 & 52 & 55,8 & & 88,5 & \\
\hline \multirow{2}{*}{ ECO } & 1 & 52 & 50,0 & \multirow{2}{*}{0,1854} & 94,2 & \multirow{2}{*}{0,2428} \\
\hline & 2 & 52 & 67,3 & & 88,5 & \\
\hline \multirow{2}{*}{ Cat } & Primípara & 35 & 54,3 & \multirow{2}{*}{0,6339} & 77,1 & \multirow{2}{*}{0,250} \\
\hline & Multípara & 69 & 60,9 & & 98,6 & \\
\hline \multirow{2}{*}{ PPP } & 1 & 56 & $48,2 b^{\prime}$ & \multirow{2}{*}{0,0165} & 89,3 & \multirow{2}{*}{0,6835} \\
\hline & 2 & 48 & $70,8 a^{\prime}$ & & 93,7 & \\
\hline \multirow{2}{*}{ ECC } & 4 & 27 & 70,4 & \multirow{2}{*}{0,5732} & 85,2 & \multirow{2}{*}{0,8386} \\
\hline & 5 & 77 & 54,6 & & 93,6 & \\
\hline \multirow{4}{*}{ Touro } & 1 & 5 & - & \multirow{4}{*}{-} & $100 a$ & \multirow{4}{*}{0,0004} \\
\hline & 2 & 44 & - & & $100 a$ & \\
\hline & 3 & 43 & - & & $95,3 a$ & \\
\hline & 4 & 12 & - & & $41,7 b$ & \\
\hline \multicolumn{7}{|c|}{ Interações } \\
\hline & & $\mathrm{n}$ & TPIATF (\%) & $p=$ & TPEM (\%) & $p=$ \\
\hline \multirow{2}{*}{ Primípara } & PPP1 & 14 & - & \multirow{2}{*}{-} & $57,1 \mathrm{~A}$ & \multirow{2}{*}{0,0210} \\
\hline & PPP2 & 21 & - & & $90,5 \mathrm{~B}$ & \\
\hline \multirow{2}{*}{ Multípara } & PPP1 & 42 & - & \multirow{2}{*}{-} & 100,0 & 0.3265 \\
\hline & PPP2 & 27 & - & & 96,3 & \\
\hline PPP1 & ECC 4 & 8 & - & 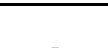 & 87,5 & 08631 \\
\hline Prtit & ECC 5 & 48 & - & - & 89,6 & (1,000 \\
\hline PPP? & ECC 4 & 19 & - & & $84,2 \mathrm{~B}^{\prime}$ & 00828 \\
\hline PPPL & ECC 5 & 29 & - & - & $100 A^{\prime}$ & $0,08<8$ \\
\hline & & & terações & & & \\
\hline & ${ }^{*}$ Cat & - & - & 0,9519 & - & 0,5817 \\
\hline & PPP & - & - & 0,4220 & - & 0,5623 \\
\hline & ECC & - & - & 0,6543 & - & 0,3249 \\
\hline & ECO & - & - & 0,4556 & - & 0,8942 \\
\hline & PPP & - & - & 0,6599 & - & 0,0690 \\
\hline & $\mathrm{ECC}$ & - & - & 0,1494 & - & 0,6024 \\
\hline & ECO & - & - & 0,6319 & - & 0,3475 \\
\hline & ${ }^{*} E C C$ & - & - & 0,9122 & - & 0,0185 \\
\hline & *ECO & - & - & 0,5343 & - & 0,1017 \\
\hline & *ECO & - & - & 0,8763 & - & 0,3498 \\
\hline Tra & at*PPP & - & - & 0,9383 & - & 0,9764 \\
\hline Trat & $a t^{\star} E C O$ & - & - & 0,8861 & - & 0,9351 \\
\hline Trat' & $P^{*} E C O$ & - & - & 0,8384 & - & 0,9077 \\
\hline Cat* & $P^{*} E C O$ & - & - & 0,2650 & - & 0,1053 \\
\hline
\end{tabular}

Período pós-parto: PPP1 (32 a 55 dias) e PPP2 (56 a 90 dias)

$a \neq b$ pelo teste de Tukey $(p<0,05)$

$a^{\prime} \neq b^{\prime}, A \neq B$ e $A^{\prime} \neq B^{\prime}(p<0,05)$ 


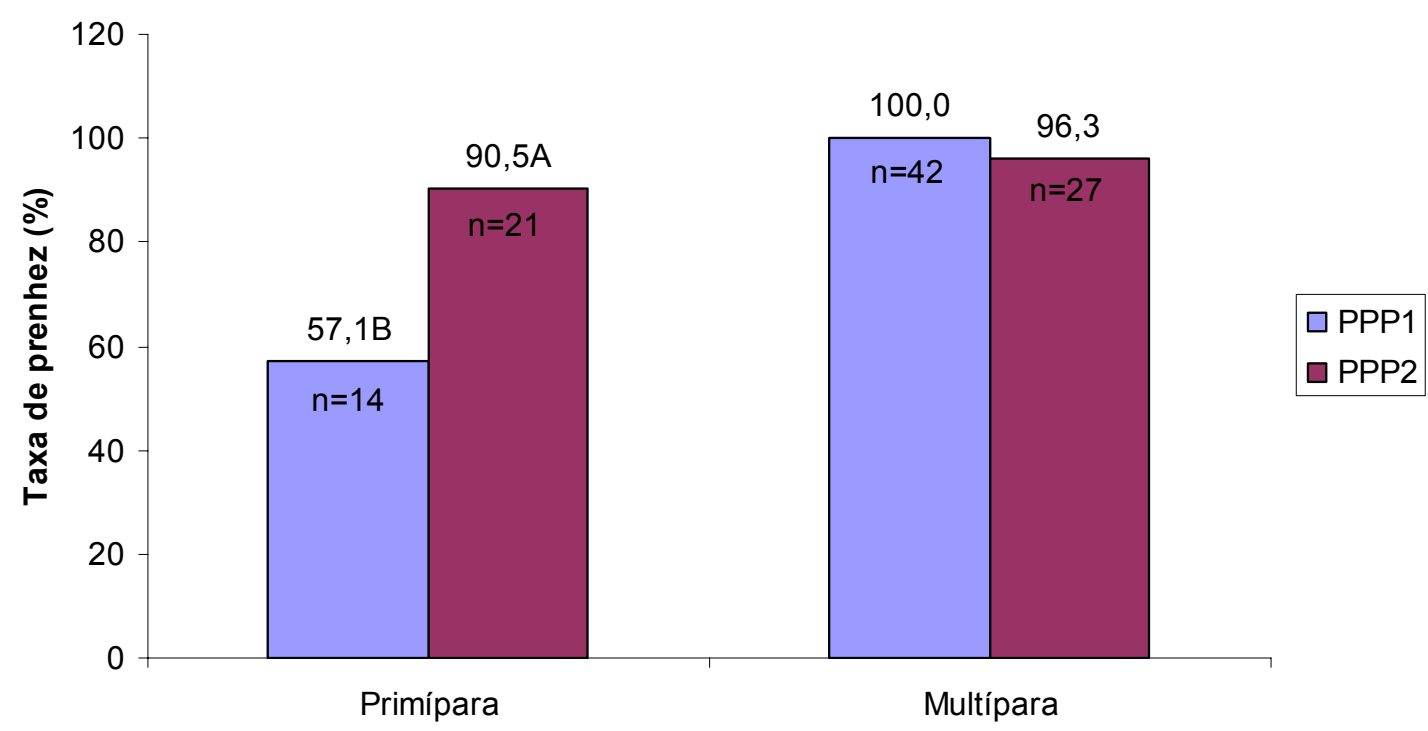

Gráfico 5 - TPEM de primíparas e multíparas segundo período pósparto

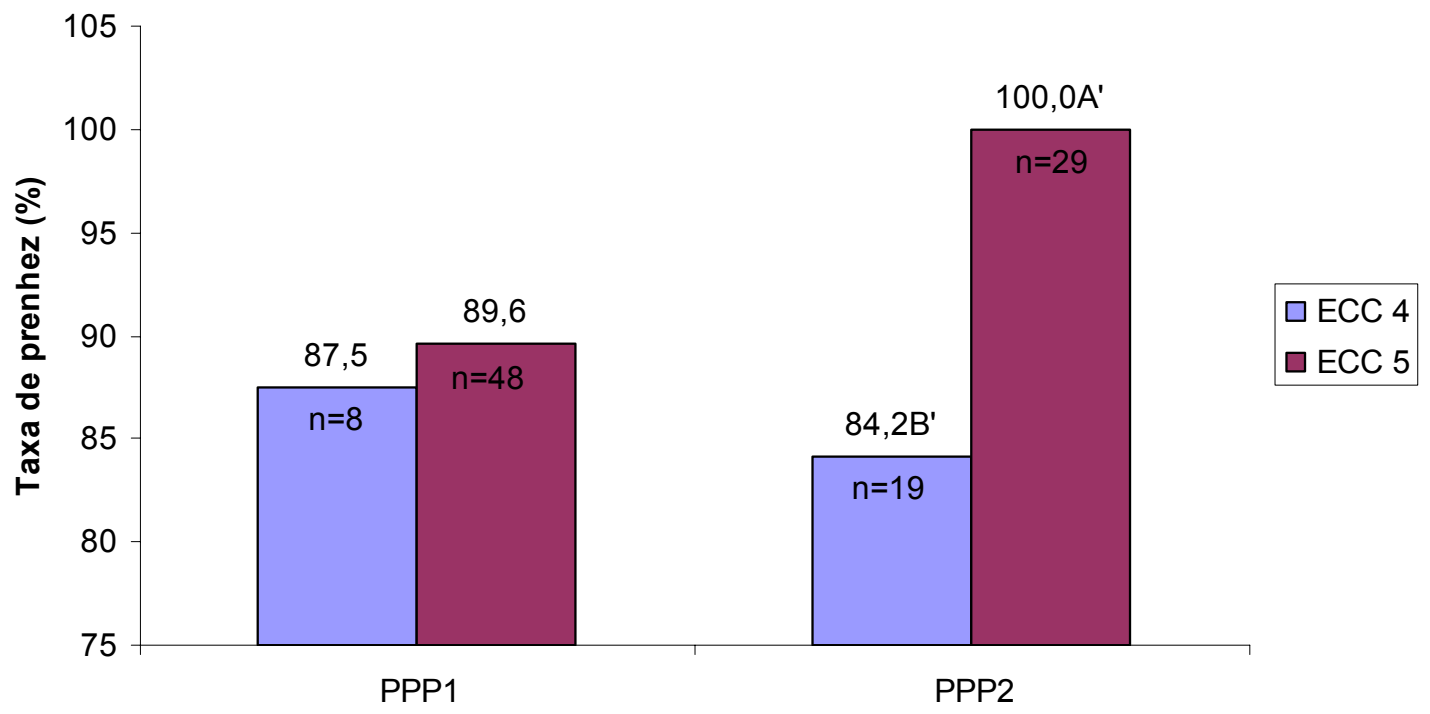

Gráfico 6 - TPEM nos PPP1 e PPP2 segundo escore de condição corporal 


\section{DISCUSSÃO}

Para uma melhor demonstração dos sinais de estro e de uma fase luteínica normal, níveis elevados de $\mathrm{P}_{4}$ são de extrema importância (BÓ, 2000). $A$ exposição à $\mathrm{P}_{4}$ exógena aumenta a freqüência de pulsos de $\mathrm{LH}$, a produção de $E_{2}$ folicular, os receptores para $\mathrm{LH}$ e a luteinização das células foliculares (CROWE et al., 1993). Desta forma, protocolos nos quais são utilizados dispositivos para liberação sustentada de $\mathrm{P}_{4}$ (CAVALIERI et al., 2002) e que apresentam altas taxas de sincronização de estro e ovulação, possibilitando a IATF (BÓ et al., 2002), proporcionam um ambiente uterino e condições ovarianas propícios à ocorrência da ovulação e estabelecimento da gestação. Todas estas afirmações podem ser aplicadas a este trabalho, no qual protocolos muito semelhantes aos descritos foram utilizados, atingindo resultados de TPIATF de $66,2 \%$ para o experimento 1 e $58,7 \%$ para o experimento 2 .

Bó et al. (2002) verificaram boas e semelhantes taxas de prenhez em um trabalho comparando $\operatorname{CIDR}^{\circledR}\left(61,5 \%-1^{\circ}\right.$ uso e $41,9 \%-2^{\circ}$ uso $)$ e $\operatorname{DIB}^{\circledR}$ $\left(60,7 \%-1^{\circ}\right.$ uso e $46,8 \%-2^{\circ}$ uso) em programas de IATF. No experimento 1 , também foram encontradas estas semelhanças nas TPIATF entre os dispositivos de $1^{\circ}$ uso $\operatorname{DIB}^{\circledR}(66,7 \%)$ e $\operatorname{Progestar}^{\circledR}(65,8 \%)$. No entanto, no experimento 2, foram encontradas TPIATF mais elevadas com os dispositivos de $2^{\circ}$ uso $\left(\right.$ DIB $^{\circledR}-61,2 \%$ e Progestar ${ }^{\circledR}-55,8 \%$ ), provavelmente devido às boas condições nutricionais e corporais em que os animais se encontravam (74\% dos animais do experimento 2 apresentavam escore de condição corporal igual a 5), o uso de eCG em todos os animais, assim como uso de sêmen de boa qualidade.

Em um estudo, foi avaliada a eficiência do $\operatorname{CIDR}^{\circledR}$ de $1^{\circ}$ e de $2^{\circ}$ usos e as taxas de prenhez proporcionadas foram de $62 \%$ e $73 \%$, respectivamente. Concluiu-se assim, que não houve perda de eficiência com emprego de dispositivo novo ou usado (WHITTAKER et al., 2002). Embora, no presente estudo, não se possa fazer uma comparação entre os resultados de $1^{\circ}$ e $2^{\circ}$ usos dos dispositivos, pode-se dizer, pela semelhança de resultados, que não houve perda de eficiência. Entretanto, no trabalho de Barufi (2002) foram 
encontradas taxas de prenhez para o $\mathrm{CIDR}^{\circledR} 1^{\circ}$ uso de $28,8 \%$ e para o dispositivo de $2^{\circ}$ uso de $38,7 \%$. Estes resultados, mesmo com equivalência entre eles, foram inferiores devido ao pior escore de condição corporal (média de 4,4 ) e não uso de eCG em todos os animais.

Taxas de prenhez de aproximadamente $50 \%$, em programas de IATF, podem ser consideradas muito boas e em acordo com resultados de outros autores (BÓ et al., 1994; BRIDGES et al., 1999; ROSSA, 2002). Neste trabalho, todos os resultados na IATF foram superiores a esta taxa de prenhez de referência e esta superioridade pode ser explicada pelo bom escore de condição corporal (experimento 1 - 90,4\% dos animais apresentavam escore maior ou igual a 5 e experimento $2-74 \%$ ), boa ciclicidade no período pósparto ( $72 \%$ no experimento 1 e $50 \%$ no experimento 2$)$, categoria animal (66,9\% de multíparas no experimento 1 e $66,3 \%$ no experimento 2), assim como o uso de eCG em $100 \%$ dos animais do experimento.

A eCG possui ação folículo estimulante e luteinizante, em fêmeas bovinas (MURPHY; MARTINUK, 1991) e assim, é capaz de aumentar as concentrações plasmáticas de $\mathrm{P}_{4}$, principalmente quando administrada após a fase de divergência folicular. Como resultado, em animais zebuínos, ocorre um aumento da taxa de crescimento folicular, culminando com um maior folículo dominante (com eCG - 1,22mm vs sem eCG: $1,04 \mathrm{~mm}$ ) e CL maior (com eCG: $1,93 \mathrm{~mm}$ vs sem eCG: $1,82 \mathrm{~mm}$ ), além de maior número de ovulações, maior taxa de concepção e de prenhez, em relação às fêmeas que não foram tratadas com eCG (BARUSELLI et al., 2003). A dose de 400Ul de eCG, em protocolos de IATF, com uso de dispositivos de $\mathrm{P}_{4}$, beneficia, principalmente, animais em condições de anestro (não cíclicos), baixa condição corporal (menor ou igual a 4) e período pós-parto precoce (menor do que 40 dias) (BÓ; BARUSELLI; MARTINEZ, 2003), aumentando significativamente a taxa de prenhez (CUTAIA et al., 2003), pelo estímulo da maturação final dos folículos (ROSSA, 2002). Neste experimento, os animais apresentavam bom escore de condição corporal, boa ciclicidade e somente animais do experimento 2 $(53,8 \%)$ apresentavam um período pós-parto muito precoce (32 a 55 dias). Como resultado, mesmo com uma dose de $300 \mathrm{UI}$ de eCG, boas TPIATF foram obtidas. 
Cutaia et al. (2003) mostraram taxas de prenhez superiores de vacas cíclicas $(56,3 \%)$, em relação a vacas não cíclicas $(47 \%)$. Em ambos os experimentos, os animais classificados como cíclicos e não cíclicos, no primeiro dia do protocolo, apresentaram bons resultados de TPIATF (experimento 1 - 67,3\% - cíclicos e $63,2 \%$ - não cíclicos e experimento 2 - 50\% - cíclicos e 67,3\% - não cíclicos). Esta observação pode ser explicada, pois tratamentos com $\mathrm{P}_{4}$ são indutores da retomada da ciclicidade no período pósparto de fêmeas bovinas (MIHM, 1999), além de que o uso de eCG, em todos os animais, contribuiu para o aumento na taxa de prenhez dos animais não cíclicos. Em outro estudo com protocolos de IATF, com uso do Crestar $^{\circledR}$, o efeito da ciclicidade foi evidenciado, quando novilhas zebuínas cíclicas apresentaram taxa de prenhez de $63,3 \%$, enquanto que as novilhas não cíclicas apresentaram uma taxa de $28,6 \%$ (GASPAR, 2005). Este autor descreve que esta grande diferença é proveniente da imaturidade das novilhas não cíclicas (impúberes), mais sensíveis ao feedback negativo de $E_{2}$ sobre o eixo hipotálamo-hipofisário. No presente trabalho, não houve diferença na taxa de prenhez das vacas cíclicas e não cíclicas.

Alta correlação foi encontrada entre escore de condição corporal e taxa de prenhez (CUTAIA et al., 2003). Em um estudo com vacas de condição corporal inferior a 5, a taxa de prenhez encontrada foi de apenas $29,3 \%$, enquanto que os animais com condição corporal igual ou maior do que 5 apresentaram 50,8\% (BARUFI, 2002). Vacas com escore de condição corporal maior ou igual a 5 , no período pós-parto, reassumem a ciclicidade mais precocemente do que vacas que apresentem este escore menor do que 5 (MIHM, 1999). Short et al. (1995) demonstraram uma menor disponibilidade de gonadotrofinas, em vacas com escore de condição corporal ruim.

No presente trabalho, as TPIATF foram boas independentemente do escore corporal dos animais (experimento 1: $4-53,8 \%, 5-68,7 \%$ e $6-66,1 \%$ e experimento 2: $4-70,4 \%$ e $5-54,6 \%$ ). No experimento 1 , somente $9,5 \%$ dos animais apresentavam escore de condição corporal 4 e, no experimento 2 , este número foi de $25,9 \%$. A união da boa ciclicidade apresentada pelos animais ao uso de eCG, ajudou a minimizar este efeito negativo, da condição corporal sobre a taxa de prenhez. É importante salientar que, neste trabalho, 
todos os animais estavam bem nutridos, com boa disponibilidade e qualidade de forragens e suplementação mineral.

Tanto nos rebanhos comerciais, como em condições experimentais, um desempenho reprodutivo inferior é esperado das primíparas em relação às multíparas (WILTBANK, 1970). As primíparas ainda não completaram totalmente sua fase de crescimento e devem também disponibilizar energia para a amamentação, além de constituir uma classe hierárquica inferior à das multíparas (disputa ao cocho de suplementação, pastagens e água). Também apresentam menores amplitudes de pulsos de LH e um anestro pós-parto mais prolongado (1 a 4 semanas a mais do que as multíparas) (GUEDON et al., 1999).

O efeito do balanço energético negativo, no período pós-parto, é mais pronunciado nas primíparas do que nas multíparas (BELLOWS et al., 1978), causando redução da disponibilidade de glicose e maior mobilização de colesterol e triglicerídeos para a produção de energia. Animais no período pósparto devem estar em boas condições corporais, para um rápido retorno à ciclicidade, pois crescimento e reservas corporais possuem prioridade sobre a reprodução (SHORT et al., 1995).

No trabalho de Almeida (2003), no qual nem todos os animais receberam eCG, os valores foram diferentes para primíparas e multíparas, tanto na TPIATF (35\% e 52,7\%, respectivamente), quanto na TPEM $(71,9 \%$ e $90,2 \%$, respectivamente). Soto Belloso et al. (2002), na Venezuela, com o uso de eCG, para as primíparas, atingiram taxas de prenhez de $41,1 \%$. No presente estudo, não houve diferença na TPIATF para primíparas e multíparas (experimento 1: primíparas $-63,3 \%$ e multíparas $-71,4 \%$ e experimento 2 : primíparas - 54,3\% e multíparas - 60,9\%). Estes bons resultados apresentados pelas primíparas são devidos à alta ciclicidade do rebanho, uso de eCG e boa disponibilidade e qualidade de pastagens, suplementação mineral e água.

Nos animais do experimento 2, ocorreu uma interação entre categoria animal e período pós-parto, na TPEM. Assim, as primíparas com PPP1 (32 a 55 dias) apresentaram uma menor taxa de prenhez $(57,1 \%)$ em relação às mesmas, com PPP2 de 56 a 90 dias (90,5\%). Por outro lado, as multíparas não apresentaram esta diferença de resultados, segundo o PPP1 e PPP2 (100\% vs 
$96,3 \%$, respectivamente). A soma dos fatores maior balanço energético negativo (período pós-parto precoce) (BELLOWS et al., 1978) e maior sensibilidade das primíparas a este balanço energético fizeram com que as mesmas apresentassem um resultado inferior nesta taxa de prenhez.

No experimento 1 foram sincronizadas 14 vacas (10,2\%) solteiras. Esta classificação se refere às vacas multíparas que não se tornaram gestantes na estação de monta anterior (vacas problema). Estes animais apresentavam bom escore de condição corporal e ciclicidade e, assim, atingiram TPIATF (40\%) e TPEM $(86,7 \%)$ não diferentes das demais categorias (primíparas e multíparas).

O anestro pós-parto, em bovinos de corte, é a principal causa de baixo desempenho reprodutivo sendo reconhecido como uma condição fisiológica natural, induzido, principalmente, pelo efeito da amamentação e condições nutricionais desfavoráveis (MACMILLAN; PETERSON, 1993). Esta ausência de ciclicidade é conseqüência da falha na ovulação dos folículos dominantes, causada pelas baixas concentrações de LH (JOLLY et al., 1995). Neste processo, estão envolvidos mecanismos complexos de relação entre hipotálamo, hipófise, ovários e útero. No período pós-parto, os estoques de LH estão reduzidos, devido ao feedback negativo do $E_{2}$ no hipotálamo e da presença de $\mathrm{P}_{4}$ no final da gestação. Após o parto, as concentrações de FSH aumentam rapidamente, permitindo o recrutamento e a seleção do folículo dominante. No entanto, a ovulação deste folículo não ocorre enquanto não houver o restabelecimento do estoque de LH na hipófise anterior (NETT, 1987). Este estoque começa a ser restabelecido, em vacas de corte amamentando, entre os 35 e 60 dias pós-parto (STAGG et al., 1995).

No período compreendido entre os dias 14 e 21 após o parto, ocorre o processo de involução uterina e, nesta fase, o animal encontra-se em recuperação das perdas metabólicas sofridas durante toda a gestação (SHORT et al., 1995). Melhores taxas de prenhez, em protocolos de sincronização de fêmeas bovinas, com maior período pós-parto, se devem principalmente à maior proporção de animais com ciclicidade ovariana (BEAL et al., 1984), uma vez que, nestes animais, ocorre também uma menor mobilização de lipídeos (HUMBLOT et al., 1996).

No presente trabalho, aproximadamente metade dos animais do experimento $1(47,5 \%)$ encontravam-se no PPP1 (45 a 70 dias) e os outros 
$52,4 \%$, no PPP2 (71 a 90 dias). Este pós-parto não muito precoce, aliado aos $90,4 \%$ dos animais com escore de condição corporal igual ou maior do que 5 , proporcionou uma ciclicidade de $72 \%$. Já no experimento 2 , mais da metade dos animais (53,8\%) apresentavam PPP1 (32 a 55 dias) e 46,1\% pertenciam ao grupo do PPP2 (56 a 90 dias). Esta maior precocidade no período do pósparto, somado ao menor número de animais, com escore corporal igual a 5 , resultou em uma ciclicidade menor (50\%) em relação ao experimento 1.

Animais zebuínos de corte, apresentando diferentes períodos pós-parto (28 a 40, 41 a 60 e maior do que 60 dias), tratados com o dispositivo CIDR ${ }^{\circledR}$, obtiveram TPIATF de $43 \%$, 59\% e 54\%, respectivamente (BRIDGES et al., 1999). Estas afirmações, com respeito ao desempenho inferior na IATF, de animais com período pós-parto precoce, também foram observadas neste trabalho. No experimento 2, os animais que apresentavam PPP1 (32 a 55 dias), obtiveram uma taxa de prenhez menor $(48,2 \%)$, em relação aos animais com período PPP2, de 56 a 90 dias $(70,8 \%)$. Por outro lado, os animais pertencentes ao experimento 1 (período pós-parto mais adiantado em relação ao do experimento 2), não tiveram diferença na taxa de prenhez segundo o período PPP1 (70,7\%, 45 a 70 dias) e PPP2 (68,7\%, 71 a 90 dias), concordando com trabalho de Marques et al. (2003) que obtiveram TPIATF de $65 \%$ e $53,3 \%$ (com período pós-parto de 41 a 60 dias e 61 a 80 dias, respectivamente). É importante notar que, com um bom manejo nutricional, boa ciclicidade e uso de eCG, os animais dos 2 experimentos obtiveram taxas de prenhez superiores em relação ao trabalho de Bridges et al. (1999) e Marques et al. (2003), que atingiram, aproximadamente, $50 \%$ de TPIATF em vacas zebuínas.

Uma severa restrição alimentar, ou um período pós-parto precoce, fazem com que os animais não sofram ovulação após a sincronização, com uso de dispositivos de $\mathrm{P}_{4}$ (GRIMARD et al., 1997). Animais de corte, com boa condição corporal, possuem a primeira ovulação, no período pós-parto entre 27 e 37 dias, enquanto que animais com uma pior condição corporal ovulam entre 60 e 120 dias após o parto (MURPHY; MARTINUK, 1991). Estes dados puderam ser observados, pois no experimento 1 , ocorreu uma interação entre período pós-parto e escore de condição corporal na TPIATF, na qual animais com PPP1 (45 a 70 dias) e escore corporal 4 apresentaram um valor de 20\% 
contra 72,4\% e 79,2\% (de animais com escores corporais 5 e 6, respectivamente), enquanto que nos animais com PPP2 (71 a 90 dias) as médias não diferiram, segundo o escore corporal $(4-75 \%, 5-65,8 \%$ e 6 $72,2 \%)$.

Após 30 dias do parto, a presença do bezerro em amamentação estimula o feedback negativo do $E_{2}$ no hipotálamo, inibindo a liberação de pulsos de $\mathrm{GnRH}$ e conseqüentemente de LH (ACOSTA et al., 1983), por meio da liberação dos opióides endógenos (ZALESK et al., 1990) e, com o balanço energético negativo, este atraso do aumento de freqüência de $\mathrm{LH}$, em vacas de corte, é intensificado (MIHM, 1999). Esta influência negativa da presença do bezerro sobre as taxas de prenhez pode ser observada em ambos os experimentos. No experimento 1 ocorreu uma interação entre período pósparto e escore de condição ovariana, na TPIATF, na qual animais com PPP2 (71 a 90 dias) e não cíclicos apresentaram um valor de $50 \%$ contra $75 \%$ dos animais cíclicos. No entanto, para os animais com PPP1 (32 a 55 dias) não houve diferença entre cíclicas $(69,4 \%)$ e não cíclicas $(72,7 \%)$. Já no experimento 2, a interação ocorreu entre o período pós-parto e escore de condição corporal, na TPEM, em que animais com PPP2 (56 a 90 dias), com escore corporal 4 , obtiveram taxa de $84,2 \%$, contra $100 \%$ dos animais com escore corporal 5, enquanto que no PPP1 (45 a 70 dias) os animais não apresentaram diferença segundo escore corporal (4-87,5\% e $5-89,6 \%)$. Desta forma, pode-se afirmar que, a presença do bezerro com o estímulo da amamentação juntamente com a falta de ciclicidade, ou escore de condição corporal desfavorável, prejudicaram o desempenho nas taxas de prenhez.

A qualidade de sêmen congelado, usado nos protocolos de IATF, interfere sobremaneira em seus resultados, observando-se variações de 0 a $80 \%$ na taxa de prenhez (FULLENWILDER et al., 2001). No presente trabalho, todos os animais sincronizados foram inseminados com o sêmen congelado, de uma mesma partida, atingindo resultados muito satisfatórios para os experimentos 1 e 2 (TPIATF de $66,2 \%$ e 58,7\%, respectivamente).

$\mathrm{Na}$ estação de monta, é de fundamental importância a escolha do touro adequado e o exame andrológico é uma das melhores maneiras para o sucesso nesta escolha. Foi encontrada uma grande variação de resultados na TPEM de $60,6 \%$ a $96,5 \%$, com o uso de diferentes touros em regime de monta 
natural (SANTOS, 2000). No presente trabalho, as TPEM foram muito satisfatórias (experimento 1: $94,9 \%$ e experimento 2: $91,3 \%$ ). No experimento 1 , não houve diferença nas boas TPEM, proporcionadas pelos 5 diferentes touros (1 - 86,7\%, 2 - 100\%, 3 - 95,6\%, $4-97,4 \%$ e 5 - 85,7\%). Entretanto, no experimento 2 existiu diferença neste resultado final, no qual o touro 4 obteve desempenho inferior em relação aos demais $(1-100 \%, 2$ - 100\%, 3 $95,3 \%$ e $4-41,7 \%$ ). É importante ressaltar que não foi realizado o exame andrológico nos touros e que o touro 4 do experimento 2 foi o mesmo touro 5 do experimento 1 (touro número 141). Desta forma, pode-se concluir que um problema de origem desconhecida ocorreu a este touro, durante o período da estação de monta, ocasionando uma diminuição de seu desempenho reprodutivo.

Rathbone et al. (2002) encontraram resultados muito semelhantes na liberação in vitro entre o $\mathrm{CIDR}^{\circledR}$ e um dispositivo de PCL. No ensaio de liberação in vivo de $\mathrm{P}_{4}$, em vacas de leite, obtiveram valores e tempos para a concentração máxima plasmática de $P_{4}\left(C I D R^{\circledR}: 5,1 \mathrm{ng} / \mathrm{mL}\right.$ nas 14,4 horas e dispositivo de PCL: 5,3ng/mL nas 9,6 horas). Lembrando que os níveis de $\mathrm{P}_{4}$ encontrados na circulação estão sujeitos à metabolização hepática e a meia vida da $\mathrm{P}_{4}$ é ao redor de 22 a 36 minutos (SANGSRITAVONG, 2002), vacas de leite pelo maior fluxo sanguíneo, causado pela grande produção de leite, apresentam concentrações de $\mathrm{P}_{4}$ mais baixas (RABIEE et al., 2001). Em estudo de Valentim (2004), utilizando animais da raça Nelore, o dispositivo $\mathrm{DIB}^{\circledR}$, atingiu a concentração máxima de $\mathrm{P}_{4}$ de $4,5 \mathrm{ng} / \mathrm{mL}$ (24 horas após sua inserção), entretanto, suas colheitas de sangue se iniciaram 24 horas após a inserção.

No trabalho de Rathbone et al. (2002) foram encontrados também semelhantes valores de tensão superficial de deformação do dispositivo de PCL $(4,02 \mathrm{Kg})$ e do $\operatorname{CIDR}^{\circledR}(3,8 \mathrm{Kg})$, característica esta de fundamental importância para a manutenção do dispositivo no interior da cavidade vaginal dos animais durante o período de sincronização. Gangrade e Price (1991) observaram a formação de cristais superficiais, com a conseqüente redução de flexibilidade, quando superado o limite de $5 \%$ de $\mathrm{P}_{4}$ na mistura com o PHB. Foram encontradas taxas de retenção do $\mathrm{CIDR}^{\circledR}-1^{\circ}$ uso de $96,4 \%$ (RYAN et al., 1995) a 99,5\% (VAN CLEEF et al., 1996) do total de animais tratados. No 
experimento 1 , a taxa de retenção dos dispositivos novos foi de $100 \%$ para o $\mathrm{DIB}^{\circledR}$ e Progestar $^{\circledR}$, enquanto que no experimento 2 , este valor foi de $92,3 \%$ e $98 \%$, respectivamente. O Progestar ${ }^{\circledR}$ contém $8 \%$ de $\mathrm{P}_{4}$, entretanto a formação de cristais na superfície do mesmo não foi objeto de estudo dos presentes experimentos. Além disto, na confecção do $\operatorname{Progestar}^{\circledR}$, utilizou-se uma composição polimérica de PHB e PCL o que contribuiu para melhorar a flexibilidade do dispositivo.

Em trabalho de Pimentel (2006), a liberação in vitro de $\mathrm{P}_{4}$, em uma solução de álcool/água, no aparelho dissolutor de comprimidos, foi estudada comparando os dispositivos DIB $^{\circledR}$ e o Progestar ${ }^{\circledR}$. Somente nas primeiras 24 horas a liberação foi diferente entre eles (DIB ${ }^{\circledR}: 499 \mathrm{mg}$ e Progestar ${ }^{\circledR}: 377 \mathrm{mg}$ ), nas 48, 72 e 96 horas restantes de ensaio, ambos dispositivos apresentaram uma liberação muito semelhante. Estes dispositivos também foram utilizados em fêmeas zebuínas ovariectomizadas, no ensaio de liberação in vivo de $\mathrm{P}_{4}$, proporcionando uma concentração plasmática média de $4,94 \mathrm{ng} / \mathrm{mL}$ para 0 $D B^{\circledR}$ e de $4,06 n g / m L$ para o Progestar ${ }^{\circledR}$. A cinética de liberação da $P_{4}$, para ambos dispositivos, consistiu em uma rápida elevação dos teores plasmáticos, com queda lenta e constante, sendo que, o único momento em que a concentração de $\mathrm{P}_{4}$ diferiu entre os dispositivos, foi 4 horas após sua inserção (DIB ${ }^{\circledR}: 11,45 \mathrm{ng} / \mathrm{mL}$ e Progestar $^{\circledR}: 9,23 \mathrm{ng} / \mathrm{mL}$ ) e os teores de $P_{4}$ se mantiveram sempre maiores do que $1 \mathrm{ng} / \mathrm{mL}$ durante os 16 dias de ensaio. Apesar das pequenas diferenças encontradas nos ensaios, ambos dispositivos foram considerados equivalentes em relação às liberações in vitro e in vivo de $\mathrm{P}_{4}$.

A maturação do folículo dominante, durante a fase de proestro do ciclo estral, ocorre em concentrações de $\mathrm{P}_{4}$ plasmáticas inferiores à $1 \mathrm{ng} / \mathrm{mL}$ (STOCK; FORTUNE, 1993). Por outro lado, uma menor freqüência de LH causada por elevadas concentrações de $\mathrm{P}_{4}$, limita $\mathrm{O}$ crescimento folicular (TAYLOR; RAJAMAHENDRAN, 1994). Durante a fase luteínica os níveis de $\mathrm{P}_{4}$ interferem na freqüência de pulsos de $L H$ e, conseqüentemente, no crescimento e diâmetro do folículo dominante (BERGFELT et al., 1991). Portanto, é aconselhável que um dispositivo de liberação sustentada de $\mathrm{P}_{4}$ proporcione uma concentração plasmática acima de $1,0 \mathrm{ng} / \mathrm{mL}$ no momento de sua retirada (RATHBONE et al., 2002). No trabalho de Valentim (2004), foi encontrado, em animais Nelore, a concentração de 2,6ng/mL, no dia 8 após 
inserção do dispositivo $D^{\circledR}{ }^{\circledR}$. Este resultado também foi encontrado no estudo de Pimentel (2006), no qual os valores proporcionados no dia 8 e 16 após a inserção do DIB $^{\circledR}$ e do Progestar $^{\circledR}$ foram de $2,44 \mathrm{ng} / \mathrm{mL}$ vs $1,89 \mathrm{ng} / \mathrm{mL}$ e $1,56 \mathrm{ng} / \mathrm{mL}$ vs $1,21 \mathrm{ng} / \mathrm{mL}$, respectivamente

Apesar das pequenas diferenças encontradas na liberação in vitro e in vivo, nos diferentes trabalhos, com os dispositivos de liberação de $\mathrm{P}_{4}$, incluindo os novos dispositivos à base dos biopolímeros PHB e PCL, todos são capazes de proporcionar condições favoráveis à sincronização e ao crescimento normal de um folículo dominante, para a sua posterior ovulação e, consequentemente, gestação nos animais. Esta afirmação pode ser comprovada no trabalho de Rathbone et al. (2002), no qual as TPIATF, em animais da raça holandesa, foram semelhantes (PCL - 40,2\% e CIDR ${ }^{\circledR}-35,7 \%$ ), assim como no presente trabalho, em animais da raça Nelore, no qual as TPIATF foram similares, tanto no $1^{\circ}$ quanto no $2^{\circ}$ uso (experimento 1 : $\mathrm{DIB}^{\circledR}-66,7 \%$ e Progestar $^{\circledR}-65,8 \%$ e experimento 2: DIB ${ }^{\circledR} 2-61,2 \%$ e $\operatorname{Progestar}^{\circledR} 2-55,8 \%$ ). 


\section{CONCLUSÃO}

O novo dispositivo intravaginal fabricado a partir dos biopolímeros PHB e PCL (Progestar ${ }^{\circledR}$ ) possui semelhante eficiência, tanto no $1^{\circ}$ quanto no $2^{\circ}$ uso, nas taxas de prenhez, oriundas da IATF e ao final da estação de monta em fêmeas da espécie bovina, quando comparados ao $1^{\circ}$ e $2^{\circ}$ usos do dispositivo à base de silicone DIB $^{\circledR}$.

Ambos tratamentos têm potencial para proporcionar TPIATF acima de $50 \%$ e TPEM acima de $90 \%$. 


\section{REFERÊNCIAS}

ABIEC. Associação Brasileira das Indústrias Exportadoras de Carne. Balanço da Pecuária Bovídea de Corte. Disponível em: <

http://www.abiec.com.br/estatisticas/14.pdf >. Acesso em: 27 mar. 2008.

ABR. Plástico biodegradável. Plástico biodegradável produzido em São Paulo será testado na Alemanha. Disponível em:

<http://www.radiobras.com.br/ct/1999/materia_220199_3.htm>. Acesso em: 21 jun. 2007.

ACOSTA, B.; TARNAVSKY, T. E.; PLATT, T. E.; HAMERNIK, D. L.; BROWN, J. L.; SCHOENMANN, H. M.; REEVES, J. J. Nursing enhances the negative effect of stogen on LH release in the cow. Journal of Animal Science, v. 57, p. 1530-1536, 1983.

ADAMS, G. P.; MATTERI, R. L.; KASTELIC, J. P.; KO, J. C. H.; GINTHER, O. $\mathrm{J}$. Association between surges of follicle-stimulating hormone and the emergence of follicular waves in heifers. Journal of Reproduction and

Fertility, v. 94, p. 177-188, 1992.

ADAMS, G. P.; KOT. K.; SMITH, C. A.; GINTHER, O. J. Effect of the dominant follicle on regression of its subordinates in heifers. Canadian Journal of Animal Science, v. 73, p. 267-275, 1993.

ALMEIDA, A. B. Reutilização de implantes de norgestomet em vacas da raça Nelore. 76 f. Dissertação (Mestrado) - Faculdade de Medicina Veterinária e Zootecnia, Universidade de São Paulo, Pirassununga, 2003.

ANBR. Agência de Noticias Brasil. Na liderança do agronegócio. Disponível em: <http://www.anba.com.br/especial.php?id=353>. Acesso em: 23 jun. 2007.

ANDERSON, A. J.; DAWES, E.A. Occurrence, Metabolism, Metabolic Role, and Industrial Uses of Bacterial Polydroxyialcanoates, American Science for Microbiology, v. 54, p. 450-472, 1990.

ASBIA. Associação Brasileira de Inseminação Artificial. Relatório Estatístico de Produção, Importação e Comercialização de Sêmen. Disponível em:

<http://www.asbia.org.br/download/mercado/relatorio2007.pdf >. Acesso em: 27 mar. 2008. 
BARROS, C. M.; FIGUEIREDO, R. A.; PINHEIRO, O. L. Estro, ovulação e dinâmica folicular em zebuínos. Revista Brasileira de Reprodução Animal, v.19, p.9-12, 1995.

BARROS, C. M.; MOREIRA, M. P. B.; FIGUEIREDO, R. A.; TEIXEIRA, A. B.; TRINCA, L. A. Synchronization of ovulation in beef heifers (Bos indicus) using $\mathrm{GnRH}, \mathrm{PGF}_{2 \alpha}$ and estradiol benzoate. Theriogenology, v. 53, p. 1121-1134, 2000.

BARUFI, F. B. Sincronização do ciclo estral e da ovulação em bovinos de corte usando tratamentos com Crestar, CIDR ou CIDR reutilizado, seguidos ou não pela administração de eCG. 68 f. Dissertação (Mestrado) Faculdade de Medicina Veterinária e Zootecnia, Universidade de São Paulo, São Paulo, 2002.

BARUSELLI, P. S.; MARQUES, M. O.; CARVALHO, N. A. T.; MADUREIRA, E. H.; CAMPOS FILHO, E. P. Efeito de diferentes protocolos de inseminação artificial em tempo fixo na eficiência reprodutiva de vacas de corte lactentes. Revista Brasileira de Reprodução Animal, v. 26, p. 218-221, 2002.

BARUSELLI, P. S.; MARQUES, M. O.; NASSER, L. F.; REIS, E. L.; BÓ, G. A. Effect of eCG on pregnancy rates of lactating zebu beef cows treated with CIDR-B devices for timed artificial insemination. Theriogenology, v. 59, p. 214, 2003. Abstract.

BARUSELLI, P. S.; MARQUES, M. O.; REIS, E. L.; NASSER, L. F. T.; SILVA, R. C. P.; MENEGATTI, J. A.; VALENTIN, R.; SANTOS, I. C. C. Adequação da dose de FSH (Folltropin-v) em protocolos de superovulação de vacas nelore (Bos taurus indicus) com inseminação artificial em tempo fixo (SOTF). Acta Scientiae Veterinarie, v. 31, p. 244-245, 2004.

BEAL, W. E.; GOOD, G. A.; PETERSON, L. A. Estrus synchronization and pregnancy rates in cyclic and noncyclic beef cows and heifers treated with Syncro-Mate B or norgestomet and alfaprostol. Theriogenology, v. 22, p. 5966, 1984.

BELLOWS, R. A.; SHORT, R. E. Effects of precalving fedd level on birth weight, calving difficulty and subsequent fertility. Journal of Animal Science, v. 46, p. 1522, 1978. 
BERGFELT, D. R.; KASTELIC, J. P.; GINTHER, O. J. Continued periodic emergence of follicular waves in nonbred progesterone-treated heifers. Animal Reproduction Science, v. 24, p. 193-204, 1991.

BÓ, G. A. Sincronización de cellos para programas de inseminación artificial y transferência de embriones bovinos. In: Simpósio sobre Controle Farmacológico do Ciclo Estral em Ruminantes. Anais... São Paulo, p. 35-60, 2000.

BÓ, G. A.; ADAMS, G. P.; NASSER, L. F.; PIERSON, R. A.; MAPLETOFT, R. $J$. Effect of estradiol valerate on ovarian follicles, emergence of follicular waves and circulating gonadotropins in heifers. Theriogenology, v. 40, p. 225-239, 1993.

BÓ, G. A.; ADAMS, G. P.; PIERSON, R. A.; MAPLETOFT, R. J. Effect of progestogen plus $E-17 \beta$ treatment on superovulatory response in beef cattle. Theriogenology, v. 45, p. 897-910, 1996.

BÓ, G. A.; ADAMS, G. P.; PIERSON, R. A.; MAPLETOFT, R. J. Local versus systemic effects of exogenous estradiol on ovarian follicular dynamics in heifers with progestogen ear implant. Animal of Reproduction Science, v. 59, p. 141$157,2000$.

BÓ, G. A.; ADAMS, G. P.; PIERSON, R. A.; TRIBULO, H. E.; CACCIA, M.; MAPLETOFT, R. J. Follicular wave dynamics after estradiol-17 $\beta$ treatment of heifers with or without a progestogen implant. Theriogenology, v. 41, p. 15551569, 1994.

BÓ, G. A.; BARUSELLI, P. S.; MARTÍNEZ, M. F. Pattern and manipulation of follicular development in Bos indicus cattle. Animal Reproduction Science, v. 78, p. 307-326, 2003.

BÓ, G. A.; BARUSELLI, P. S.; MORENO, D.; CUTAIA, L.; CACCIA, M.; TRIBULO, R.; TRIBULO, H.; MAPLETOFT, R. J. The control of follicular wave development for self-appointed embryo transfer programs in cattle.

Theriogenology, v. 51, n. 1, p. 52-57, 2002.

BÓ, G. A.; CACCIA, M.; MARTINEZ, M.; ADAMS, G. P.; PIERSON, R. A.; MAPLETOFT, R. J. The use of estradiol-17 $\beta$ and progestogen treatment for the control of follicular wave dynamics in beef cattle. Theriogenology, v. 40, p. 165, 1995. 
BODENSTEINER, K. J.; KOT, K.; WILTBANK, M. C.; GINTHER, O. J. Synchronization of emergence of follicular waves in cattle. Theriogenology, $v$. 45, p. 1115-1128, 1996.

BRIDGES, P. J.; LEWIS, P. E.; WAGNER, W. R.; INSKEEP, E. K. Follicular growth, estrus and pregnancy after fixed timed insemination in beef cows treated with intravaginal progesterone inserts and estradiol benzoate. Theriogenology, v. 52, p. 573-583, 1999.

BROWNING, R. JR.; ROBERT, B. S.; LEWIS, A. W.; NEUENDORFF, D. A.; RANDEL, R. D. Effects os postpartum nutrition and once-daily suckling on reproductive efficiency and preweaning calf performance in fall-calving Brahman (Bos indicus) cows. Journal of Animal Science, v. 72, p. 984-989, 1994.

BUNT, C. R.; RATHBONE, C.; BURGRAAF, C. R.; OGLE, C. R.; BURKE, C. R. Elevation of plasma progesterone levels in cattle using a poly ( $\varepsilon$-caprolactone) and cyclodextrin intravaginal insert containing progesterone. In: SYMP. CONTROL. REL. BIOACT. MATER., 26, 1999, Boston. Proceedings..., p. 1172-1173.

BURGRAAF, S.; RATHBONE, M. J.; BUNT, C. R.; PICKERING, K. L. Effect of silicone shore hardness, inert fillers and progesterone particle size upon the release of progesterone from a controlled release intravaginal drug delivery system. Proc. Int. Symp. Control. Rel. Bioact. Mater, v. 24, p. 147-148, 1997.

BURSI, R.; GROEN, M. B. Application of (quantitative) structure-activity relationships to progestagens: from serendipity to structure-based design. Europa Journal Medicine Chemist, n. 35, p. 787-798, 2000.

CACCIA, M.; BÓ, G. A. Follicle wave emergence following treatment of CIDR-B implanted beef cows with estradiol benzoate and progesterone.

Theriogenology, v. 49, p. 341, 1998.

CARVALHO, J. B. P.; CARVALHO, N. A. T.; REIS, E. L.; NICHI, M.; SOUZA, A. H.; BARUSELLI, P. S. Effect of early luteolysis in progesterone-based timed Al protocols in Bos indicus, Bos indicus x Bos taurus, and Bos taurus heifers.

Theriogenology, v. 69, n. 2, p. 167-175, 2007. 
CAVALIERI, J.; COLEMAN, C.; RODRIGUES, H.; MACMILLAN, K. L.; FITZPATRICK, L. A. The effect of timing of administration of oestradiol benzoate on characteristics of oestrus, timing of ovulation and fertility in Bos indicus heifers synchronized with a progesterone releasing intravaginal insert.

Australian Veterinary Journal, v. 80, p. 217-223, 2002.

CAVALIERI, J.; RUBIO, I.; KINDER, J. E.; ENTWISTLE, K. W.; FITZPATRICK, L. A. Synchronization of estrus and ovulation and associated endocrine changes in Bos indicus cows. Theriogenology, v. 47, p. 801-814, 1997.

CEPEA. Centro de Estudos em Economia Aplicada ESALQ - USP. Valores do PIB e sua participação no PIB do Brasil. Disponível em: < http://www.cepea.esalq.usp.br/pib/>. Acesso em: 27 mar. 2007.

CHANDRA, R.; RUSTGI, R. Biodegradable Polymers. Progress Polymer Science, v. 23, p. 1273-1335, 1998.

CHANG, H. I.; WILLIANSON, M. R.; PERRIE, Y.; COOMBES, A. G. A. Precipitation casting of drug-loaded microporous PCL matrices: Incorporation of progesterone by co-dissolution. Journal of Controlled Release, v. 106, p. 263272, 2005.

CHASE JR, C. C.; KIRBY, C. J.; HAMMOND, A. C.; OLSON, T. A.; LUCY, M. C. Patterns of ovarian growth and development in cattle with a growth hormone receptor deficiency. Journal of Animal Science, v. 76, p. 212-219, 1998.

CHENAULT, J. R. Pharmaceutical control of estrous cycles. In: H. H. VAN HORN; WILCOX, J. Large dairy herd management. Savoy: American Dairy Science Association, Savoy, 1992, p. 153.

CHENOWETH, P. J. Aspects of reproduction in female Bos indicus cattle: a review. Aust. Vet. Journal, v. 71, p. 422-426, 1994.

CHIELLINI, E.; SOLARO, R. Biodegradable polymeric materials. Advanced Materials. v. 8, n. 4, p. 305-313,1996.

CHIELLINI, E.; SOLARO, R. "Environmentally Degradable Polymers and Plastics. An Overview", in: Anais do International Workshop on Environmentally Degradable and Recyclabe Polymers in Latin America. 1988, Campinas. Anais..., p. 15-20. 
CHRISTIAN, R. E.; CASIDA, L. E. Effect of progesterone in altering the oestrus cycle of the cow. Journal of Animal Science, v. 7, p. 540, 1948, Abstracts...

COLAZO, M. G.; SEFCHEK, M.; ILLUMINATI, H.; MEGLIA, G.; SCHMIDT, E.; BÓ, G. A. Fixed-timed artificial insemination in beef cattle using CIDR-B, progesterone and estradiol benzoate. Theriogenology, v. 51, p. 404, 1999. Abstract.

COOPER, M. J. Control of oestrus cycle of heifers with a synthetic prostaglandin analogue. Veterinary Record, v. 95, p. 200-203, 1974.

CROWE, M. A.; GOULDING, D.; BAQUISI, A.; BOLAND, M. P.; ROCHE, J. F. Induced ovulation of the first postpartum dominant follicle in beef suckler cows using a GnRH analogue. Journal Reproduction Fertility, v. 99, p. 551-555, 1993.

CUPP, A. S.; STUMPF, T. T.; KOJIMA, N.; WERTH, L. A.; WOLFE, M. W.; ROBERSON, M. S.; KITTOK, R. J.; KINDER, L.E. Secretion of gonadotropins change during the luteal phase of the bovine oestrus cycle in the absence of corresponding changes in progesterone or $17 \beta$ estradiol. Animal Reproduction Science, v. 37, p. 109-119, 1995.

CUTAIA, L.; TRIBULO, R.; MORENO, D.; BÓ, G. A. Pregnancy rates in lactating beef cows with progesterone releasing devices, estradiol benzoate and equine chorionic gonadotropin (eCG). Theriogenology, v. 59, p. 216, 2003.

DERVAL, S.R.; FILHO, R.P.; AGNELLI, J.A.M. Avaliação da biodegradação de poli- $\beta$-(hidroxibutirato), Poli- $\beta$-(hidroxibutirato-co-valerato) e Poli- $\in$ (caprolactona) em solo compostado. Polímeros: Ciência e Tecnologia, v. 12 n. 4, p. 311-317, 2002.

DISKIN, M. G.; AUSTIN, E. J.; ROCHE, J. J. Exogenous hormonal manipulation of ovarian activity in cattle. Domestic Animal Endocrinology, v. 23, p. 211228, 2002.

DRIANCOURT, M. A. Regulation of ovarian follicular dynamics in farm animals. Implications for manipulation of reproduction. Theriogenology, v. 55, p. 12211239, 2001. 
FIGUEIREDO, R. A.; BARROS, C. M.; PINHEIRO, O. L.; SOLER, J. M. P. Ovarian follicular dynamics in Nelore breed (Bos indicus) cattle.

Theriogenology, v. 47, p. 1489-1505, 1997.

FORTUNE, J. E.; QUIRK, S. M. Regulation of esteroidogenesis in bovine preovulatory follicles. Journal of Animal Science, v. 66, p. 1-8, 1988, Supplement, 2.

FRISCH, J. E.; O'NEILL, C. J. Calving rates in a tropical beef herd after treatment with a synthetic progestágeno, norgestomet or a prostaglandin analogue, cloprostenol. Australian Veterinary Journal, v. 73, p. 98-102, 1996.

FUCHS, A. R.; BEHERENS, O.; HELMER, H.; LIU, C. H.; BARROS, C. M.; FIELDS, M. J. Oxytocin and vasopressin receptors in bovine endometrium and myometrium during the estrous cycle and early pregnancy. Endocrinology, v. 127, p. 629-636, 1990.

FULLENWILDER, J.; KEMPFER, R.; BARTHLE, C.; LEMASTER, W.; YELICH, $J$. Use of intravaginal progesterone-releasing device (CIDR) for timed aritificial insemination (AI) incrossbreed cattle of Bos indicus breeding. Beef Cattle Report, v. 35, p. 36-40, 2001.

GALINA, C. S.; ARTHUR, G. H. Review on cattle reproduction in the tropics. Oestrus cycle. Animal Breed Abstract, v. 58, Part 4, p. 697-707, 1990.

GANGRADE, N.; PRICE, J. C. Poly(hydroxybutyrate-hydroxyvalerate) microspheres containing progesterone: preparation, morphology and release properties. J. Microencapsul., v. 8, n. 2, p. 185-202, 1991.

GASPAR, P. S. Inseminação artificial em tempo fixo em novilhas mestiças zebuínas: efeito da sincronização da emergência de onda folicular por valerato ou benzoato de estradiol sobre a taxa de prenhez. $74 \mathrm{f}$. Dissertação (Mestrado) - Faculdade de Medicina Veterinária e Zootecnia, Universidade de São Paulo, São Paulo, 2005.

GILCHRIST, R. L.; RYU, K.; JI, I.; JI, T. The luteinizing hormone/chorionic gonadotropin receptor has distinct transmembrane conductors for camp and inositol phosphate signals. The Journal of Biological Chemistry, v. 271, p. 19283-19287, 1996. 
GIMENES, L. U.; CARVALHO, N. A. T.; SÁ FILHO, M. F.; SANTIAGO, L. L.; CARVALHO, J. B. P.; MAPLETOFT, R. J. Capacidade ovulatória em novilhas Bos indicus. Acta Scientiae Veterinary, v. 33, p. 209, 2005.

GINTHER, O. J.; BERGFELT, D. R.; KULICK, L. J.; KOT, K. Selection of dominant follicle in cattle: establishment of follicle deviation in less than 8 hours through depression of FSH concentration. Theriogenology, v. 52, p. 10791093, 1999.

GINTHER, O. J.; KASTELIC, J. P.; KNOPF, L. Composition and characteristics of follicular waves during the bovine estrous cycle. Animal of Reproduction Science, v. 20, p. 187-200, 1989.

GINTHER, O. J.; KOT, K.; KULICK, L. J.; WILTBANK, M. C. Emergence and deviation of follicles during the development of follicular waves in cattle.

Theriogenology, v. 48, p. 75-87, 1997.

GINTHER, O. J.; WILTBANK, M. C.; FRICKE, P. M.; GIBBONS, J. R.; KOT, K. Selection of the dominant follicle in cattle. Biology of Reproduction, v. 55, p. 1187-1194, 1996.

GOMES, J.G.C.; BUENO NETTO, C.L. Produção de Plásticos Biodegradáveis por Bactérias, Rev. Bras. Eng. Quim., v. 17, p. 24-29, 1997.

GONG, J. G.; BRAMLEY, T. A.; GUTIERREZ, C. G.; PETERS, A. R.; WEBB, R. Effects of chronic treatment with a gonadotroping-releasing hormone agonist on peripheral concentrations of FSH and $\mathrm{LH}$, and ovarian function in heifers. Journal of Reproductive and Fertility, v. 105, p. 263-270, 1996.

GOSPODAROWICZ, D.; CHENG, J.; LUI, G. M. Corpus luteum angiogenic factor is related to fibroblast growth factor. Endocrinology, v. 117, n. 6, p.23832392, 1985.

GRIMARD, B.; HUMBLOT, P.; MIALOT, J. P.; JEANGUYOT, N.; SAUVANT, D.; THIBER, M. Absence of response to oestrus induction and synchronization treatment is related to lipid mobilization in suckled beef cows. Reproduction Nutrition and Development, v. 37, p. 129-140, 1997. 
GUEDON, L.; SAUMANDE, J.; DESBALS, B. Relationships between calf birth weight, prepartum concentration of plasma energy metabolites and resumption of ovulation postpartum in Limousine suckled beef cows. Theriogenology, $v$. 52, p. 779-789, 1999.

HAFEZ E. S. E., HAFEZ B. Reprodução Animal. 7 ed. Barueri: Manole, 2004.

HANSEL, W.; CONVEY, E. M. Phisiology of estrous cycle. Journal of Animal Science, v. 57, p. 404-424, 1983. Supplementum 2.

HIXON, J. E.; HANSEL, W. Evidence for preferential transfer of prostaglandin F2alpha to the ovarian artery following intrauterine administration in cattle.

Biology of Reproduction, v. 11, p. 543-552, 1974.

HORTON, E. W.; POYSER, N. L. Uterine luteolytic hormone: a physiological role for prostaglandin $F_{2 \alpha}$. Physiology Review, v. 56, p. 595, 1975.

HUANG, J. C.; SHETTY, A. S.E, WANG, M. S. Biodegradable plastics: a review. Adv. Polym. Technol., v. 10, p. 23, 1990.

HUMBLOT, P.; GRIMARD, B.; RIBON, O.; KHIREDDINE, B.; DERVISHI, V.; THIBIER, M. Sources of variation of postpartum cyclicity, ovulation and pregnancy rates in primiparous Charolais cows treated with Norgestomet implants and PMSG. Theriogenology, v. 46, p. 1085-1096, 1996.

JOHNSON, S. K.; LEWIS, P. E.; INSKEEP, E. K. Steriods and cAMP in follicles of postpartum beef cows treated with norgestomet. Journal of Animal Science, v. 69, p. 3747-3753, 1991.

JOLLY, P. D.; MCDOUGALL, S.; FITZPATRICK, L. A.; MACMILLAN, K. L.; ENTWISTLE, K. W. Physiological effects of undernutrition on postpartum anoestrum in cows. Journal of Reproduction and Fertility, v. 49, p. 477-492, 1995.

KASTELIC, J. P.; GINTHER, O. J. Factors affecting the origin of the ovulatory follicle in heifers with induced Luteolysis. Animal Reproduction Science, v. 26, p. 13-24, 1991. 
KINDER, J. E.; KOJIMA, F. N.; BERGFELD, E. G. M.; WEHRMAN, M. E.; FIKE, K. E. Progestin and estrogen regulation of pulsatile $\mathrm{LH}$ release and development of persistent ovarian follicles in cattle. Journal of Animal Science, v. 74, p. 1424-1440, 1996.

KOJIMA, N.; STUMPF, T. T.; CUPP, A. S.; WERTH, L. A.; ROBERSON, M.; WOLFE, M. W.; KITTOK, R. J.; KINDER, J. E. Exogenous progesterone and progestins as used in estrous synchrony regimens do not mimic the corpus luteum in regulation of luteinizing hormone and $17 \beta$ estradiol in circulation of cows. Biology of Reproduction, v. 47, p. 1009-1017, 1992.

LAMOTHE-ZAVALETA, C.; FREDRISKSSON, G.; KINDAHL, H. Reproductive performance of zebu cattle in Mexico. 1. Sexual behavior and seasonal influence on estrous cyclicity. Theriogenology, v. 36, p. 887-896, 1991.

LANDAETA-HERNÁNDEZ, A. J.; PALOMARES-NAVEDA, R.; SOTOCASTILHO, G.; ATENCIO, A.; CHASE JR, C. C.; CHENOWETH, P. J. Social and breed effects on the expression of a PGF2a-induced oestrus in beef cows. Reproduction in Domestic Animals, v. 39, p. 315-320, 2004.

LARSON, L. L.; BALL, P. J. Regulation of estrous cycle in dairy cattle: A review. Theriogenology, v. 38, p. 255-267, 1992.

LAUDERDALE, J. W.; MACALLISTER, J. F.; KRATZER, D. D.; MOODY, E. L. Use of prostaglandin $\mathrm{F}_{2 \alpha}$ in cattle breeding. Acta Veterinaria Scandinavica, $v$. 77, p. $181,1981$.

LAVERDIERE, G.; ROY, G. L.; LAVOIE, D.; DUFOUR, J. J. Estrus synchronization efficiency of $\mathrm{PGF}_{2 \alpha}$ injection in Shorthorn-Hereford and crossbred Charolais cattle not having exhibited estrus at 4 or 7 days prior to treatment. Theriogenology, v. 43, p. 899-991, 1995.

LEMASTER, J. W.; YELICH, J. V.; KEMPFER, J. R.; SCHRICK, F. F. Ovulation and estrus characteristics in crossbred Brahman heifers treated with an intravaginal progesterone-releasing insert in combination with prostaglandin F2 $\alpha$ and estradiol benzoate. Journal Animal Science, v. 77, p. 1860-1868, 1999. 
LUCY, M. C.; BILLINGS, H. J.; BUTLER, W. R.; EHNIS, L. R.; FIELDS, M. J.; KESLER, D. J.; KINDER, J. E.; MATTOS, R. C.; SHORT, R. E.; THATCHER, W. W.; WETTEMANN, R. P.; YELICH, J. V.; HAFS, H. D. Efficacy of an intravaginal progesterone insert and an injection of PGF $_{2 \alpha}$ for synchronizing estrus and shortening the interval to pregnancy in post-partum beef cows, and peripubertal beef heifers and dairy heifers. Journal of Animal Science, v. 79, p. 982-995, 2001.

LUO, S.; NETRAVALI, A.N. A study of physical and mechanical properties of poly-hydroxybutyrate-co-hydroxyvalerate during composting. Polymer Degradation and Stability, v. 80, p. 59-66, 2003.

MACMILLAN, K. L.; BURKE, C. R. Effects of oestrus cycle control on reproductive efficiency. Animal of Reproduction Science, v. 42, p. 307-320, 1996.

MACMILLAN, K. L.; PETERSON, A. J. A new intravaginal progesterone releasing device for cattle (CIDR-B) for estrous synchronization, increasing pregnancy rates and the treatment of post-partum anestrous. Animal Reproduction Science, v. 33, p. 1-25, 1993.

MACMILLAN, K. L.; TAUFA, V. K.; BARNES, D. R.; DAY, A. M. Plasma progesterone concentrations in heifers and cows treated with a new intravaginal device. Animal of Reproduction Science, v. 26, p. 25-40, 1991.

MADUREIRA, E. H.; BARBUIO, J. P.; ARRUDA, R. P.; BERTAN, C. M.; MIZUTA, K.; BRAZZACH, M. L.; BARNABE, R. C.; RODRIGUES, P. H. M. Sincronização do estro em fêmeas bovinas usando acetato de melengestrol (MGA) associado a prostaglandina $F_{2 \alpha}$ e ao $17 \beta$ estradiol. Revista Brasileira de Reprodução Animal, v. 21, p. 94-97, 1997.

MADUREIRA, E. H.; PIMENTEL, J. R. V. IATF como ferramenta para melhorar a eficiência reprodutiva. Congresso Brasileiro de Reprodução Animal, n. 16, 2005, Goiânia. Proceedings... Goiânia: Colégio Brasileiro de Reprodução Animal, 2005, p.16.

MARQUES, M. O.; REIS, E. L.; CAMPOS FILHO, E. P.; BARUSELLI, P. S. Efeitos da administração de eCG e de Benzoato de Estradiol para sincronização da ovulação em vacas Bos taurus taurus X Bos taurus indicus no período pós-parto. In: SIMPÓSIO INTERNACIONAL DE REPRODUÇÃO ANIMALA 5., 2003, Córdoba, 2003, v.1, p.392, 2003. 
MARTINEZ, M. F.; ADAMS, G. P.; BERGFELT, D.; KASTELIC, J. P.; MAPLETOFT, R. J. Effect of LH or GnRH on the dominant follicle of the first follicular wave in heifers. Animal of Reproduction Science, v. 54, p. 757-769, 2000.

MEMBRIVE, C. M. B. Estudo da sincronização das ondas foliculares e das características de estros, por radiotelemetria, em novilhas cruzadas (Bos taurus indicus $x$ Bos taurus taurus) tratadas com acetato de melengestrol e prostaglandina F2 $\alpha$ associados a hCG, GnRH ou 17-beta-estradiol + progesterona. 156 f. Dissertação (Mestrado) - Faculdade de Medicina Veterinária e Zootecnia, Universidade de São Paulo, São Paulo, 2000.

MCCRACKEN, J. A. Prostaglandins and luteal regression - a review. Prostaglandins, v. 1, p. 1-4, 1972.

MIHM, M. Delayed resumption of cyclicity in postpartum dairy and beef cattle. Reproduction Domestic animal, v. 34, p. 277-284, 1999.

MIHM, M.; BAGUISI, A.; BOLAND, M. P.; ROCHE, J. F. Association between the duration of dominance of the ovulatory follicle and pregnancy rate in beef heifers. Journal of Reproduction and Fertility, v. 102, p. 123-130, 1994.

MILVAE, R. A.; HINCKLEY, S. T.; CARLSON, J. C. Lutetropic and luteolytic mechanisms in the bovine corpus luteum. Theriogenology, v. 45, p. 13271349, 1996.

MIZUTA,K. Estudo comparativo dos aspectos comportamentais do estro e dos teores plasmáticos de $\mathrm{LH}, \mathrm{FSH}$, progesterona e estradiol que precedem a ovulação em fêmeas bovinas Nelore (Bos taurus indicus), Angus (Bos taurus taurus) e Nelore $x$ Angus (Bos taurus indicus $x$ Bos taurus taurus). $98 \mathrm{f}$. Tese (Doutorado) - Faculdade de Medicina Veterinária e Zootecnia da Universidade de São Paulo, São Paulo, 2003.

MONNIAUX, D.; MONGET, P.; BESNARD, N.; HUET, C.; PISSELET, C. Growth factors and antral follicular development in domestic ruminants. Theriogenolgy, v. 47, p. 3-12, 1997.

MOREIRA, F.; DE LA COSTA, R. L.; DIAZ, T.; THATCHER, W. W. Effect of day of the estrous cycle at the initiation of a timed insemination protocol on reproductive responses in dairy heifers. Journal of Animal Science, v. 78, p. 1568-1576, 2000. 
MURPHY, B. D.; MARTINUK, S. D. Equine chorionic gonadotropin. Endocrine Rewiews, v. 12, p. 27-44, 1991.

NETT, T. M. Function of the hypothalamic-hypophysial axis during the postpartum in ewes and cows. Journal of Reproduction and Fertility, v. 34, p. 201-213, 1987.

NISWENDER, G. D.; JUENGEL, J. L.; SILVA, P. J.; ROLLYSON, M. K.; MCINTUSH, E. W. Mechanisms controlling the function and life span of the corpus luteum. Physiology Rev., v. 80, p. 1-29, 2000.

ODDE, K. G. A review of synchronization of estrus in postpartum cattle. Journal of Animal Science, v. 68, p. 817-830, 1990.

PETERS, K. E.; BERGFELD, E. G.; CUPP, A. S.; KOJIMA, F. N.; MARISCAL, V.; SANCHEZ, T.; WEHRMAN, M. E.; GROTJAN, H. E.; HAMERNIK, D. L.; KITTOK, R. J.; KINDER, J. E. Luteinizing hormone has a role in development of fully functional corpora lutea $(C L)$ but is not required to maintain $C L$ function in heifers. Biology of Reproduction, v. 51, n. 6, p. 1248-1254, 1994.

PIMENTEL, J. R. V. Emprego de matriz polimérica biodegradável, em dispositivos vaginais, para liberação sustentada de progesterona em fêmeas bovinas: testes in vitro e in vivo. 97 f. Dissertação (Mestrado) Faculdade de Medicina Veterinária e Zootecnia, Universidade de São Paulo, São Paulo, 2006.

PINHEIRO, O. L.; BARROS, C. M.; FIGUEIREDO, R. A.; VALLE, E. R.; ENCARNAÇÀO, R. O.; PADOVANI, C. R. Estrous behavior and the estrus-toovulation interval in Nelore cattle (Bos indicus) with natural estrus or estrus induced with prostaglandine $F_{2 \alpha}$ or norgestomet and estradiol valerate. Theriogenology, v. 49, p. 667-681, 1998.

PITT, C. G.; CHASALDO, F. J.; HIBIONADA, J. M.; KLIMAS, D. M.; MARKS, T. A.; SCHINDLER, A. Appl. Polym. Sci., v. 28, p. 3779, 1981.

PITT, C. G., MARKS, T. A.; SCHINDLER, A. In Baker, R. (Ed.). Controller Release of Bioactive Materials, Academic Press, New York, 1980, p. 9.

PURSLEY, J. R.; KOSOROK, M. R.; WILTBANK, M. C. Reproductive management of lactating dairy cows using synchronization of ovulation. Journal of Dairy Science, v. 80, p. 301-307, 1997. 
PURSLEY, J. R.; MEE, M. O.; WILTBANK, M. C. Synchronization of ovulation in dairy cows using $\mathrm{PGF}_{2 \alpha}$ and $\mathrm{GnRH}$. Theriogenology, v. 44, p. 915-923, 1995.

PURSLEY, J. R.; WILTBANK, M. C.; STEVENSON, J. S.; OTTOBRE, J. S.; GARVERICK, H. A.; ANDERSON, L. L. Pregnancy rates per artificial insemination for cows and heifers inseminated at a synchronization ovulation or synchronized estrus. Journal of Dairy Science, v. 80, p. 295-300, 1997.

RABIEE, A. R.; MACMILLAN, K. L.; SCHWARZENBERGER, F. Excretion rate of progesterone in milk and faeces in lactating dairy cows with two levels of milk yield. Reproduction Nutrition Development, v. 41, p. 309-319, 2001.

RAGHAVAN, D. Characterization of Biodegradable Plastics. Polym. Plast. Technol. Eng., v. 42, n. 1, p. 41-63, 1995.

RAHE, C. H.; OWENS, R. E.; FLEEGER, J. L.; NEWTON, H. J.; HARMS, P. G. Pattern of plasma luteinizing hormone in the cyclic cow: dependence upon the period of the cycle. Endocrinology, v. 107, p. 498-503, 1980.

RATHBONE, M. J.; BUNT, C. R.; OGLE, C. R.; BURGGRAAF, S.; MACMILLAN, K. L.; PICKERING, K. Development of an injection molded poly(epsilon-caprolactone) intravaginal insert for the delivery of progesterone to cattle. J. Controlled Release, v. 85 (1-3), p. 61-71, 2002.

RATHBONE, M. J.; KINDER, J. E.; FIKE, K.; KOJIMA, F.; CLOPTON, D.; OGLE, C. R.; BUNT, C. R. Recent advances in bovine reproductive endocrinology and physiology and their impact on drug delivery system design for the control of the estrous cycle in cattle. Advanced Drug Delivery Reviews, v. 50, p. $277-320,2001$.

REVAH, I.; BUTLER, W. R. Prolonged dominance of follicles and reduced viability of bovine oocytes. Journal of Reproduction and Fertility, v. 106, p. 39-47, 1996.

RHODES, F. M.; FITZPATRICK, L. A.; ENTWISTLE, K. W.; KINDER, J. E. Hormone concentrations in the caudal vena cava during the first ovarian follicular wave of the oestrus cycle in heifers. Journal of Reproduction and Fertility, v. 104, p. 33-39, 1995. 
RICHARDS, M. W.; WETTEMAN, R. P.; SCHOENEMAN, H. M. Effect of restricted intake on cyclic ovarian activity and estrus in Hereford cows. Animal Science Research Report, Oklahoma, v. 118, p. 308-311, 1986.

ROBERSON, M. S.; WOLFE, M. W.; STUMPF, T. T.; KITTOK, J. E. Luteinizing hormone secretion and corpus luteum function in cows receiving two levels of progesterone. Biology of Reproduction, v. 41, n. 6, p.997-1003, 1989.

ROCHA, J. L. Sincronização hormonal da onda folicular e do estro em novilhas de corte mestiças monitoradas por radiotelemetria. $156 \mathrm{f}$. Tese (Doutorado) - Faculdade de Medicina Veterinária e Zootecnia, Universidade de São Paulo, São Paulo, 2000.

ROCHE, J. F.; CROWE, M. A.; BOLAND, M. P. Postpartum anoestrus in dairy and beef cows. Animal of Reproduction Science, v. 28, p. 371-378, 1992.

ROSA D. S.; CHUI, Q. S. H.; FILHO, R. P.; AGNELLI, J. A. M. Avaliação da Biodegradação de Poli-b-(Hidroxibutirato), Poli-b-(Hidroxibutirato-co-valerato) e Poli-e-(caprolactona) em Solo Compostado. Polímeros, v. 12, n. 4, 2002.

ROSA, D.S.; FRANCO, B.L.M. Análise do Desenvolvimento de Dióxido de Carbono de Polímeros Biodegradáveis quando Submetidos a Lodo Ativado.In: Congresso Brasileiro de Polímeros, 5., 1999. Local. Anais..., p.1241.

ROSSA, L. A. F. Sincronização da ovulação por eCG ou benzoato de estradiol em vacas de corte tratadas com Crestar no período pós-parto. 80 f. Dissertação (Mestrado) - Faculdade de Medicina Veterinária e Zootecnia, Universidade de São Paulo, São Paulo, 2002.

ROWSON, L. E. A.; TERVIT, R.; BRAND, A. The use of prostaglandin for synchronization of estrus in cattle. Journal of Reproduction and Fertility, $v$. 29, p. 145, 1972.

RYAN, D. P.; SNIJDERS, S.; YAAKUB, H.; O'FARRELL, K. J. An evaluation os estrus synchronization programs in reproductive management of dairy herds. Journal of Animal Science, v. 28, p. 3687-3695, 1995. 
SÁ FILHO, M. F.; AMARAL, M. E.; MANTOVANI, A. P.; REIS, E. L.; NICHI, M.; BARUSELLI, P. S. Effect os synthetic progesterone (Afisterone ${ }^{\circledR}$ ) administration at the moment of $\mathrm{CIDR}^{\circledR}$ insertion on follicular wave emergence in beef heifers. In: INTERNATIONAL CONGRESS ON ANIMAL REPRODUCTION, 1., 2004, Porto Seguro. Proceedings... Belo Horizonte: Colégio Brasileiro de Reprodução Animal, p. 127, 2004.

SANGSRITAVONG, S.; COMBS, D. K.; SARTORI, R.; ARMENTANO, L. E.; WILTBANK, M. C. High feed intake increases liver blood flow and metabolism $f$ progesterone and estradiol-17beta in dairy cattle. Journal of Dairy Science, v. 85, p. 2831-2842, 2002.

SANTOS, M. D. Comportamento sexual, qualidade seminal e eficiência reprodutiva de touros da raça Nelore em regime de monta natural. $88 \mathrm{f}$. Tese (Doutorado) - Faculdade de Medicina Veterinária, Universidade Federal de Viçosa, Viçosa, 2000.

SARTORI, R.; FRICKLE, P. M.; FERREIRA, J. C. P.; GINTHER, O. J.; WILTBANK, M. C. Follicular deviation and acquisition of ovulatory capacity in bovine follicles. Biology of Reproduction, v. 65, p. 1403-1409, 2001.

SAVIO, J. D.; KEENAN, L.; BOLAND, M. P.; ROCHE, J. F. Pattern of growth dominant follicles during the oestrus cycle of heifers. Journal of Reproduction and Fertility, v. 83, p. 663-671, 1988.

SCHMITT, E. J. P.; DIAZ, T.; DROST, M.; THATCHER, W. W. Use of a gonadotropin-releasing hormone agonist or human chorionic gonadotropin for timed insemination cattle. Journal of Animal Science, v. 74, p. 1084-1091, 1996.

SHORT, R. E.; BELLOWS, R. A.; STAIGMILLER, R. B.; BERARDINELLI, J. G.; CUSTER, E. E. Physiological mechanisms controlling anestrus and infertility in postpartum. Journal of Animal Science, v. 68, p. 799-816, 1995.

SHEMESH, M.; HANSEL, W. Levels of prostaglandin F (PGF) in bovine endometrium uterine venous, ovarian arterial and jugular plasma during the estrous cycle. Proc. Soc. Exp. Biol. Med., v. 148, p. 123-126, 1975. 
SILVA, J. F. S.; CNOP. F. P.; SÁNCHEZ, R. J. R.; VIANNA, S. A. B.; SOUZA, G. V.; ELIGIO, C. T.; RIBAS, J. A. S.; COSTA, D. S. Avaliação da dinâmica útero-ovárica da égua sob o efeito de um implante subcutâneo de microcápsulas de polihidroxibutirato contendo progesterona. Revista Portuguesa de Ciências Veterinárias, v. 101, p. 225-230, 2006.

SIROIS, J.; FORTUNE, J. E. Ovarian follicular dynamics during the estrous cycle in heifers monitored by real-time ultrasonograph. Biology of Reproduction, v. 39, p. 308-317, 1988.

SMITH, M. F.; BURREL, W. C.; SHIPP, L. D.; SPROTT, L. R.; SONGSTER, W. N.; WILTBANK, J. N. Hormone treatments and use calf removal in postpartum beef cows. Journal of Animal Science, v. 48, p. 1285-1294, 1979.

SMITH, R. D.; POMERANZ, A. J.; BEAL, W. E.; MCCANN, J. P.; PILBEAM, T. E.; HANSEL, W. Insemination of Hostein heifers at a preset time after estrus cycle synchronization using progesterone and prostaglandin. Journal of Animal Science, v. 58, p. 792, 1984.

SOTO BELLOSO, E.; PORTILHO MARTÍNEZ, G.; DE ONDIZ, A.; ROJAS, N.; SOTO CASTILHO, G.; RAMÍREZ INGLESIA, L.; PEREA GANCHOU,F. Improvement of reproductive performance in crossbred zebu anestrous primiparous cows by treatment with norgestomet implants or $96 \mathrm{~h}$ calf removal. Theriogenology, v. 57, p. 1503-1510, 2002.

SOUZA, C.A.Z.; AMARAL, F.A.; NEVES, S.; FOSECA, C.P. Aplicação de Poli-b - (hidroxibutirato) e Poli-b-(hidroxibutirato-co-valerato) como eletrólitos sólidos Poliméricos biodegradáveis. Sociedade Brasileira de Química (SBQ) In: Reunião Anual da Sociedade Brasileira de Química, 29., 2000, Águas de Lindóia. Anais..., p. 50-55.

SPICER, L. J.; ECHTERNKAMP, S. E. The ovarian insulin and insulin-like growth factor system with an emphasis on domestic animals. Domestic Animal Endocrinology, v. 12, p. 223-245, 1995.

STAGG, K.; DISKIN, M. G.; SREENAN, J. M.; ROCHE, J. F. Follicular development in long-term anoestrous suckler beef cows fed two levels of energy postpartum. Animal Reproduction Science, v. 38, p. 49-61, 1995.

STATISTICAL ANALISYS SYSTEM. SAS user's guide: Versão 8. Cary: SAS, 2001. 
STEVENS, M. P. "Polymer chemistry an introduction". New York, Oxford University Press, 1999.

STEVENSON, J. S. A review of oestrous behaviour and detection in dairy cows. In: Diskin MG, Editor: BSAS Occcasional Publication, v. 1, n. 26, p. 43-62, 2001.

STOCK, J.; FORTUNE, J. E. Ovarian follicular dominance in cattle: relationship between prolonged growth of the ovulatory follicle and endocrine parameters. Endocrinology, v. 132, p. 1108-1116, 1993.

STUMPF, T. T.; WOLFE, M. W.; DAY, M. L.; STOTTS, J. A.; WOLFE, P. L.; KITTOK, R. J.; KINDER, J. E. Effect of $17 \beta$ estradiol on the preovulatory surge of LH in the bovine female. Theriogenology, v. 36, n. 2, p. 201-207, 1991.

SUH, D. Y.; HUNT, T. K.; SPENCER, E. M. Insulin-like growth factor-I reverses the impairment of wound healing induced by corticosteroids in rats.

Endocrinology, v. 131, n. 5, p. 2399-2403, 1992.

SUNDERLAND, S. J.; CROWE, M. A.; BOLAND, M. P.; ROCHE, J. F.; IRELAND, J. J. Selection, dominance and atresia of follicles during the oestrous cycle of heifers. Journal of Reproduction and Fertility, v. 101, p. 547-555, 1994.

TANABE, T. Y.; HANN, B. Synchronized estrus and subsequent conception in dairy heifers treated with prostaglandin F2 $\alpha$. I. Influence of stage of cycle at treatment. Journal of Dairy Science, v. 58, p. 805-811, 1984.

TAYLOR, C.; RAJAMAHENDRAN, R. Effect of mid-luteal phase progesterone levels on the first wave dominant follicle in cattle. Canadian journal of Animal Science, v. 74, p. 281-285, 1994.

TRIBULO, H. E.; GO, G. A.; KASTELIC, J. P.; PAWLYSHYN, V.; BARTH, A. D.; MAPLETOFT, R. J. Estrus synchronization in cattle with estradiol-17 $\beta$ and CIDR-B vaginal devices. Theriogenology, v. 43, p. 340, 1995. Abstract.

TWAGIRAMUNGU, H.; GUIBAUT, L. A.; DUFOUR, J. J. Synchronization of ovarian follicular waves with a gonadotropin-releasing hormone agonist to increase the precision of estrus in cattle: A review. Journal of Animal Science, v. 73, p. 3141-3151, 1995. 
VACA, L. A.; GALINA, C. S.; FERNÁNDEZ - BACA, S.; ESCOBAR, F. J.; RAMÍREZ, B. Oestrus cycles, oestrus and ovulation of the zebu in the Mexican tropics. The Veterinary Record, v. 117, n. 26, p. 434-437, 1985.

VALENTIM, R. Concentrações plasmáticas de progesterona e eficiência reprodutiva de diferentes dispositivos de liberação lenta de progesterona usados em inseminação artificial em tempo fixo. $89 \mathrm{f}$. Tese (Doutorado) Faculdade de Medicina Veterinária e Zootecnia, Universidade de São Paulo, São Paulo, 2004.

VAN CLEEFF, J.; MACMILLAN, K. L.; DROST, M.; LUCY, M. C. Effects of administering progesterone at selected intervals after insemination of synchronized heifers on pregnancy rates and resynchronization of returns to service. Theriogenology, v. 46, p. 1117-1130, 1996.

VISCARRA, J. A.; WETERMANN, R. P.; SPITZER, J. C.; MORRISON, D. G. Body condition at parturition and post-partum weight gain influence luteal activity and concentrations of glucose, insulin and nonesterified fatty acids in plasma of primiparous beef cows. Journal of Animal Science, v. 76, p. 493500, 1998.

WHITTAKER, P. R.; COLAZO, M. G.; MARTINEZ, M. F.; KASTELIC, J. P.; MAPLETOFT, R. J. New or used CIDR-B devices and estradiol benzoate, with or without progesterone, for fixed-timed Al in beef cattle. Theriogenology, $\mathrm{v}$. 57, n. 1, p. 391, 2002.

WILTBANK, M. C. How information of hormonal regulation of the ovary has improved understanding of timed breeding programs. Theriogenology, p. 8397, 1997.

WILTBANK, M. C. Nuevos conceptos sobre los efectos de la nutrición em la reproducción. In: SIMPOSIO INTERNACIONAL DE REPRODUCCION ANIMAL, 5., 2003, Córdoba. Anais... Cordoba, p. 145-150, 2003.

WILTBANK, J. N. Research needs in beef cattle reproduction. Journal of animal Science, v. 31, p. 755, 1970.

WILTBANK, J. N.; KASSON, C. W. Synchronization of estrus in cattle with an oral progestacional agent and an injection of an estrogen. Journal of Animal Science, v. 27, n. 1, p. 113-116, 1968. 
WILTBANK, M. C.; SHIAO, T. F.; BERGFELD, D. R.; GINTHER, O. J. Prostaglandin receptors in the early bovine corpus luteum. Biology of Reproduction, v. 52, n. 1, p. 74-78, 1995.

WILTBANK, M. C.; PURSLEY, J. R.; FRICKE, P. M.; VASCONCELOS, J.; GUENTHER, J. N.; GIBBONS, J. R.; GINTHER, O. J. Development of Al and ET programs that do not require detection of estrus using recent information on follicular growth. In: ANNUAL CONVENTION PORTLAND, 15., 1996, Oregon. Proceedings... Oregon: American Embryo Transfer Association, 1996, p. 2344.

WINZENBURG, G.; SCHMIDT, C.; FUCHS, S.; KISSEL, T. Biodegradable polymers and their potential use in parenteral veterinary drug delivery systems. Advanced Drug Delivery Reviews. v. 56, p. 1453-1466, 2004.

WINKLER, V. W.; BRORODKIN, S.; WEBEL, S. K.; MANNEBACH, J. T. In vitro and in vivo considerations of a novel matrix-controlled bovine progesteronereleasing intravaginal device. Journal of Pharmacy Science, v. 66, p. 816818, 1977.

YAVAS, Y.; JOHNSON, W. H.; WALTON, J. S. Modification of follicular dynamics by exogenous FSH and Progesterone, and the induction of ovulation using hCG in postpartum beef cows. Theriogenology, v. 52, p. 949-963, 1999.

XU, Z. Z.; GARVERICK, H. A.; SMITH, G. W.; SMITH, M. F.; HAMILTON, S. A.; YOUNGQUIST, R. S. Expression of FSH and LH receptor messenger ribonucleic acids in bovine follicles during the first follicular wave. Biology of Reproduction, v. 53, p. 951-957, 1995.

XU, Z. Z.; MCKNIGTH, D. J.; VISHWANATH, R.; PITT, C. J.; BURTON, L. J. Estrous detection using radiotelemetry or visual observation and tail painting for dairy cows on pasture. Journal of Dairy Science, v. 81, p. 2890-2896, 1998.

ZALESK, D. D.; FORREST, D. W.; MCARTHUR, N. H.; WILSON, J. M.; MORRIS, D. L.; HARMS, P. G. Suckling inhibits release of luteinizing hormonereleasing hormone from bovine median eminence following ovariectomy.

Journal of Animal Science, v. 68, p. 444-448, 1990.

ZIMBELMAN, R. G.; SMITH, L. W. Control of ovulation in cattle with melengestrol acetate. 1. Effects on dosage and route of administration. Journal of Reproduction and Fertility, v. 11, p. 185-189, 1966. 